\title{
Reinventando la Universidad
}

\section{Jesús M. de Miguel *}

El presente documento analiza el Informe Universidad 2000, un estudio global sobre la reforma del sector universitario en España, publicado en la red en marzo de 2000. Es el resultado de un encargo de la Conferencia de Rectores de las Universidades Españolas - CRUE - a un equipo de doce personas: Baró, Bricall, Fermoso, lapiedra, Michavila, Oroval, Quin. tanilla, Rivero, Roig, San Segundo, Solà y Tejerina. Llevan a cabo el informe en año y medio. En España, la Ley General de Educación de 1970 y la Ley de Reforma Universitaria de 1983 son las dos grandes reformas de la enseñanza superior en el siglo Xx. El Informe Universidad 2000 es el primer proyecto de reforma de la Universidad desde la LRU. El informe incluye: la descripción de la situación del sector universitario español, algunas críticas al sistema actual, posibles reformas y propuesta de innovaciones sobre todo organizativas y de poder. El informe incluye al inicio 35 tablas, varias de ellas con datos comparativos de la OCDE. El informe analiza luego sectores básicos como: funciones de la Universidad, docencia, investigación, financiación, profesorado (y otro personal), evaluación de la calidad, organización/poder, aplicación de nuevas tecnologías y redes de universidades. No incluye los otros tres objetivos básicos de la Universidad: cultura, socialización y compromiso social. $\mathrm{El}$ informe tiene otras carencias importantes: a) el papel de los/as estudiantes; $b$ ) el proceso de feminización, que es el más importante de la enseñanza superior española; $c$ ) un análisis por carreras y disciplinas; $d$ ) no diferencia universidades privadas/públicas; $e$ ) no incluye el tema nacionalista, ni un estudio sobre diferencias regionales, ni siquiera por Comunidades Autónomas, y $f$ no analiza la universalización de la educación superior. Se opone a la gratuidad de la enseñanza, prefiriendo aumentar las becas que los presupuestos públicos universitarios. Propone mantener la proporción actual del coste de matrículas (24\%). El informe es partidario de una reforma organizativa de la Universidad, que resume en la necesidad de una «pla- nificación estratégica». Propone un nuevo sistema de estratificación de profesorado con tres carreras y siete niveles; en algunos no es necesario el doctorado ni investigar. Propone aumentar los contratos de dedicación parcial, y el nombramiento directo por la Universidad. Se muestra contrario al poder establecido del profesorado y a la estructura actual por Departamentos universitarios. Los rectores y gestores deben tener todo el poder ejecutivo, e incluso el nombramiento del profesorado. Aplica un modelo universitario muy similar al actual de Estados Unidos - -aunque sin citarlo- siguiendo la Declaración de Bolonia de los Ministros de Educación europeos de 1999. No queda claro en nombre de quién habla el informe, o cuál es su autoridad. No parece ser la posición oficial de la CRUE, ni del Consejo de Universidades, ni del Ministerio de Educación, Cultura, y Deporte. Es bastante crítico del Gobierno central. El informe es una muestra de la propia realidad que critica: la falta de investigación seria sobre el sistema universitario español. Con esos aciertos y fallos el Informe Universidad 2000 es uno de los documentos más importantes sobre la enseñanza superior en España, que conviene evaluar sociológicamente. Aquí se analizan sus ideas principales ${ }^{1}$.

En marzo del año 2000 se publica en España el Informe Universidad 2000. Es conocido como el «Informe Bricall» en referencia a uno de sus doce autores -el catedrático Josep M. Bricall- que durante los años noventa fue rector de la Universidad de Barcelona ${ }^{2}$. El informe tiene dos características especiales que le dan un valor importante. En primer lugar, es el primer informe global sobre la Universidad española desde la Ley de Reforma Universitaria (LRU) de $1983^{3}$. La segunda innovación es que es un informe que aparece en red, pudiendo ser consultado por cualquier persona. Es la primera vez que un informe de esta envergadura se puede consultar por Internet antes de su publicación. Eso permite una accesibilidad inmediata, y una posibilidad de debate que los autores señalan como 
el objetivo principal. Las páginas que siguen analizan ese informe, especialmente sus críticas a la situación actual y las propuestas que realiza.

No es un informe del gobierno como su antecesor Libro Blanco de la Educación en España en $1969^{4}$, que a su vez había sido prologado por el Proyecto Regional Mediterráneo seis años antes. Ambos cristalizan en la Ley General de Educación de $1970^{5}$. El Libro Blanco es el intento más serio realizado en España durante la dictadura franquista, que da origen a una reorganización del sector educativo. Fue criticado por el informe Foessa de 1970, y por otros estudios sociológicos, especialmente el Libro Negro ${ }^{6}$. Estos estudios -así como sus críticas- supusieron un nivel importante de debate entre la dictadura y la profesión sociológica. Luego con la democracia aparecen estudios analizando la organización y estructura de las universidades, por ejemplo, Anatomía de una Universidad en $1979^{7}$. El estudio con mejores datos y más polémico es Universidad fábrica de parados, escrito por Jaime MARTín MORENO y Amando DE Miguel ese mismo año ${ }^{8}$. Amparo Almarcha publica varios estudios interesantes, particularmente Autoridad y privilegio en la universidad española en $1982^{\circ}$. En 1997 se realiza un análisis de la discriminación contra las mujeres en el profesorado, escrito por Marisa GARCía DE CORTÁzAR y María A. GARCÍA DE LeÓN ${ }^{10}$. Ese mismo año se publica en inglés un artículo seminal titulado «From bureaucratic centralism to self regulation: The reform of higher education in Spain», que es imprescindible consultar ${ }^{11}$. Al año siguiente aparece un estudio interesante de Francisco Michavila y Benjamín Calvo ${ }^{12}$. Estos estudios citados son los más importantes para entender las reformas sucesivas de la Universidad española. Sin embargo, el Informe Universidad 2000 ignora esos estudios y debates. No hay referencia a los temas e ideas de las décadas anteriores, a pesar de la importancia que tienen para entender la situación española actual ${ }^{13}$.

El Informe Universidad 2000 no es un informe del gobierno, aunque tiene un cierto origen oficialista, ya que es un encargo de la Conferencia de Rectores de las Universidades Españolas (la reunión de todos los/as rectores de las universidades espanolas, conocida también como CRUE), a una docena de personas, en diciembre de 1998. Cada uno de los autores contribuye con aspectos parciales. Estos trabajos son luego integrados y debatidos, dando origen al informe final tal y como se conoce en red, fechado en Barcelona el 15 de marzo de 2000. Se tarda, pues, aproximadamente un año y medio en elaborar el informe final, que tiene cerca de quinientas páginas. En red aparece íntegro, contando con 35 tablas y seis gráficos, aunque sin referencias bibliográficas ${ }^{14}$. Es, pues, un informe particular, con el apoyo (al menos inicial) y legitimidad de la CRUE. Mantiene un posicionamiento crítico, y opuesto a la política educativa del Partido Popular en el Gobierno de la nación ${ }^{15}$. Supone un nivel de crítica considerable, incluyendo varias propuestas de reforma. Es un informe que es importante analizar y, sobre todo, poner en relación con los otros estudios sobre el sector universitario español, dentro del contexto de cambio de las universidades en el mundo. Es también importante de cara a la probable reforma universitaria durante la presente legislatura 2000-2003.

La profesión sociológica en España ha realizado críticas generales y detalladas del sector universitario, dentro del marco del sistema educativo y la estructura social del país. El resumen de ese análisis del sector de enseñanza superior aparece en el libro Estructura y cambio social en España en $1998^{16}$. Más recientemente -en junio de 2000 - se realiza un informe titulado Excelencia: Calidad de las universidades españolas, que es el primer intento comparativo de medición de la calidad de las universidades públicas y privadas en España. Incluye un capítulo extenso sobre el futuro de la Universidad ${ }^{17}$. Todos estos informes y contra-informes son parte de una polémica mundial que se enmarca en los cambios producidos en la Universidad por los procesos de globalización y de desarrollo de nuevas tecnologías de la información ${ }^{18}$. El debate profundo es el cambio de estructura (y de poder) de las universidades, en el contexto de producción y diseminación del conocimiento.

\section{El Informe Universidad 2000}

La sociedad española está llena de promesas de estudios sobre el sector universitario - y la enseñanza superior- que luego no se llevan a cabo. El Ministerio correspondiente (actualmente Ministerio de Educación, Cultura, y Deporte, MECD), el Consejo de Universidades, La Conferencia de Rectores de las Universidades Españolas (CRUE), varias universidades españolas, asociaciones diversas del profesorado, la Generalitat de Cataluña, la Agencia para la Calidad del Sistema Universitario en Cataluña, etc., anuncian repetidamente que están realizando «el estudio definitivo» sobre las universidades españolas y su calidad. Sin embargo, esos informes no se materializan. En España el nivel de análisis científico de las instituciones públicas oficiales es muy limitado.

El Informe Universidad 2000 tiene como objetivo explícito proponer los elementos para un debate nacional sobre la reforma de la Universidad (BARó et al., 2000: iii) ${ }^{19}$. Así lo explica en la página 43 del informe, hacia el final del capítulo primero: «La presentación de los cambios producidos en las universidades en este último cuarto de siglo y la específica circunstancia de las universidades españolas obligan a un debate riguroso que muestre las oportunidades que tienen ante si y los riesgos que deberian afrontar. Éste es un paso obligado para conocer las líneas de actuación sobre las que habrán de decidir los responsables 
del conjunto del sistema universitario -las Administraciones Públicas- y los responsables de cada una de las instituciones del mismo -los responsables del gobierno universitario-.» El objetivo del informe es, pues, provocador de ese debate, de cara a la reforma conservadora del Gobierno central para cambiar la LRU.

La estrategia analítica del informe se basa en cuatro niveles no siempre diferenciados por los autores: $a$ ) análisis de la situación actual de la Universidad española según nueve temas globales: funciones de la Universidad, docencia, investigación, financiación, profesorado (y otro personal), evaluación de la calidad, organización y poder, nuevas tecnologías, y redes de universidades; $b$ ) crítica de los aspectos que los autores consideran como más negativos o problemáticos; $c$ ) posibles reformas que se pueden realizar en algunos aspectos concretos, aunque no todos los que se han criticado, y d) propuesta de una nueva organización de las universidades en aspectos concretos con referencia al tema principal que se analiza en cada capítulo. Los capítulos (el noveno son en realidad dos temas distintos, aunque incluidos en un mismo capítulo) siguen aproximadamente este esquema.

Las críticas b) son de los autores respectivos de cada parte. Supongo que se ha realizado una cierta integración de los textos, pero la forma en que están redactados, el estilo, y lo que se escribe, dejan claro que los autores son distintos. Incluso las ideas son diferentes y a menudo contradictorias. Hay capítulos (como el primero y segundo) con un tono antiguo, barroco lleno de obviedades; y otros capítulos (como el de investigación) que mantienen un estilo moderno, señalando de forma atinada los problemas principales del sector. Las reformas $c$ ) y las propuestas de reorganización $d$ ) no queda claro en nombre de quién se escriben. El informe adopta un tono de reforma-desde-arriba, sin explicitar quién propone las reformas, ni en nombre de quién. Se puede suponer que es la decisión de la CRUE - es decir, del conjunto de rectores de todas las universidades españolas- pero en otros párrafos se entiende que eso no puede ser así. Los doce autores del informe, aunque hayan sido elegidos por la CRUE, hablan en nombre propio. Es un informe contradictorio, pues no es un análisis sociológico serio del sector universitario, ni es tampoco un informe de propuesta gubernamental -0 al menos oficialista - de reforma. No se escribe desde la autoridad científica (pues su análisis no alcanza ese nivel) ni tampoco desde la autoridad política. Pretende un debate público que, a pesar de las expectativas de los autores, no genera. Pocas personas han leído el informe completo, y apenas se ha escrito seriamente sobre el mismo ${ }^{20}$.

El informe es un conjunto poco armonizado de diez estudios de otros tantos aspectos del sistema universitario español. En varios temas el informe mantiene posiciones distintas. La calidad de la investigación en la Universidad española es baja, y la cantidad de investigación que se financia debe duplicarse o triplicarse. El Informe Universidad 2000 es una muestra del nivel de análisis científico que se realiza en España. Presenta datos y tablas, pero apenas los analiza. En realidad, las tablas son copiadas de otros informes, sin un nivel de elaboración adicional; y a pesar de su posible interés apenas se comentan. La bibliografía que se utiliza es muy limitada. No se mencionan los estudios nacionales e internacionales básicos, y apenas si hay referencias a otros países que no sean europeos. Esto es curioso, pues la propuesta final de reforma es fundamentalmente el modelo de enseñanza superior de Estados Unidos. Las citas bibliográficas no están incluidas en el texto accesible por red, con lo que es imposible medir el nivel de conocimiento sobre la literatura específica. Se ignoran los estudios mundiales más importantes, y también la mayoría de las investigaciones sociológicas previas realizadas en España.

El informe es una muestra de lo mismo que critica. Las ideas que presenta no están basadas en datos ni en un análisis serio, sino en las opiniones de los autores respectivos. El nivel científico es inadecuado; tampoco es un estudio académico propiamente dicho, sino una especie de pronunciamiento de reforma o de debate. Tiene la pretensión (fallida) de generar un debate público y un cambio en la política gubernamental. La publicación coincide con las elecciones generales, que refuerzan el poder mayoritario del Partido Popular, y a José M. Aznar como presidente de gobierno. La nueva ministra de Educación es la catedrática Pilar del Castillo, antes presidenta del Centro de Investigaciones Sociológicas. Es muy probable que el Gobierno realice una reforma universitaria durante la presente legislatura, es decir, en el año 2001 o bien en el 2002.

En varios aspectos la reforma que propone el Informe Universidad 2000 es una copia del modelo de enseñanza superior de Estados Unidos, realizado con información de segunda mano. La propuesta de un primer ciclo de estudios generalista (algo muy similar al college norteamericano), la expansión de la enseñanza superior no universitaria, la distinción entre «universidad» y otras instituciones superiores, la diversificación de instituciones de enseñanza superior, el incremento de la investigación básica y esponsorizada, la introducción de préstamos a estudiantes, la organización multicampus, etc., son características del modelo estadounidense. Cada vez ese modelo norteamericano es más copiado por los países europeos (además de Australia, Japón y demás países de la OCDE). Sin embargo, el informe de Ezequiel BARó et al. no se refiere explícitamente a la situación de Estados Unidos, aunque la copia casi literalmente.

El informe tiene a veces el tono de los antiguos ensayos españoles, lejano a la racionalidad y enfoque práctico de los estudios científicos. No maneja la bibliografía actual. También le falta teoría. El formato se parece más a lo que se producía antes de 1975 en España que lo que se escribe en el mundo ${ }^{21}$. El esquema en nueve capítulos está desordenado. La Univer- 
sidad tiene —como ya es sabido desde Clark KerR en The Uses of the University - cinco objetivos básicos: cultura, docencia, investigación, socialización y compromiso social. Como organización concentra recursos y consigue ciertos niveles de productividad. El informe no distingue los objetivos ni los niveles de organización de forma sistemática. Poco se dice sobre el objetivo de cultura: la universidad como sintetizadora y transmisora de una cultura global (pero no la «cultura occidental»), ni del objetivo de compromiso social (salvo referencias vagas a incluir representantes de la comunidad). Tampoco aparece el tema nacionalista, que es básico para entender las tensiones dentro del sector universitario español, a pesar de que el informe es liderado por un ex-rector catalán. De ahí que haya recibido serias críticas desde algunos gobiernos autonómicos ${ }^{22}$. El informe tampoco incluye el tema de estudiantes, salvo un apartado sobre becas. Los/as estudiantes no tienen un papel en el esquema de poder que se propone. No se debaten los temas de socialización, ni de organización estudiantil. No debe, pues, sorprender que el informe sea inmediatamente atacado por los movimientos y asociaciones estudiantiles, con la acusación de que propone un incremento de los costes de matrícula. El Informe Universidad 2000 nunca explica la subida del precio de las matrículas, aunque lo deja implícito. Propone conservar la aportación proporcional actual $(24 \%)$, pero dentro de un modelo de expansión presupuestaria (incremento de $22 \%$ por lo menos). Es, pues, partidario de la subida del precio de las matrículas. El informe tampoco diferencia las universidades privadas de las públicas, no se analiza la problemática especial del sector privado, ni de los procesos de privatización que se están produciendo en el sector. Es como si las universidades privadas no existiesen en España, y sólo hubiese un sector público.

El informe es «funcionalista», en el sentido de que explica lo que hay, con algunas críticas a aspectos parciales, proponiendo sólo ciertas innovaciones funcionalistas. No plantea un análisis del impacto del proceso de globalización en la universidad del futuro, ni la forma de remediar los efectos (negativos) de ese proceso de globalización. Ni siquiera analiza el fenómeno de globalización en las universidades actuales. Trata el tema de nuevas tecnologías, y su impacto en la educación a distancia, pero no debate un modelo de universidad virtual. Es un informe lleno de obviedades, con poca innovación. No queda claro cuáles son las ideas nuevas y diferentes que propone. Algunos cambios (como la clasificación de profesorado por niveles y tipos nuevos, o de las carreras) parecen caprichosos, sin suponer un nivel de originalidad. No queda claro en nombre de quién habla el informe, ni cuál es su fuente de autoridad. El talante de los autores es progresista, pero con contradicciones. No representan la opinión de la CRUE, ni de un partido político concreto.

\section{Comparaciones básicas}

«En nuestra economía basada en el conocimiento, las universidades forman la infraestructura crucial del desarrollo económico.» La frase aparece en un artículo del extra de opinión en The Chronicle of Higher Education, seguramente la revista con más prestigio en el mundo entero sobre enseñanza superior ${ }^{23}$. Define las diez cosas que debe realizar el próximo Presidente de Estados Unidos a favor de la enseñanza superior, refiriéndose al sucesor de Clinton. El Informe Universidad 2000 es un documento similar: explica al Gobierno español lo que debe hacer para reformar la Universidad.

El capítulo primero sirve como introducción a todo el informe. Se titula «Un período de transición en la Universidad». Es un conjunto de ideas generales sobre las funciones de la Universidad, así como una serie de comparaciones internacionales. Incluye 35 tablas, todas las que hay en el informe. Sigue el modelo típico del pronunciamiento: lanza una crítica desde la periferia (CRUE y Barcelona), proponiendo un cambio supuestamente drástico, para crear un debate nacional. Para tener un impacto mayor se presenta en Internet. Apenas incluye datos, y los que existen son periféricos al argumento que presenta. No se realiza un análisis científico riguroso, ni se pretende. No incluye un estudio de los precursores ni de los estudios previos: Libro Blanco de 1969, Libro Negro, Informe Foessa 1970, otros informes Foessa, estudios parciales de universidades como el de Granada por Julio IgLeSIAS DE UsSeL, ni análisis estructurales del sector (De Miguel, 1998; De Miguel, Caís y VAQUERA, 2000). No conoce ni cita los estudios internacionales más básicos como los de Clark KeRR o la Fundación Carnegie ${ }^{24}$. Supone un nivel de reflexión limitado, que en el contexto analítico de sus precursores parece retroceder más que avanzar.

El tono es de discurso, más que de estudio cientifico. Supone un nivel básico de obviedad sobre la situación de las universidades españolas. Mantiene una cierta ambigüedad, no dejando clara casi nunca su posición. Un ejemplo del propio informe: «La adaptación de la educación a las nuevas exigencias de nuestro tiempo no es una cuestión que afecte exclusivamente a las actuales instituciones de enseñanza superior. Se trata de un tema que interesa y que, en muchos países, preocupa hondamente al conjunto de la sociedad. Además de dichas instituciones, los distintos agentes y organismos de la vida económica y social y las Administraciones Públicas se ven implicadas en la nueva fase de estructuración de los niveles superiores del sistema educativo y, en particular, de las universidades» (BARÓ et al., 2000: 10). Cualquier persona estaría de acuerdo con planteamientos tan generales. Otra frase que resume la primera parte es que «las instituciones de enseñanza superior han de organizarse de la forma más eficiente para el cumplimiento de 
los objetivos que les señala la sociedad actual» (BARÓ et al., 2000: 17). Son ideas que difícilmente pueden rebatirse ${ }^{25}$.

España mantiene una de las tasas universitarias más altas del mundo, al menos de los países avanzados; las comparaciones son de los países de la OCDE. Pero si España está tan atrasada en el sector universitario, no se explica que tenga una posición tan ventajosa en la tasa de estudiantes universitarios. A principios de la última década del siglo $\mathrm{xx}$ los/as nuevos matriculados en la universidad suponen más del $40 \%$ de los varones y casi el $50 \%$ de las mujeres de su edad. Pero no se explica que el sistema sea tan poco productivo, pues apenas terminan la carrera la mitad de esas proporciones. El informe no analiza el proceso de feminización, que - junto con el proceso de expansión - es seguramente el más importante de la universidad española. El que haya más mujeres en la universidad española no se menciona como una conquista. Que existan más mujeres (profesoras también) no se considera como un objetivo futuro. Reconoce que las mujeres suponen el $54 \%$ de los estudiantes universitarios al final del siglo Xx en España, pero no explica las razones por las que se ha producido ese crecimiento rápido, ni que las mujeres sean en estos momentos más numerosas que los varones.

La primera crítica es sobre la falta de flexibilidad y la uniformidad excesiva del sistema universitario español (BARó et al., 2000: 18). El mercado europeo, según el informe, va a ofrecer a los/as estudiantes españoles más oportunidades de enseñanzas nuevas, y a su vez más flexibles. El sistema universitario español ha sido hasta ahora bastante rígido, compuesto por pocas carreras, y con una capacidad de elección escasa. Pero yo no creo que ése sea el problema principal de la universidad española. El crecimiento súbito del número de estudiantes - debido sobre todo al acceso masivo de la mujerha supuesto una dificultad especial para mantener los recursos a la par. Si el sistema quiere mantener unos niveles comparativos de calidad con el resto de Europa debería duplicar y hasta triplicar los recursos económicos, algo que el informe no llega a proponer. Más bien afirma que los obstáculos «nacen de la dificultad de modificar el sistema de enseñanza superior» (BARÓ et al., 2000: 19). Con un cierto tono moralizante llama la atención sobre «el riesgo político que a veces supone tomar decisiones valientes para la transformación de las estructuras universitarias» $^{26}$.

La segunda crítica importante es que en España se equipara prácticamente enseñanza superior con educación universitaria. España es uno de los países con menor proporción de enseñanza superior no-universitaria. El informe achaca la situación española a la Ley General de Educación de 1970. Desde entonces la mayor parte de la enseñanza superior está confiada a las universidades, y casi todas ellas ofrecen títulos de doctorado. El informe presenta una de sus propuestas más radicales, aunque sea solamente semántica: que el concepto de «educación universitaria» debe reservarse para las instituciones que otorguen títulos de doctorado. En ese sentido sigue, aproximadamente, el modelo de Estados Unidos en donde las cuatro mil instituciones de enseñanza superior se clasifican - a veces con fronteras ambiguas- en universities, por un lado, y colleges (de dos y de cuatro años), por el otro ${ }^{27}$.

El informe mantiene una opinión bastante crítica del profesorado, de los intereses corporativos de los/as docentes, y del actual sistema de Departamentos. La reforma socialista de 1983 (LRU) no se pudo aplicar bien, según el informe, debido a los intereses corporativos del profesorado ${ }^{28}$. Es un poco exagerado considerar que los problemas de la Universidad española se deben a los intereses del profesorado, y del sistema de Departamentos, que además depende de una «tradición estamental legada por la Dictadura». Las actuales profesiones, y los intereses profesionales no son un invento del general Franco. La división y competición de profesiones y Departamentos por recursos escasos es inevitable. Se acusa a los intereses de los/as profesores el alargamiento de los estudios, creando carreras de licenciatura o equivalente, lo que ha uniformado la enseñanza superior española, y ha impedido su variedad. El informe insinúa que el problema fundamental de la Universidad española proviene del profesorado, y sobre todo del sistema de Departamentos universitarios. Es una crítica que creo equivocada e injusta. El profesorado tiene serios problemas de salarios y de recursos. Con dificultad puede investigar. Achacarle los problemas de la universidad española es incongruente. Además, hay una contradicción en el texto, pues si se considera que los intereses departamentales son el motor del cambio, lógicamente eso debería haber llevado a una multiplicidad de carreras distintas (en base a intereses departamentales); lo que no ha ocurrido. El sistema universitario español es poco flexible debido a los gobernantes y a los rectores (y equipos rectorales), no a los profesores.

Otra crítica del informe - ésta más realista - es que el sistema suspende mucho. Da la vuelta al calcetín presentando la situación como «tasa de abandonos» cuando en realidad es «tasa de expulsión». Muchos/as estudiantes nunca acaban la carrera, y los que lo hacen tardan más que la duración oficial de la carrera. Según los datos que el informe incluye, España tiene muchos estudiantes universitarios pero pocos acaban la carrera. Eso supone unos niveles de productividad muy bajos. El informe señala además la ignorancia que existe sobre los «itinerarios del estudiante» en la realización de la carrera. Nunca explica las razones por las que la universidad española suspende tanto y pone notas tan bajas a su alumnado. A nivel internacional supone una dificultad grave para que los/as estudiantes obtengan becas, algo que el informe tampoco analiza.

Acepta la existencia de una cierta corrupción institucional, es decir, de la Administración Pública y del gobierno de las universidades, expresando la crítica de forma barroca: «La 
expansión de la financiación universitaria durante estos años se ha visto condicionada por la herencia de lamentables descuidos seculares. La necesidad de afrontar urgencias inaplazables puede explicar algunas de las características de un sistema que muestra una manifiesta dificultad para adaptarse a procedimientos más racionales que el puro incrementalismo como forma de atribución de las subvenciones, que tolera déficits presupuestarios o que opera, a menudo, de forma poco transparente en la distribución de las subvenciones directas» ${ }^{29}$. No queda claro lo que significa lamentables descuidos seculares.

El informe critica que el gasto en educación en España es bajo debido a que existe masificación, es decir, muchos estudiantes por profesor. Sin embargo, los propios datos que publica el informe lo desmienten, ya que España tiene 17 estudiantes por profesor, mientras que la media de la OCDE es apenas uno menos (16 estudiantes por profesor). No puede ser ésa la causa. El informe añade que el problema proviene también de los salarios bajos del profesorado: y ésa sí es la causa. Aproximadamente la mitad del profesorado universitario español está en una situación precaria, e incluso los que cobran como funcionarios tienen un salario escaso. Por otro lado, la ayuda a estudiantes universitarios es en España de las más bajas del mundo. Estas críticas - unas exactas y otras equivocadas en el informe- llevarían a considerar que el problema fundamental del sistema universitario español es el de recursos, que deben seguramente duplicar o incluso triplicar si se quiere estar a la altura de los otros países avanzados. El problema no es aumentar el profesorado en número (aunque sí su dedicación), sino elevarles el salario de forma consistente, y mejorar sus condiciones de trabajo. Los/as estudiantes deben recibir más becas y de mayor cuantía. El presupuesto público debe duplicar.

Sugiere que la estructura de profesorado de la LRU ha sido desvirtuada, y utilizada de forma inadecuada. Parece que se refiere a la categoría de «profesor asociado» que en vez de ser un/a profesional externo, de prestigio, que se dedica a tiempo parcial a la universidad se ha utilizado como fórmula para proletarizar a una buena parte del profesorado (representa el $36 \%)$. El informe señala que «La aparición del sistema de ensenanza superior ha requerido el aumento del personal docente en la Universidad. No obstante, las estructuras de selección del profesorado y las diferentes clases de personal docente no han podido evitar lo que parece ya una tradición de la Universidad española: la aparición de un número considerable de profesores sobre cuya necesidad no parece haber discusión pero que, en cambio, se encuentran en una situación jurídicamente anómala, ya que están adscritos a la institución mediante una discutible utilización de algunas de las figuras contempladas por la Ley. Parece existir, pues, una falta de adecuación de estas figuras con la realidad de las necesidades de la enseñanza y la investigación» (BARÓ et al., 2000: 32). Es difícil saber a qué se refiere exactamente. Tampoco queda claro a quién atri- buye esa responsabilidad. Se supone que es sobre todo al Gobierno, y dentro de las universidades al rectorado y gerencia. Se tiende a solucionar las necesidades de profesorado puestos de trabajo precarios, con salarios bajos: asociados, y titulares de escuela universitaria. Algunas universidades han exagerado esa tendencia, proletarizando a una parte considerable del profesorado, manteniendo la otra mitad en situación de funcionarios. Eso lleva a un sistema dicotómico que es el peor resultado de todos. No es una responsabilidad del profesorado, como alguna persona puede intuir al leer el informe, sino de la gerencia y del rectorado de las universidades.

La mitad del profesorado está contratado, pero no se sabe cuántos están en período de formación (realizando el doctorado) y los que son profesionales establecidos colaborando parcialmente con la universidad. El informe se refiere así (sin citarlo con esas palabras) a los penenes, y a la presión que realizan para conseguir la idoneidad ${ }^{30}$. «El elevado número de contratos precarios ha sido el factor detonante de las peticiones de una reforma de la vigente LRU que permita la estabilización de una buena parte del personal actualmente contratado, como ya hiciera dicha Ley a partir de 1983» (BARÓ et al., 2000: 34). La situación es problemática, y potencialmente creadora de conflictos. El informe prefiere no mantener ninguna posición ni aplicar solución. Se limita a sugerir que se necesita una «planificación estratégica» de las universidades, sin explicar a qué se refiere con ese término. Esa expresión está de moda pero es relativamente críptica. El informe en este asunto, como en otros complicados, no toma partido ni propone una solución innovadora.

Critica la endogamia del personal universitario, utilizando esa expresión «endogamia», que «conduce a una escasa movilidad del personal universitario tanto por razones de tipo corporativo, como de tipo social, económico y político» (BARÓ et al., 2000: 36). Muchos concursos terminan en reclamaciones sobre procedimientos de selección del personal, sobre el perfil profesional en la convocatoria del puesto de profesorado, y otras «imperfecciones» ${ }^{31}$. De nuevo, el informe critica una situación, pero no señala los responsables, ni la forma de solucionarlo. El capítulo primero está lleno de críticas al sistema actual, pero no sugiere soluciones ni presenta ideas nuevas. Cita problemas, pero no concreta, sobre todo en los temás más peliagudos. Los contratos temporales alcanzan aproximadamente a la mitad del profesorado, lo que puede intuirse como una crítica. El informe parece primero ser partidario de reducir esa proporción. Luego propone aumentar el profesorado a tiempo parcial. Informa que la proporción de doctores es cuatro de cada diez profesores. Existe una cierta variedad entre universidades. Pero no dice si esa proporción del $43 \%$ es alta o baja, y si conviene aumentarla o reducirla. Tampoco si la variedad entre universidades es positiva o negativa. El nivel de concreción es reducido en el informe; en los temas difíciles los autores optan por la ambigüedad. 
Una crítica obvia es la carencia de investigación $(I+D)$ en el sistema universitario español y sobre todo la falta de investigación internacionalmente competitiva. El gasto en $\mathrm{I}+\mathrm{D}$ en España es reducido; siempre ha sido bajo. La falta de investigación de la universidad no es más que un reflejo de la situación global de carencia que el informe reconoce. El gasto en $\mathrm{I}+\mathrm{D}$ debería de duplicarse, e incluso triplicarse, para llegar a niveles adecuados. El tema de la investigación sobre la organización universitaria es un ejemplo. Hay muy pocos estudios realizados sobre la Universidad. La mayor parte de lo que se escribe es bastante ideológico o ensayístico ${ }^{32}$.

Un ejemplo de carencias de investigación es el propio informe. El capítulo primero incluye 35 tablas, con datos comparativos la mayoría. Pero el análisis que se realiza en el texto es mínimo. Solamente se cita algún dato global de esas tablas, sin realizar análisis comparativos o causales adecuados. Es una muestra de la falta de utilización de los propios recursos estadísticos. La crítica fácil es al sector privado: «son consecuencias de la debilidad del conjunto del sistema de I $+D$ español, en gran medida debido al bajo esfuerzo en $\mathrm{I}+\mathrm{D}$ que realizan las empresas privadas» (BARÓ et al., 2000: 40). A nivel proporcional comparativo la universidad española — según el informe - realiza «demasiada» investigación si se la compara con la empresa privada. La concentración en Madrid es muy alta (más de un tercio de la $\mathrm{I}+\mathrm{D}$ ) y desigual. Pero el informe sólo incluye un estudio global con datos absolutos y porcentajes. Con ese nivel de análisis es imposible que llegue a conclusiones novedosas u originales. Sería necesario realizar análisis de correlaciones y causales. Su contribución al entendimiento y solución del problema es reducido.

El informe reconoce que el modelo universitario español es bastante descentralizado territorialmente. Cuando se complete la transferencia de las competencias de enseñanza superior a las Comunidades Autónomas España será el país de la OCDE con una mayor descentralización universitaria. No queda claro si el informe señala eso como una crítica o como un logro. Por otro lado, se contradice al señalar en un párrafo la descentralización de universidades y en otro la concentración de la investigación.

En el capítulo primero el informe no propone ideas nuevas. Solamente hacia el final sugiere que: 1) la educación superior debería tener una diversificación mayor de instituciones, y 2) debería haber una flexibilidad mayor de los planes de estudio. Se desaprovechan los datos de las tablas que aparecen al final, como apéndice. Su análisis llevaría a una serie de ideas más concretas y prácticas para la reforma de las universidades españolas. Ese estudio no ha sido elaborado por los redactores del informe, desaprovechando así la posibilidad de llegar a pautas sobre lo que hay que reformar en el sector de enseñanza superior, universidades, e I $+D^{33}$. Sería conveniente realizar un análisis comparativo serio, utilizando los datos de la OCDE que son los que el informe copia casi literalmente. Algunas de las ideas que se pueden extraer de los datos de esas tablas se pueden resumir en quince conclusiones adicionales.

1. El alumnado universitario en España ha aumentado mucho en el último medio siglo, multiplicándose por diez el numero total de estudiantes. Pero esta pauta de crecimiento está descendiendo relativamente, llegando a un nivel de estabilidad. Las bajada de natalidad que cada vez incide más en las generaciones de dieciochoañeros - mujeres y varones- supone que si se conserva los 1,6 millones de puestos universitarios actuales, con 340.000 nuevas personas matriculadas cada año, en el año 2015 más del $90 \%$ de la cohorte inicial podría matricularse en alguna universidad. Sin tener que aumentar ni uno los puestos universitarios se podría lograr la universalización de la universidad, que es posible pero que nadie parece estar planificando actualmente ${ }^{34}$. El crecimiento de la proporción de estudiantes desciende relativamente. En datos absolutos sólo descendió en tres años: 1978-1980. El Plan de Estabilización sorprende a España con una tasa muy baja de estudiantes universitarios $(2,5$ por mil de población). Pero en una sola década - la del desarrollo, los años sesenta- el número absoluto se multiplica por 2,0; en la década de los setenta se multiplica por 1,8; y en los ochenta todavía se mantiene multiplicándose por 1,7. En la década de los noventa ya el factor multiplicador del número total de estudiantes baja a 1,4. En la primera década del siglo XXI es posible que la población universitaria se estabilice. Eso supone que relativamente hablando no se necesitan más profesores, y seguramente no más puestos universitarios; aunque una tendencia a la diversidad de carreras, redistribución regional, y público/privado es probable que se produzca. A la muerte de Franco se llega al medio millón de estudiantes universitarios; en 1988 a un millón; y en 1995 al millón y medio. Lo «anormal», pues, ha sido el crecimiento de profesorado y de estudiantes durante la democracia, no al estancamiento actual del número absoluto de estudiantes. Los crecimientos más importantes coinciden con situaciones de desarrollo económico máximo: 1963-1965, y 1972-1977. Es una situación que seguramente no volverá a repetirse. $\mathrm{La}$ «normalidad» va a ser la estabilidad numérica de estudiantes y profesorado. No puede decirse que eso suponga una crisis. Sencillamente, los Departamentos deben acostumbrarse a una nueva realidad: el numerus clausus de profesores. La Tabla 1 del informe sugiere hacia dónde debe ir la planificación del sector universitario público/privado: la universalización de la educación universitaria. Al menos la universalización debe ser del primer ciclo (seguramente una combinación de primer y segundo ciclos), con un aumento pequeño del número de profesores, pero una mejora sustancial de sus salarios. Los datos de la tabla no señalan la realidad: que la expansión del número de estudiantes se debe a un proceso de feminización acelerado, que casi ha finalizado. La proporción de estudiantes-mujeres es superior a la media (53\%) aunque la proporción de mujeres profesoras (33\%) debe todavía aumentar bastante. 
El crecimiento del estudiantado universitario es, pues, explicable en parte por el proceso de feminización. Recientemente se observa una tendencia hacia la universalización. Por ello se entiende alcanzar cotas que sobrepasen $75 \%$ de estudiantes de enseñanza superior en cada cohorte inicial.

2. A nivel comparativo con los países más avanzados del mundo (los que pertenecen a la OCDE) España tiene una tasa bastante alta de estudiantes en enseñanza superior, sobre todo en los grupos de edad más jóvenes de dieciocho a veintiún años ${ }^{35}$. Hacia el final del siglo xx España cuenta con más del $27 \%$ de jóvenes de dieciocho a veintiún años matriculados en la universidad. Eso supone $18 \%$ más que la media de la OCDE. Sin embargo, son $24 \%$ menos que la vecina Francia, o 21\% menos que Estados Unidos. Los valores relativamente altos de estudiantes en España se mantienen también en el siguiente grupo de edad, de veintidós a veinticinco años de edad, teniendo entonces $17 \%$ más estudiantes que la media de la OCDE, e incluso $6 \%$ más que Francia, aunque $8 \%$ menos que Estados Unidos. En el grupo siguiente de edad, en que lógicamente se realiza el doctorado o el tercer ciclo (veintiséis a veintinueve años), España cuenta con $9 \%$ menos estudiantes que la media de la OCDE, aunque sigue en posición ventajosa respecto de Francia (41\% más que Francia), pero mucho peor que Estados Unidos (44\% menos). La realidad es que en España se matriculan bastantes estudiantes - sobre todo muchas estudiantas - pero tardan en terminar la carrera. Bastantes estudiantes (sobre todo los varones) no terminan nunca. Así se explica que haya tantos estudiantes entre los dieciocho y los veintiún años realizando la carrera, y no el doctorado posteriormente. La Tabla 2 del informe (que se limita a reproducir los datos de la OCDE sin ningún tipo de análisis correlacional ni causal) sugiere que la proporción de jóvenes de dieciocho a veintiún años estudiando en la universidad no es necesariamente un indicador de desarrollo; las tasas máximas corresponden, por ese orden, a: Corea, Canadá, Bélgica, Grecia y Francia. De media los países de la OCDE están matriculando unos cuatro de cada diez jóvenes que están en edad de empezar estudios superiores (diecinueve años, aunque varía un poco de país a país). Pero hay diferencias considerables: España tiene el cuádruple de estudiantes que México. Los países de la OCDE no presentan una pauta homogénea, y la diversidad es la norma. En ese maremágnum de estructuras universitarias España destaca por tener muchos estudiantes. El objetivo de la universidad española no es aumentar el número absoluto de estudiantes, aunque sí algo el número de profesores, y su dedicación. El problema no es de número de personas (estudiantes o profesores), sino de recursos: equipamiento, salarios y becas. No se requiere una reforma de la estructura de la universidad. Tampoco es preciso reinventar planes estratégicos, ni formas más alambicadas de escoger profesorado. Simplemente se necesitan más recursos económicos; el doble, como evidencian otras tablas del informe.

3. Pocos estudiantes españoles terminan la carrera, sobre todo si son varones. La situación parece mejorar algo, pero muy despacio.
Un objetivo básico no es que se matriculen más estudiantes, sino conseguir que aprueben y que terminen la carrera. El sector privado (universidades privadas) ha entendido hace tiempo esa necesidad. El sector público, y tradicionalmente los estudios más técnicos, mantienen un modelo que iguala calidad a proporción de suspensos, repetidores y personas que abandonan la carrera. La Tabla 3 del informe publica datos comparativos elaborados por una persona del equipo redactor del informe, María Jesús SAN Segundo, en 1998 (previo al encargo del informe) utilizando datos de seis años antes. En España la proporción de personas que terminan la carrera en relación con las que empezaron la carrera (según las edades teóricas de comenzar y terminar esos estudios) es aproximadamente la mitad: $49 \%$ si es varón y $59 \%$ si es mujer. Cuatro años antes era $46 \%$ varones y $58 \%$ mujeres; es decir, que la situación mejora, pero lentamente. En la OCDE la relación es $60 \%$ para varones y $75 \%$ para mujeres. Así pues, el sistema universitario español suspende demasiado. Bastantes personas no se gradúan, o tardan mucho más tiempo del normal en terminar la carrera. Dado que realizar una carrera puede teóricamente durar una vida, es imposible calcular estadísticas completas de graduación. Si se comparan los datos globales de España con la media de la OCDE, la proporción de personas que empiezan la carrera es bastante más alta en España (37\% más si son varones, $64 \%$ si son mujeres). A pesar de la baja productividad, la proporción de estudiantes que terminan la carrera en la edad supuesta es aún mayor en España que en la OCDE ( $11 \%$ mayor en el caso de varones, $38 \%$ si son mujeres). La tasa de personas que empiezan estudios universitarios es mayor en España que en Francia (sobre todo en varones) y bastante más que en Gran Bretaña (sobre todo mujeres). Sin embargo, la tasa de terminación de carrera es mucho menor en España que en Gran Bretaña o en Estados Unidos (sobre todo en varones, con un tercio menos). El problema no es la cantidad de jóvenes que deciden matricularse, pues son ya bastantes, sino la baja productividad de nuestro sistema universitario. No se necesitan más plazas universitarias, ni muchos más profesores, sino conseguir que nuestras universidades públicas - las privadas ya lo están haciendo- sean más exitosas a nivel docente. Un sistema con pocos recursos, además de profesores con salarios bajos que les impide (a la mitad) trabajar a tiempo completo en la universidad, y con carencias manifiestas en proyectos de investigación, no es capaz de aumentar la productividad del sistema docente. Se requiere un incremento de recursos de todo tipo. Las diferencias por género, sugieren que el problema es más complicado de lo que parece. El sector universitario está siendo, relativamente, exitoso con las mujeres pero muy poco con los varones. Pero este fenómeno no es privativo de España, sino que se produce en muchos países. La mujer es mejor estudiante, obtiene mejores notas y termina la carrera en menos años. Aunque luego obtiene empleos peor pagados y sufre más paro. 
4. En la población española se produce una polarización de los niveles educativos. Muchas personas tienen una educación solamente básica, pocas educación secundaria, y bastantes educación universitaria. Es un modelo de estratificación educativa antiguo $y$ desigual. Esta situación puede crear tensiones sociales considerables durante los próximos años. España tiene $70 \%$ de la población con estudios básicos (o menos), 13\% con secundarios, y una proporción algo mayor (18\%) con estudios superiores casi siempre universitarios. La vecina Francia, por ejemplo, tiene la misma población con estudios universitarios (19\%), pero muchas más personas con estudios secundarios (41\%), y $40 \%$ con estudios primarios. La situación de Francia es casi idéntica a la media de la OCDE ( $40 \%$ básicos, $40 \%$ secundarios, $20 \%$ superiores). Según se desarrollan los países, disminuye al mínimo la población con educación básica, aumenta a más de la mitad la población con estudios secundarios y la población con estudios superiores supera la tercera parte. Estados Unidos distribuye su población en $14 \%$ con estudios básicos, $52 \%$ secundarios y $34 \%$ superiores. La posición de España no es posible cambiarla más que gradualmente, ya que la población que ha llegado a esos niveles de estudios es ya adulta. Es posible elevar la tasa de población con estudios universitarios, pero eso polarizaría aún más las diferencias educativas en la sociedad. El objetivo no es expandir el número de universitarios/as. España tiene una población universitaria que es igual que la media de la OCDE, e incluso 30\% más que Francia (aunque 50\% menos que Estados Unidos) ${ }^{36}$. El esfuerzo que debe realizar España no es aumentar mucho más la población universitaria (aunque algo sí debe hacerlo en los próximos años), sino disminuir drásticamente - a la mitad por lo menos_ la población que sólo tiene educación básica; y triplicar la proporción de personas con educación secundaria. Los datos comparativos llevan a una conclusión sorprendente para un informe sobre Universidad: no es necesario expandirla mucho en número, sino más bien contenerla basta que la distribución educativa de la población sea más equilibrada. Mientras tanto se trata de mejorar la calidad de la Universidad. A la larga, el objetivo debe ser la universalización de la enseñanza superior, es decir, que más de $75 \%$ de cada cohorte de jóvenes entren en la Universidad.

5. En la Universidad española se ba producido un proceso rápido de feminización del estudiantado. Actualmente existe una proporción mayor de mujeres que de varones estudiando. Durante la última década del siglo Xx se produce una lenta sobrefeminización, que es mayor aún entre graduados. Las mujeres terminan la carrera en bastante mayor proporción que los varones. La proporción de mujeres entre los nuevos matriculados varía de año a año, lo que sugiere que el proceso de feminización no se ha estabilizado del todo, o que depende de otras variables. En cambio, la proporción de mujeres-profesoras aumenta de forma más lineal, aunque todavía por debajo de la proporción de estudiantas: hay $54 \%$ de mujeres entre los nuevos matriculados, $53 \%$ en el total de las carreras, y solamente
$33 \%$ de profesoras. El proceso de feminización es el más importante en la enseñanza superior española durante el siglo $\mathrm{XX}$, que a su vez está estrechamente relacionado con el crecimiento del número total de estudiantes. La sorpresa es que la feminización ha superado la mitad de los estudiantes. La Universidad española se está feminizando más de lo previsto; no así el profesorado, que sigue manteniendo una estructura de poder bastante masculina. Es preciso analizar estos procesos y evaluar los cambios en una sociedad en que va a haber más mujeres que varones con estudios superiores.

6. No existe un gradiente de educación superior en España. El modelo de enseñanza superior es diferente del resto de los países avanzados con una proporción muy baja de estudiantes en educación superior no universitaria. Parece, pues, que lo que bay que expandir es la educación superior no universitaria, y el doctorado. En los países de la OCDE uno de cada cinco estudiantes de enseñanza superior no está en la Universidad. En las edades jóvenes - de dieciocho a veintiún años- esa proporción aumenta a $23 \%$. En España es menos de 4\%. En Gran Bretaña hay 17\% de estudiantes en educación superior fuera de la Universidad. En Estados Unidos son 37\%. En algunos países, como Bélgica, la educación superior no universitaria supera $50 \%$. A niveles de edad algo mayores - veintidós a veinticinco años- la proporción española es incluso la mitad $2 \%$, frente a $18 \%$ en la OCDE, $23 \%$ en Gran Bretaña y 34\% Estados Unidos. España tiene su estructura educativa excesivamente polarizada: mucha población con sólo educación básica frente a la población con enseñanza superior. Además, este último grupo está compuesto masivamente por estudiantes universitarios ${ }^{37}$. Es preciso, pues, incrementar la educación superior no universitaria. El Informe Universidad 2000 propugna un modelo de reforma basado en la diferenciación de instituciones de enseñanza superior, concentrando más estudiantes en educación superior no universitaria. Ése es el modelo de Estados Unidos, donde una proporción alta de estudiantes se matriculan para realizar cuatro años de estudios (a veces solamente dos) en colleges y no en universidades. Se propugna que en España haya más instituciones superiores no universitarias, y que se creen carreras básicas de primer ciclo, con estudios generalistas; y no profesionales como las actuales diplomaturas. Supone un cambio considerable de la estructura universitaria española, con un nivel de productividad dudoso. No sería aconsejable mantener al mismo tiempo dos modelos. Es posible que el modelo español siga siendo de baja diferenciación de los estudios superiores, con un gradiente escaso de las instituciones. No parece haber interés en crear estudios superiores no universitarios, ni instituciones que se dediquen exclusivamente a ello ${ }^{38}$. Lo que en España se denominan «estudios universitarios», a nivel comparativo realmente es un college, con la salvedad de que apenas existen estudios graduados. Sólo hay unos programas de doctorado, escasos y poco intensivos, que sirven para formar endogámicamente al personal propio de las universidades. Legalmente 
(en las estadísticas) aparecen como «estudios universitarios», pero a nivel comparativo bastantes de ellos podrían ser clasificados como estudios superiores no universitarios. El objetivo no debe ser cambiar el sistema actual de diplomaturas y licenciaturas, sino crear estudios verdaderos de doctorado. Varias de las tablas incluidas en el informe abundan en la idea de que en la sociedad tener estudios universitarios discrimina más que el número de años de estudio o el título obtenido. Los estudios universitarios crean en España una desigualdad socioeconómica más que proporcional. Sociológicamente la falta de gradiente, así como la indiferenciación de universidades según tipos y ranking, son preocupantes, pues extreman las diferencias en la sociedad y son fuente potencial de conflictos.

7. La Universidad en España marca un nivel cualitativo de salarios por encima de otros estudios. La población está segmentada entre los que tienen y no tienen educación universitaria. Ir a la Universidad y terminar una carrera es el factor que crea mayores diferencias sociales. Algunos datos del informe son difíciles de entender, pues falta información adecuada ${ }^{39}$. Cuantifica los salarios de las personas con licenciatura en $49 \%$ por encima de las personas con estudios medios. A su vez, las personas con estudios medios ganan un salario $22 \%$ mayor que las personas con educación básica. Se observa que el corte mayor está en «estudios universitarios». Así, las personas con diplomatura ganan 30\% más que las que tienen estudios medios, y las personas con licenciatura $14 \%$ más que las diplomadas ${ }^{40}$. El proceso reciente de feminización (de hecho es sobre-feminización) de la educación universitaria puede crear en el futuro diferencias importantes en la distribución de salarios por género. En estos momentos $58 \%$ de las personas que terminan la carrera universitaria son mujeres. Si la tendencia continúa, la estructura social, familiar y de poder va a cambiar de forma apreciable en la sociedad española.

8. Los estudios universitarios producen un nivel bajo de desempleo, sobre todo si ya se tiene experiencia de trabajo. La Universidad española no es una «fábrica de parados», como se decía hace unas décadas; más bien lo contrario, es una fábrica de empleos. Eso sin contar con que la necesaria expansión de inversiones en $\mathrm{I}+\mathrm{D}$ dentro de la Universidad es generadora además de puestos de trabajo, directa e indirectamente. Las personas con educación universitaria tienen $38 \%$ menos paro que la media nacional ${ }^{41}$. El desempleo a mediados de los años noventa es $20 \%$, pero entre licenciados/as es solamente $12 \%$. La población con estudios tiene sistemáticamente menos paro que la media: las personas con bachillerato $12 \%$ menos paro, con diplomatura $32 \%$, las personas con licenciatura $38 \%$ menos paro. Se sabe que la experiencia laboral (años de trabajo tras terminar los estudios) es un factor clave en la disminución del desempleo. Entre todas las personas que tienen un año de experiencia laboral $48 \%$ están desempleadas, pero ese porcentaje disminuye mucho según los años de experiencia laboral: $39 \%$ a los tres años de experiencia laboral, $28 \%$ cinco, y $25 \%$ con siete años de experiencia. Los estudios de licenciatura completados reducèn más que proporcionalmente el desempleo: $7 \%$ menos que la media con un año de experiencia laboral, $31 \%$ menos con dos años, $41 \%$ menos con cinco, y $62 \%$ menos en el caso de siete años de experiencia laboral. Los datos sugieren que en España el género y la educación son los dos factores que mejor explican la tasa de empleo. Otro factor que no analiza son las diferencias regionales. La diferencia fundamental está entre la educación universitaria y la no universitaria. No se ofrecen datos a nivel de doctorado, pero seguramente la tasa de desempleo es aún menor. Los estudios universitarios son la mejor inversión económica que puede realizar una persona; cuantos más años, mejor.

9. La carencia global de recursos del sector universitario en España es llamativa. Es la variable que tiene más importancia en el desarrollo del sector, mucho más que los cambios de organización. Es preciso duplicar el gasto en enseñanza superior (en relación con el producto interior bruto), y seguir incrementando proporcionalmente el gasto del sector público. El gasto en Universidad relativo al PIB debería elevarse hasta $2 \%$, y el gasto del sector público llegar al $90 \%$ del total. El gasto por estudiante debería duplicarse o incluso triplicarse. Hacia 1985 el gasto en enseñanza superior (en relación con el PIB) era en España 50\% de la OCDE; una década después es $85 \%$. La proporción de gasto de $1,1 \%$ del PIB es similar a Francia o Alemania, e incluso un poco mayor que Gran Bretaña, aunque supone solamente $65 \%$ de lo que gasta Suecia, y $46 \%$ de lo que gasta Estados Unidos en enseñanza superior. Eso significa que España está progresando relativamente, aunque el punto de partida en relación con la OCDE es muy bajo. A veces se tiene la impresión de que la enseñanza superior en España está masivamente en manos del sector público; pero no es cierto. La proporción del gasto público en España es $73 \%$, sólo un poco por encima de la media de la OCDE que es $69 \%$. El sector público en enseñanza superior es $91 \%$ en la vecina Francia, y alcanza $94 \%$ en Suecia. En Italia es también alta: $87 \%$. Gran Bretaña tiene una situación muy similar a la española, con $70 \%$ del gasto público en enseñanza superior. La media de la OCDE es más baja debido a Estados Unidos cuyo gasto público no llega ni a la mitad (46\%). En el contexto europeo es esperable que España expansione aún más el sector público universitario. Pero no está sucediendo sino que la expansión de sector privado es más rápida ${ }^{42}$. El objetivo debería ser la expansión global de los recursos universitarios (llegando a duplicarlos), y la expansión del sector público basta $90 \%$ del gasto aproximadamente. Éstos son los dos objetivos básicos de la enseñanza superior en España si quiere acortar distancias con los otros países europeos dominantes, que a su vez están en una situación deficitaria respecto de Estados Unidos. A nivel de gasto por estudiante España debe gastar 1,6 veces más si quiere estar a la altura de la media de la OCDE. Francia gasta 33\% más dinero por estudiante que España, y Gran Bretaña 46\% más. En España se está rea- 
lizando un cierto progreso, pues al inicio de la época socialista en el gobierno el gasto en universidades era la tercera parte de la OCDE, y al final de la época socialista solamente $61 \%$ del gasto de la OCDE por estudiante. Pero la diferencia con Estados Unidos es todavía 3,3 veces menor. Hay que tener en cuenta que Estados Unidos gasta el doble que la media de la OCDE. España debe, pues, duplicar los recursos por estudiante si quiere parecerse al resto de Europa, y triplicarlos si pretende acercarse a la situación de Estados Unidos. La variable recursos-por-estudiante es la que presenta más diferencias dentro del estudio comparativo del sector de enseñanza superior. Debe ser remediada lo antes posible. Actualmente el gasto está bastante bien equilibrado entre sector público (76\%) y sector privado (24\%). Si se sigue el modelo europeo debe expandirse el sector público relativamente hasta $90 \%$. Si se sigue un modelo estadounidense ( $48 \%$ público), japonés (43\% público) o australiano (65\% público) se debe aumentar la privatización; como ya está sucediendo. Todo sugiere que la privatización del sistema universitario español se está produciendo a destiempo, lo que puede inclinar la organización hacia un modelo no europeo. Conviene controlar, pues, esa tendencia, con una inversión mayor en el sector público.

10. Dentro del contexto en que el gasto en educación superior es la mitad de lo que debiera, las ayudas a estudiantes es el factor más bajo. La contribución económica a estudiantes - en forma de becas o préstamos-debe triplicarse. Las becas actuales son pocas e insuficientes para permitir su independencia y supervivencia. Pero el gasto en becas y préstamos no debe detraerse del gasto general público. Eso significa que el sector privado (familias) está sufragando el sistema universitario español, a pesar de que el precio de matrícula universitaria es relativamente alto. La proporción de becarios/as disminuye en los últimos años. España gasta 2,6 veces menos en ayudas a estudiantes que la media de la OCDE. Apenas 7\% del gasto del sector público es para becas de estudiantes. La media de la OCDE es $18 \%$, pero hay países como Gran Bretaña que duplican esa proporción (38\%). En España hay 17\% de estudiantes universitarios con beca, con una retribución mensual media de 19.000 pesetas. El número de becarios/as desciende, pues en 1990 la proporción era $21 \%{ }^{43}$. La tendencia mundial es a reducir el número de becas y aumentar préstamos. El sistema español debe empezar por aumentar la proporción de becarios/as, y la cuantía de las becas, para evolucionar luego a un sistema de préstamos. La carencia de becas universitarias está llevando a los/as estudiantes universitarios a una dependencia llamativa respecto de sus padres, que en un contexto internacional se considera una situación anormal. Está relacionada con tasas de nupcialidad y natalidad muy bajas. Teniendo en cuenta que más de la mitad de cada cohortes de jóvenes está en la Universidad, el que no haya un buen programa de becas supone niveles de dependencia familiar inusuales. Como en el resto de recursos económicos, el gasto debe por lo menos duplicarse, pero nunca a costa de otras inversiones públicas ${ }^{44}$.
11. El número de profesores, en relación al número de estudiantes, debe todavia expandirse un poco. Pero lo más importante es multiplicar por dos, o por tres, el salario medio del profesorado. Hay además graves diferencias internas, que deben también acortarse entre profesorado contratado y funcionario. Existe una proporción baja de catedráticos que genera un sistema excesivamente jerárquico. No es ya un problema de número de profesores, sino de su dedicación, y sobre todo de salarios. España tiene 17 estudiantes por profesor, cuando la media de la OCDE es solamente un $6 \%$ menor. Es decir, que el problema no es el número de profesores/as, aunque una cierta expansión numérica es todavía previsible, y sobre todo un aumento de dedicación. El problema es que el salario medio del profesorado universitario en España es 1,8 veces menos que en la OCDE, y 3,2 veces menos que en Estados Unidos. Francia tiene salarios que son $41 \%$ más elevados que los españoles, y Suecia salarios que son 2,7 veces más altos. A pesar de esos datos muchos países europeos y norteamericanos se quejan de que los salarios universitarios no son competitivos con el sector empresarial privado, y que las diferencias aumentan. Duplicar o triplicar el salario del profesorado español supone reconvertir muchos profesores a tiempo parcial (que actualmente tienen salarios muy bajos) a profesorado con dedicación exclusiva. Supone además expandir la proporción de funcionarios (profesores con temure en el lenguaje internacional), y aumentar la proporción de catedráticos... iy sobre todo de catedráticas! No es necesario cambiar la organización del profesorado ni sus tipos, sino aumentar su dedicación, salario, seguridad en el empleo, recursos para que investiguen, e independencia. Éstas son medidas que el Informe Universidad 2000 no contempla. Es necesario expandir las retribuciones del profesorado, pero hay que tener en cuenta que casi la mitad del presupuesto, $46 \%$, va directamente a pagar al profesorado. Ese porcentaje es alto. El gasto en equipamiento y funcionamiento tiene que aumentar más que proporcionalmente, para que la proporción de gasto en personal descienda relativamente. Deben, pues, expandirse los gastos corrientes que no son de personal, y reducir proporcionalmente los gastos de capital. Los datos comparativos son consistentes: se debe duplicar los recursos españoles si se quiere homologar la Universidad española con la OCDE (lo que es un objetivo deseable), y triplicar si se desea aproximar al modelo de enseñanza superior de Estados Unidos.

12. El modelo español de educación superior es muy descentralizado. El gasto público regional (de Comunidades Autónomas sobre todo) es alto, y el local bajo. Es un modelo que puede generar en el futuro diferencias regionales considerables. En España el gasto de la Administración Central supone 47\%, la Administración Autonómica 52\% y la Local apenas 1\%. En Europa, el modelo es más regionalizado en Alemania y Bélgica. En la media de OCDE el gobierno central concentra $78 \%$ del gasto, con $18 \%$ a nivel regional y $4 \%$ local. En contraste con España, en Francia el gasto de la Administración Central es $91 \%$, pero hay cuatro 
veces más gasto a nivel local que en nuestro país. El modelo español, altamente descentralizado, se parece mucho más a países federales como Estados Unidos, que tiene menos gasto central $(37 \%)$ un poco más regional $(56 \%)$ y siete veces más de gasto local que España (7\%). En el total de los países de la OCDE el sistema está $66 \%$ más centralizado que el español. Por ejemplo, dentro de España, Cataluña gasta en universidades $15 \%$ más que el llamado «territorio MEC» ${ }^{45}$. No parece, pues, que el problema sea conseguir una descentralización mayor de los recursos públicos universitarios; quizás lo contrario.

13. El sistema universitario español es muy barato. Pero bay grandes diferencias de gasto por Comunidades Autónomas y por universidades. Estas diferencias no son necesariamente negativas, aunque la tendencia debe variar hacia diferencias menores por Comunidades Autónomas, y mayores por universidades concretas. El gasto por estudiante en el sector público según estos datos es 543.400 pesetas, es decir, unas 45.000 pesetas al mes por estudiante (datos correspondientes a 1996). Es un coste 2,7 veces más caro que un estudiante de enseñanza general básica, y 1,6 veces más que uno de enseñanza media o de formación profesional. A su vez, las diferencias por universidades son llamativas. El gasto por estudiante en la Universidad Pompeu Fabra, en Barcelona, es 4,7 veces más alto que la Universidad de Vigo (datos de 1996). El presupuesto de la Pompeu Fabra es 3,2 veces superior a la media, Universidad Politécnica de Cataluña 1,7, y Universidad Autónoma de Barcelona 1,4 veces más que la media. Cataluña mantiene un gasto en universidades públicas que es $37 \%$ más que la media española ${ }^{46}$. Como se ha citado, Universidad Pompeu Fabra tiene un gasto per capita que es 3,2 veces más que la media, cuando la universidad madrileña paralela - Universidad Carlos III- gasta solamente 1,3 veces más que la media. Universidad Politécnica de Cataluña gasta $74 \%$ más que la media de las universidades, mientras que Universidad Politécnica de Madrid apenas 10\% más que la media. En el caso de las llamadas Autónomas, la de Barcelona gasta $44 \%$ más que la media, pero la de Madrid apenas 0,5\% más que la media. Las universidades «centrales» son ambas grandes y parecidas, pero la Universidad de Barcelona gasta 17\% más que la media, y la Complutense $5 \%$ menos que la media. Cataluña es, pues, un ejemplo de cómo las diferencias no son sólo por universidades, sino también por Comunidades Autónomas. Yo considero que las diferencias por Comunidades Autónomas deberian minimizarse, pero las diferencias entre universidades públicas dentro de cada Comunidad deberian aumentar. El objetivo es que la calidad general de los sistemas universitarios autonómicos no sea muy diferente, para que la población tenga derechos parecidos. Pero, a su vez, se trata de favorecer que haya tipos diferentes de calidad de universidad dentro de cada región, con al menos una universidad-investigadora de referencia internacional, para que los derechos de los/as estudiantes más aventajados también se cubran ${ }^{47}$.
14. En España bay una proporción excesiva de profesorado universitario con trabajo a tiempo parcial, inseguridad en el empleo y salario bajo. El sistema de personal docente está excesivamente estratificado. Es, además, un sistema con pocos doctores. Los datos provienen del sector público, pues el privado funciona de otra manera. Casi la mitad del profesorado (45\%) es profesorado no numerario («penenes» en el argot). Los/as profesores asociados, con salarios muy bajos, y dedicación parcial representan el $36 \%$ del profesorado. El profesorado numerario, es decir, funcionario (con tenure o seguridad en el empleo) se estratifica excesivamente. Hay un catedrático por cada tres profesores titulares, y en las Escuelas Universitarias uno por cada seis. En el conjunto del profesorado solamente hay un catedrático/a de universidad por cada once profesores. En total representan 9,3\% de todo el profesorado. El sistema es, pues, jerárquico, garantiza poco la seguridad, y no suele proveer un salario decente a la mayoría. Es un tema a solucionar, que no puede basarse en la expansión del profesorado a tiempo parcial, sino lo contrario. Tiene poco sentido mantener la distinción entre profesorado de Escuelas Universitarias versus de Facultades o Escuelas Técnicas Superiores. El profesorado de Escuelas Universitarias está mal pagado y sus titulares no requieren el título de doctor. Eso disminuye la calidad de la docencia y dificulta la investigación e impide los estudios de doctorado. Las categorías de profesorado de Escuela Universitaria sería mejor que desapareciesen, y que el sistema en ocho tipos de profesorado se simplificase. El sector universitario español se basa en 55\% de profesores numerarios. El porcentaje de doctores (43\%) parece bajo, pero el Informe Universidad 2000 no incluye datos comparativos ${ }^{48}$. Es necesario aumentar la proporción de doctores, sobre todo en las mejores universidades-investigadoras.

15. El gasto en investigación en España es muy bajo: menos del $1 \%$ del producto interior bruto en $I+D$. Junto con los presupuestos de las universidades, los recursos de la enseñanza superior, y los salarios del profesorado debería duplicarse. En investigación incluso se necesita triplicar el gasto. La investigación en la Universidad es un tercio del total, pero concentra a más de la mitad de los/as investigadores del país. Relativamente bablando, la Universidad debe pasar a ser menos central en los procesos de investigación, siendo las empresas privadas las que desarrollen (y financien) más la investigación. Actualmente el gasto en $\mathrm{I}+\mathrm{D}$ es dos veces y media menor de lo que gastan los países de la OCDE. España gasta una tercera parte que Francia, Alemania o Estados Unidos, y apenas $44 \%$ de lo que gasta Gran Bretaña. Durante los gobiernos socialistas el gasto en $\mathrm{I}+\mathrm{D}$-como proporción del PIB- aumentó 2,2 veces. Pero en los últimos años ya no se incrementa. Se necesitaría multiplicar por dos veces y media, o incluso por tres, el gasto en $\mathrm{I}+\mathrm{D}$ para lograr disminuir las diferencias seculares de España respecto de los países avanzados de Europa y Norteamérica. Un tercio de la investigación española se realiza en la Universidad, aunque ésta sólo financia $4 \%$ del presupuesto de I $+\mathrm{D}$ del país. Durante la última década 
del siglo $\mathrm{xx}$ la investigación que se realiza en las universidades no hace más que aumentar, pasado de la quinta parte a un tercio de $\mathrm{I}+\mathrm{D}$ en el país. Las universidades realizan una investigación barata, o de pocos recursos, concentrando $33 \%$ del gasto total en $I+D$ pero $57 \%$ de los/as investigadores. La situación parece que mejora, pues en la década de los noventa se incrementa mucho los recursos gastados ( $20 \%$ a $33 \%$ entre 1990 y 1997), pero no tanto el número de investigadores ( $50 \%$ a $57 \%$ en las mismas fechas). La investigación universitaria es barata, o quizás ineficiente (o las dos cosas al mismo tiempo), aunque la situación parece mejorar gradualmente. La Universidad cada vez concentra más investigación. La proporción de $\mathrm{I}+\mathrm{D}$ que realizan las empresas privadas es pequeña comparativamente hablando. En España las empresas privadas costean $40 \%$ de I+D y realizan $48 \%$ de la investigación. En Estados Unidos las empresas costean $60 \%$ y realizan $72 \%$ de la investigación. Los datos demuestran la importancia de las universidades en los procesos de investigación en España. Es, además, un tema central en la reforma de la Universidad. La investigación de las empresas está muy concentrada en las grandes ciudades, y sobre todo en Madrid (35\% de la investigación de las empresas). Mientras tanto, las universidades de la Comunidad de Madrid realizan solamente $19 \%$ del I+D total dentro de esa Comunidad Autónoma. En el caso del País Vasco la importancia de la Universidad es incluso menor (19\%), y en Cataluña un poco mayor (24\%). En el triángulo industrial la importancia investigadora de las universidades es relativamente menor. En cambio, en el resto de las Comunidades Autónomas las universidades realizan más de la mitad de la investigación de su región (52\%). El sistema universitario realiza bastante investigación en España — quizás demasiado relativamente-, pero concentra bastantes investigadores, con lo que su I $+D$ es más barata. Las universidades de la OCDE sólo realizan una quinta parte de la investigación de su país, mientras que en España es un tercio. España necesita aumentar (triplicar) la investigación que realiza, pero no necesariamente ese esfuerzo debe hacerse enteramente dentro de la Universidad.

Estos quince puntos resumen la información que proveen las 35 tablas que se incluyen en el apéndice del primer capítulo, y que el Informe Universidad 2000 no analiza. Sería necesario un estudio comparativo más detallado y metodológicamente más elaborado, para concluir con ideas más precisas sobre la reforma del sistema universitario español. La conclusión general de estos datos es que el problema de la Universidad española no es de organización, ni es necesario inventar un nuevo modelo de universidad. Tampoco se trata de cambiar la elección del profesorado. Es fundamentalmente un problema de recursos económicos y de diversidad. La enseñanza universitaria española requiere duplicar - y en algunas partidas triplicar- sus recursos económicos si quiere estar a la altura de los países de la OCDE. Mantener una Universidad barata, y de calidad baja, en un contexto de globalización y de competición internacional es una política equivocada ${ }^{49}$.

\section{Funciones de la Universidad}

El capítulo segundo del Informe Universidad 2000 se titula «Universidad, agente social». Debate las funciones de la Universidad y su organización básica. Es un capítulo de obviedades, crítica inconcreta y pocas ideas nuevas. Describe fundamentalmente dos de las funciones de la Universidad - docencia e investigación-, pero no analiza las otras tres funciones de elaboración de cultura, socialización y compromiso social. Tampoco tiene en cuenta las consecuencias de la introducción de las nuevas tecnologías de la información en la Universidad, ni los efectos negativos del proceso de globalización mundial. El tono del capítulo segundo es ambiguo. Muchas ideas son obvias, confusas, demasiado generales. Por ejemplo, cuando afirma: «No hay que olvidar que todo proceso formativo, todo proceso de aprendizaje, tiene una dimensión alta e insoslayablemente idiosincrática. De ello depende, especialmente, la mejora de la capacidad de absorción de los individuos» (BARÓ et al., 2000: 110). O cuando señala en negritas que: «Las universidades deberían proponerse la formación de profesionales para atender a dichas necesidades colectivas, en estrecha colaboración con el. resto de las instituciones públicas y sociales. Además, hay que insistir que la Universidad forma parte integrante de la sociedad, y comparte sus aspiraciones y, también, sus dificultades» (BARÓ et al., 2000: 123). Es difícil estar en desacuerdo con afirmaciones de este estilo, aunque no añaden nada nuevo al. conocimiento.

Denuncia el retraso tecnológico español, que se puede entender como causa y consecuencia del retraso de las universidades en el país ${ }^{50}$. Para empezar a solucionarlo el informe propone estudios más pluridisciplinares y humanísticos. Los redactores del informe parecen estar de acuerdo con más formación en Humanidades. Se sugiere «introducir materias humanísticas de manera transversal en los curricula universitarios de todos los ámbitos de especialización [...] Deberá ponerse especial cuidado en que las titulaciones humanísticas no colonicen indebidamente la anterior oferta transversal, distorsionando con acento especializado lo que ha de ser una formación generalista» (BARó et al., 2000: 118). El informe recomienda crear un primer ciclo de estudios humanistas generalistas, al estilo de la liberal arts education en Estados Unidos. El modelo del college norteamericano no se menciona nunca por su nombre, pero la idea de una educación universitaria pluridisciplinar y humanística coincide con ese modelo ${ }^{51}$. Se critica la «multiplicación y especialización de los títulos» o carreras. Una «organización más concentrada y generalista de los 
estudios universitarios en sus primeros años redundaría en un menor desajuste y en una concreción más tardía y más fundamentada del deseo de especialización de los estudiantes» (BA. Ró et al., 2000: 130). Es de difícil aplicación en España, pues la Universidad está ya organizada sobre estudios profesionalizados desde el inicio ${ }^{52}$.

El informe nunca especifica cómo se va a pasar de un modelo a otro. Sus autores equivocan la solución de los problemas de la Universidad española: no se trata de realizar otra reorganización de carreras y Departamentos, sino de incrementar el doble o el triple el presupuesto para las universidades públicas. La introducción de modelos y estructuras foráneas es arriesgado; es mucho más fácil dotar a la Universidad de recursos similares y esperar a que esos recursos eleven por sí solos la calidad de las universidades. Más reformas-sin-recursos en el sector público sería una equivocación. Tienden a derivar los/as estudiantes mejores, así como los de familias con más recursos económicos, hacia las universidades privadas.

El informe considera que la Universidad debe plantear y ayudar a solucionar los «problemas sociales». Ésa es una visión cercana a la Sociología, que cada vez se dedica más a enseñar sobre problemas sociales. Pero dudo que las universidades sean el lugar adecuado para solucionar los problemas sociales. Quizás sí para plantearlos, pero no para aplicar las políticas sociales. Se propone un cambio organizativo, incorporando representantes más sociales en la dirección de las universidades. Pero la definición exacta de a qué personas se está refiriendo no está claro en el informe: «La universidad es una institución que desempeña una actividad a menudo presionada por la urgencia de resolución de ciertos problemas. Difícilmente se podrá conseguir el diálogo aludido y el correspondiente interés universitario por los problemas sociales, económicos y culturales de su entorno sin la presencia de representantes de las entidades más significativas del mismo en sus propios órganos internos, de acuerdo con una práctica que, actualmente, se extiende por toda Europa» (BARÓ et al., 2000: 124). No se sabe si por «entidades más significativas» se refiere a partidos políticos, sindicatos, minorías étnicas, migrantes, pobres, desempleados, ONG, o a otras instituciones. También es confuso lo de «órganos internos», pues puede referirse al rectorado, gerencia, Consejo Social, Junta de Gobierno, etc. Más adelante cita de nuevo los «agentes sociales del propio territorio» que deben formar parte del Consejo Social de la universidad.

Propone un nuevo sistema de incentivos para lograr la implicación de las universidades en su entorno territorial: «El desarrollo de un nuevo sistema de incentivos que estimule esta mayor apertura hacia el entorno local o regional de las universidades. Incentivos que favorezcan una mejor percepción de los problemas económicos y sociales en este ámbito y que sean capaces de decantar los suficientes recursos (de atención y de creatividad) para su solución» (BARó et al., 2000: 137). Resulta imposible saber a qué se refiere el informe con esta idea. Hay una cierta preocupación porque la universidad se involucre más con la ciudad o región donde está, pero no se proponen ideas concretas de cómo llevarlo a cabo.

Un problema para que las universidades se involucren más con su ciudad o región (su «entorno territorial», según el informe) es la cultura universitaria, que conviene modificar. «Las universidades están aún demasiado dominadas por una cultura académica excesivamente condicionada por estrechos criterios de lealtad profesional» (BARÓ et al., 2000: 137). Esta idea se repite varias veces en el informe, en capítulos diversos. El profesorado está diversificado en profesiones, y en colegios profesionales, guardando más lealtad a su profesión que a la universidad en la que trabaja. Pero esto es una relación ya sabida en el mundo. La fidelidad es mayor al grupo de referencia. La fidelidad del profesorado no es a su universidad, ni siquiera a su centro (Facultad o Escuela), sino a sus colegas del mismo área de conocimiento. La profesión es la que evalúa, sirve de referente de calidad, concede proyectos y becas, debate y difunde la investigación realizada, promociona y juzga a los/as profesionales. En otros países la movilidad del profesorado es alta (no así en España), con lo que la fidelidad a la organización se debilita. El Informe Universidad 2000 está bastante irritado con esa realidad, achacando la división profesional «exagerada» a la dictadura franquista (sic). Está equivocado, ya que: 1) el sistema profesional no es un invento del régimen franquista; 2) la división progresiva en profesiones múltiples es un proceso inevitable, y 3) la fidelidad del profesorado a sus profesiones respectivas - y a los/as colegas del invisible college - antes que a la organización (la universidad) es un hecho que ya se observa en otros países. Por alguna razón inexplicable el Informe Universidad 2000 mantiene una actitud negativa respecto del profesorado, y su sistema de organización en profesiones, colegios profesionales, áreas de conocimiento y Departamentos universitarios. Quizás es una actitud colectiva de los rectores de las universidades en la CRUE.

Está decididamente a favor de incrementar la movilidad de los/as estudiantes Para ello el informe se muestra partidario del llamado sistema de «distrito abierto» por el que los/as estudiantes pueden elegir carrera en cualquier universidad «en todo el territorio nacional». Considera que éste es el único sistema de superar el «desajuste territorial» que existe en el sector universitario español. Luego matiza esta libertad considerando que cada universidad debería establecer sus propios criterios: «Correspondería, por tanto, a cada Universidad fijar los criterios estrictamente académicos requeridos para proseguir en sus unidades las diferentes clases de estudios, y seleccionar, por tanto, a sus estudiantes» (BARÓ et al., 2000: 131). Esta idea contradice la aceptación del sistema de distrito abierto, pues no queda claro lo que significa «criterios académicos», ni cómo podrían conciliarse esos criterios con la oferta y demanda libre de pues- 
tos universitarios. Si los criterios son diferentes según las universidades o regiones, no se garantiza la igualdad de oportunidades. Nada se dice de las universidades privadas. El informe no explica más su propuesta.

Propone un sistema de control de las universidades públicas por parte de la Administración Pública, basado en las evaluaciones de los recursos utilizados, y una acreditación final de la institución. El sistema de acreditación parece copiado del sistema estadounidense, que es donde se utiliza más. Se prefiere ese sistema al de control previo, o al de autorización para funcionar como universidad. Se trata de «formas más indirectas de intervención como son el seguimiento a distancia, el análisis de los resultados y la coordinación plurianual y revisable entre los programas establecidos por las propias Administraciones responsables, programas que han de establecer de forma clara las prioridades del período y la asignación de los medios que han de compensar el esfuerzo exigido y que las universidades estén dispuesta a asumir» (BARó et al., 2000: 141). Este sistema vale para las universidades públicas, pero nada se dice de cómo se propone regular las universidades privadas. El informe no distingue las universidades privadas de las públicas. Hay que suponer que todo lo que se propone es para el sector público.

Al final del capítulo es donde queda más clara la importancia de la CRUE como grupo de presión dentro del sector universitario. Critica abiertamente al Consejo de Universidades, que es el organismo principal de política universitaria creado por la LRU en 1983. Considera que su funcionamiento es muy complejo, aunque no demuestra con datos esa afirmación, ni explica por qué esa complejidad es negativa. Considera que el sector universitario debe estar menos regulado y ser más flexible. Para ello sugiere que el Consejo de Universidades tenga menos funciones ${ }^{53}$. Pero si de lo que se trata es de ser menos reglamentista y más flexible, la propuesta de los redactores del informe -nombrados por la CRUE- llama la atención al sustituir una institución, el Consejo de Universidades, por dos: la propia Conferencia de Rectores de las Universidades Espanolas (CRUE) que ha encargado el Informe Universidad 2000, y por un nuevo Consejo de consejeros autonómicos de educación. Por un lado, la CRUE «representaría —como ocurre en otros países- a las universidades ante las Administraciones Públicas». El otro Consejo actuaría «como órgano de coordinación de las distintas Administraciones educativas en el ámbito de la enseñanza superior y en la investigación, integrado por los Consejeros con responsabilidad en Educación Superior en cada Comunidad Autónoma y presidido por el Ministro de Educación y Ciencia» (BARÓ et al., 2000: 143). Es peculiar que las personas elegidas por la CRUE para redactar un informe sobre la reforma de la Universidad concluyan con que el organismo actual de política universitaria debe desaparecer para dar paso a dos organismos: la CRUE y otro Consejo. Dado que además esta propuesta no se fundamenta en datos, ni en una evaluación seria sobre el Consejo de Universidades actual, la propuesta de dar más importancia política a la CRUE es llamativa. Es paradójico que los autores denuncien repetidamente el gremialismo del profesorado, cuando después su propuesta es incrementar el poder de la institución que les paga el informe. El modelo de crear dos organismos, con responsabilidades solapadas, es garantía de conflictos múltiples y continuos.

El capítulo sobre la Universidad como agente social no contiene ninguna idea interesante. Las propuestas de cambio de planes de estudio y de carreras - hacia un modelo más generalista, humanista, y pluridisciplinar- es una copia del modelo de Estados Unidos, sin citarlo. Las demás ideas son críticas ambiguas, poco desarrolladas, que no suponen innovación. El remate es la propuesta de dar más poder a la CRUE, que es la institución que ha financiado el informe.

\section{Docencia}

El tercer capítulo titulado pretenciosamente «Difusión del conocimiento: Formas de aprender», se ocupa en realidad de las carreras en la universidad. El modelo que se propone es una copia del sistema de enseñanza superior en Estados Unidos, sin citarlo. Al final se presenta una estructura contradictoria, poco práctica, basada en una diferenciación dificultosa entre carreras disciplinares y carreras profesionales.

En Europa el sistema universitario está en crisis: «Por primera vez el número de estudiantes europeos en Estados Unidos ha superado el número de estudiantes norteamericanos en Europa, tendencia que parece acentuarse. Dado que los europeos que tienen más facilidades para estudiar en los Estados Unidos suelen pertenecer a familias con rentas elevadas, hay pocas dudas sobre a quién perjudicaría no emprender reformas correctas en las universidades europeas» (BARó et al., 2000: 153). Es un razonamiento rebuscado. Supone que hay que reformar la Universidad porque las personas ricas están yendo a estudiar a Estados Unidos. En realidad, las personas más ricas son también las que estudian más en las universidades europeas. No hay que reorganizar la universidad española para evitar que las personas ricas se vayan a Estados Unidos; más bien es una esperanza que lo hagan. Lo que hay que construir es un sistema universitario en España que no discrimine social. mente. En esa dirección el informe no presenta ideas originales.

Se proponen inicialmente tres cambios: la consolidación de un sector no universitario de enseñanza superior; el desarrollo de la educáción continuada; y la diversificación progresiva de la educación superior. No son tres propuestas originales, sino tendencias que ya se están produciendo en el mundo. Se reconoce que «los estudios se orientan abiertamente a satisfacer 
las demandas que emanan del mercado de trabajo» (BARÓ et al., 2000: 148). Pero esto no es enteramente cierto, pues la propia Universidad crea demandas y no sólo de profesores. Por ejemplo, en investigación la Universidad es capaz de crear puestos de trabajo mediante su propia demanda. El informe aprovecha esas tres tendencias para sugerir cambios organizacionales en la Universidad que son desproporcionados. Veámoslos.

1. La primera tendencia, el desarrollo de la enseñanza superior no universitaria, exige, según los redactores del informe, que un porcentaje alto del profesorado lo sea a dedicación parcial, y que los mecanismos de acceso a esos estudios no deban ser tan exigentes. Posteriormente incrementa la enseñanza no universitaria proponiendo reservar el nombre de «Universidad» a las instituciones educativas que conceden el título de doctor. Es el sistema estadounidense en donde la enseñanza no universitaria es extensa; diferenciando así universities de colleges.

2. La segunda tendencia es el desarrollo de los estudios de formación continuada. El informe exagera decididamente la importancia de la educación continuada en la Universidad, afirmando que «constituye uno de los aspectos más relevantes de la política social y económica de un país» (BARó et al., 2000: 154). Se equivoca, pues la educación continuada a nivel superior es un tema marginal. En mi opinión, lo importante es reducir la proporción de población española con estudios básicos, y aumentar con secundarios, y no tanto expandir mucho más los estudios superiores. El problema fundamental es la calidad de los estudios universitarios, y no tanto aumentar las enseñanzas. No queda clara la razón de poner tanto énfasis en la educación continuada. El informe la exagera para proponer cambios drásticos en la organización de la Universidad, en la estructura de Departamentos y en las carreras.

Considera la formación continuada «como un instrumento catalizador para una renovación profunda en la educación propia de la nueva etapa que se abre a la universidad, en la que este tipo de formación dejará de ser la excepción para convertirse en la regla. En este sentido, la formación continuada pone en cuestión algunas estructuras de la Universidad actual. Quiebra, por ejemplo, la división disciplinar de la misma» (BARÓ et al., 2000: 156). Esta es una afirmación arriesgada. El desarrollo de la formación continuada no ha transformado la estructura de las universidades más avanzadas del mundo (Oxbridge, Harvard, Yale, Princeton, Stanford, Chicago, California Berkeley, Heidelberg, París), ni ha supuesto una quiebra de su estructura disciplinar. El Informe Universidad 2000 mantiene en el fondo una discusión sobre el poder dentro de la Universidad, bajo apariencias de racionalización. Le viene bien exagerar al máximo la supuesta educación universitaria continuada, para sugerir que ésta debe pasar a depender de la dirección de la universidad directamente y no de los Departamentos o Centros ya existentes. La exageración llega al extremo - sin ningún datode afirmar que «los programas de formación continuada pro- yectan, pues, nuevas dudas acerca de si la organización disciplinar es la más correcta para acomodar debidamente la Universidad a la expresión de las demandas sociales, culturales y económicas actuales» (BARÓ et al., 2000: 156). No ha supuesto dudas en las mejores universidades del mundo; no tiene, pues, por qué generar inquietudes en España.

La innovación que propone el informe es crear una estructura diferente dentro de la Universidad para los cursos de formación continuada, que dependa directamente del rectorado/gerencia (es decir, del poder central de la universidad) y no de los Departamentos. El informe mantiene un nivel crítico inexplicable contra los Departamentos, que, según el propio informe, acumulan demasiado poder. El razonamiento no es convincente: «Confiar la organización de los cursos de formación continuada a los actuales departamentos universitarios supone el riesgo de abandonar su diseño a parámetros únicamente disciplinares y de investigación del personal académico. Esta opción supondría además propiciar un cierto descontrol por parte de los organismos centrales de la Universidad respecto de una actividad que conlleva una gestión económica compleja. La propia programación de los cursos requiere una estructura que sea capaz de estudiar la evolución de la demanda, de desarrollar el contenido y la forma de impartir cursos, de contratar el personal académico pertinente y de contar con una red de contactos y de relaciones que desbordan, sin duda, el cometido propio de los departamentos.» Termina el párrafo con una amenaza velada: «No tener en cuenta estas exigencias generaría un riesgo intolerable para el resto de los estudios -que actualmente se financian con cargo a fondos públicosque deberían hacerse cargo de las posibles pérdidas que pudieran resultar de una mala gestión de la formación continuada» (BARó et al., 2000: 156-157). Lo que es un «riesgo intolerable» es que se institucionalicen sistemas de contratar profesorado directamente por los servicios centrales de la universidad, sin tener en cuenta los procesos de selección adecuados a través de las áreas de conocimiento respectivas. No queda claro cómo se van a evaluar los conocimientos y preparación científica de esas personas. Tampoco parece aconsejable incrementar más la proporción de profesorado contratado en la Universidad, ni el porcentaje de profesorado a tiempo parcial, dos de los problemas principales para elevar la calidad de la Universidad española. En tercer lugar, la organización directa de cursos, que se entiende son pagados privadamente (no financiados con cargo a fondos públicos), supone una privatización encubierta de las universidades públicas que debería ser evitada al máximo. Puede producir también una discrecionalidad de recursos en manos de los rectores.

Pero el Informe Universidad 2000 deja claro que propone esa proletarización adicional de la docencia universitaria, al añadir inmediatamente: «Es indispensable contar con un número adicional de profesores con una dedicación preferentemente 
a tiempo parcial y con un régimen flexible de contratación, dada la constante renovación y modificación de los programas y cursos en este tipo de enseñanzas» de educación continuada. En un informe ambiguo como éste, en que apenas se define nada claro, la rotundidad con la que se propone que aumente el profesorado a tiempo parcial, con «contratación flexible» y sin seguir los requisitos de evaluación de los/as colegas, es $\mathrm{Ha}$ mativa. Si lo que se quiere es elevar la calidad de la Universidad española esta propuesta está equivocada. El problema universitario español no reside en el cambio de contratación del profesorado, ni en la remodelación del sistema departamental, sino en cómo duplicar los recursos económicos de la Universidad, fundamentalmente de los Departamentos y del profesorado. Es impensable que el profesorado actual realice investigación sin una dotación económica adecuada, y sin unos servicios de apoyo, organizativos, y de equipamiento mucho más elevados. Si eso no cambia, el desfase entre las universidades públicas españolas y las mejores del mundo va a aumentar. Formación continuada en una universidad poco investigadora y sin recursos no va a ser la solución de nada. Más bien va a perjudicar a la institución, proletarizando aún más al profesorado, e introduciendo sistemas de contratación no profesionales, junto con una centralización inadecuada ${ }^{54}$. Además, la calidad de esa formación continuada puede ser penosa. El informe exagera la educación continuada para cambiar la estructura de la Universidad, aumentar el poder central, puentear a los Departamentos y privatizar las universidades públicas. La propuesta del Informe Universidad 2000 es un despropósito.

3. La tercera tendencia es la progresiva diversificación de los estudios superiores (tanto universitarios como no universitarios). Se critica el excesivo reglamentismo de la burocracia española, que impide desarrollar nuevas carreras ${ }^{55}$. La crítica reglamentista se refiere también a la optatividad escasa de asignaturas en las carreras universitarias. El objetivo es que el Estado siga pagando el $76 \%$, pero no controle mucbo. El informe propone también medidas como la semestralización de los cursos académicos, y la implantación del sistema de créditos. Ambas medidas, que copian el sistema de Estados Unidos, se están poniendo ya en marcha en la mayoría de las universidades españolas. Aunque se propone la diversificación de titulaciones, se critica duramente el proceso de diversificación profesional, es decir, el hecho de que cada vez haya más especialidades académicas, e incluso subespecialidades. Esta tendencia se atribuye (equivocadamente) a la dictadura franquista: «Debería procederse a reducir progresivamente el número excesivo de profesiones y de colegios profesionales que las agrupan con criterios de exclusividad, herencia de los excesos corporativistas de la pasada Dictadura» (sic, BARÓ et al., 2000: 182). El crecimiento del número de profesiones es una tendencia inevitable en el mundo, y en España es relativamente bajo. Esa supuesta inflación de colegios profesionales no puede atribuirse a la dictadura franquista (1939-1975). El informe se contradice además en acon- sejar menor reglamentismo, para inmediatamente pedir que se reduzca el número excesivo de profesiones. Tendría que diferenciar entre universidades públicas y privadas. El modelo de diversidad, flexibilidad, optatividad y autonomía de las universidades que se propone es precisamente el modelo de Estados Unidos. La diferencia estriba en que los recursos de Estados Unidos son más del triple, y en algunos aspectos varias veces más.

Además de estas tres reformas —enseñanza superior no universitaria, educación continuada y diversificación de carreras-, se propone un nuevo modelo de enseñanzas (carreras) que el Informe Universidad 2000 denomina «sistema flexible»; aunque en realidad es lo contrario. Es una de las invenciones más polémicas, y seguramente equivocadas, del informe. Es difícil evaluarlo, pues el nivel de concreción es bajo, y las clasificaciones que se proponen no se entienden ${ }^{56}$. Afirma la «incapacidad del sistema universitario establecido para promover estudios al margen del patrón único de licenciaturas y similares» (BARÓ et al., 2000: 168). Para solucionarlo se propone un modelo de carreras doble, unas de «aproximación disciplinar» y otras de «aproximación profesional». En cada tipo puede impartirse los tres ciclos universitarios: diplomatura, licenciatura/ingeniería, y doctorado. Las carreras «disciplinares» son más generalistas y científicas, mientras que las segundas «profesionales» son más aplicadas. No queda claro en qué grupo de las dos sitúa el informe a carreras como Medicina, Derecho, Económicas o Arquitectura. La clasificación en dos tipos no es fácil. El problema es que el informe pretende un sistema de profesorado y de organización docente diferente. El modelo permite definir una especie de college (copiado del sistema estadounidense) que es el primer ciclo de la «aproximación disciplinar». Es un objetivo fundamental del informe que no sabe bien cómo introducir en el sistema español que es profesionalizante desde el primer año de estudios universitarios. El sistema español es complicado de transformar en un modelo norteamericano, pero el informe lo intenta.

Las carreras de «aproximación profesional» para los redactores del informe requieren la creación de un nuevo tipo de profesores. Afirman - sin demostrarlo- que «los departamentos no son el lugar idóneo para su incorporación a la Universidad, sino otras nuevas estructuras que cada Universidad debería establecer» (BARó et al., 2000: 171). No queda claro por qué los Departamentos no son el lugar idóneo para incorporar y formar profesores. La selección del profesorado es una tarea que sólo puede ser realizada por los/as propios colegas, que son capaces de medir el nivel de calidad científica de los/as candidatos. Cualquier otro sistema de selección es arbitrario. ¿Cuáles son esas nuevas estructuras que cada universidad debería establecer? ¿Con qué autoridad se afirma que cada Universidad debe seguir ese modelo? ¿Cuál es la base científica y documental de estas reformas? 
Las llamadas carreras de «aproximación disciplinar» incluirían un primer ciclo generalista. Se propone «unos itinerarios curriculares precisos, particularmente en la primera etapa de educación superior» ${ }^{57}$. Antes el informe define la diversificación, variedad y flexibilidad como tres características esenciales. Ahora contradice sus propias ideas proponiendo «itinerarios curriculares precisos» ${ }^{58}$. Parece referirse a la configuración de un college de cuatro años, general. Así se refiere a los estudios de carácter disciplinar de primer ciclo «de cuatro años de duración que, a su vez, se dividirían en dos tramos: un primer tramo, de carácter inicial, de una duración de dos años como mínimo, de tipo pluridisciplinar en buena medida, común a las grandes áreas científicas (ciencias, humanidades, ciencias sociales, ciencias de la vida, ingenierías) y un segundo tramo, de carácter especializado o más monodisciplinar» (BARó et al., 2000: 178). Se refiere, pues, a los two-years colleges y los four-years colleges; y a la diferenciación entre los años de freshman y sophomore, por un lado, y junior y senior, por el otro. Es prácticamente el modelo de Estados Unidos. Es una organización que funciona bien en una sociedad en que una proporción alta de la población alcanza estudios superiores, pues permite una educación de primer ciclo (cuatro años) generalista, poco profesionalizada. Posteriormente se pasa al segundo y tercer ciclo, que se denominan graduate studies, bastante más profesionalizados.

El cambio de modelo de enseñanzas en España debe planificarse dentro de un proceso de educación superior universal (para al menos el $75 \%$ de la población), sin devaluar la ESO y el bachillerato. Las personas que no acceden a la educación superior pertenecen actualmente a la mitad-pobre de las familias. Por ello cualquier expansión tendente a la universalización de la enseñanza superior va a disminuir la desigualdad social. Es, pues, un objetivo deseable. La remodelación de la enseñanza superior española hacia un college sería entonces posible y deseable. Pero no conviene alterar la posición de carreta y bueyes: primero hay que expandir la educación superior a la población más necesitada, y luego cambiar la estructura de las carreras. No al revés. Si no, se corre el peligro de que ese ciclo generalista (college) sea de calidad inferior o marginal.

La reestructuración de las enseñanzas en «disciplinares» (incluyendo un primer tramo o ciclo en forma de college) y «profesionales», lleva al informe a afirmar que las universidades españolas se pueden diversificar en tipos según su especialización. Es partidario de que exista un ranking de universidades, desde las universidades-investigadoras a las instituciones docentes de primer ciclo. Se dice explícitamente que el término «Universidad» se debe reservar para las instituciones que concedan el grado de doctor. Esta propuesta (definida en las páginas 175-177 del informe) es una de las que supondría una transformación más importante de la enseñanza superior en nuestro país. Se aumentaría la proporción de enseñanza superior no universitaria, con instituciones que sólo ofrecerían docencia de primer o segundo ciclo. Este cambio semántico (más que estructural) acercaría el modelo de enseñanza superior español al de Estados Unidos. Ese país, con cerca de cuatro mil instituciones de enseñanza superior, reserva el término university para instituciones superiores que ofrecen programas de doctorado ${ }^{59}$. Dentro de ese bloque están las research-universities (aproximadamente un centenar) que se especializan no sólo en doctorado, sino también en investigación. El Informe Universidad 2000 copia el modelo norteamericano, aunque sin citarlo. No parece conocerse ese modelo de fuentes primarias, ni entender las críticas más recientes dentro de Estados Unidos.

Preocupa que el sistema universitario español suspenda mucho y los/as estudiantes tarden demasiado en terminar la carrera. La solución que se ofrece es que «el gobierno de cada universidad debería crear los mecanismos o las instituciones adecuadas para que se solventaran situaciones de rigor desproporcionado en la evaluación de ciertas materias, introduciendo criterios razonables de calificación, teniendo en cuenta las puntuaciones que se obtienen en otras materias o atendiendo a la opinión de los responsables del asesoramiento a los estudiantes» ${ }^{60}$. En este caso «situaciones de rigor desproporcionado» es un eufemismo de «suspender». Se trata, como confiesa el informe, de sistemas poco satisfactorios de evaluación de los/as estudiantes.

El informe propone un proceso de adaptación de todo el sistema de enseñanza superior en que el Estado (en el informe se cita siempre como «Administraciones públicas») reduzca su papel, limitándose a pagar el presupuesto de las universidades, y a acreditarlas a posteriori. El Estado debe garantizar sistemas eficaces de evaluación, pero no reglamentar más; sólo supervisar. Ello incluye un sistema de información, otro de acreditación, y otro de evaluación de las instituciones; nada más. El Estado «debería limitarse a hacer públicos los objetivos generales de cada enseñanza». Posteriormente en este proceso de adaptación, los actuales Departamentos se deberían agrupar en áreas de conocimiento grandes «a las cuales se les atribuiría la responsabilidad de las enseñanzas que impartieran». Se trata, pues, de un sistema de desregularización y de destrucción del sistema actual de especialidades. Todo ello se completaría con la creación de instituciones de enseñanza superior distintas a las universidades, para impartir las enseñanzas de tipo profesional ${ }^{61}$. Pero las universidades españolas no se van a parecer a Harvard, Yale o Stanford simplemente porque cambien los rótulos de los Departamentos o de las carreras. Se requiere un cambio más drástico que el informe encargado por la CRUE no llega a entender. Quizás alguno de sus autores lo sospecha al incluir una nota de humildad al final del capítulo ${ }^{62}$.

El informe tampoco llega a ver uno de los cambios docentes más importantes de la Universidad, que es su universalización. Un objetivo importante es ampliar la enseñanza superior - sobre todo la educación universitaria - a la casi totalidad de los/as 
jóvenes. Por «casi totalidad» se entiende superar el $75 \%$ de la cohorte respectiva. Dado que la mitad de jóvenes que actualmente no acceden a la Universidad pertenecen precisamente a las familias con menos recursos económicos, el objetivo de universalización de la enseñanza superior es una conquista social considerable. Conviene programar e impulsar ese proceso de universalización, como en su día se hizo con el sistema sanitario. Es el cambio más importante que se puede conseguir en el sector universitario en el siglo XXI.

\section{Investigación}

La investigación es el objetivo que más debe cambiar si se quiere elevar la calidad global de la Universidad española. El capítulo sobre investigación en el Informe Universidad 2000 (capítulo 4, «Generación y aplicaciones del conocimiento») es el mejor. Explica la situación actual española; es atinado en su análisis y recomendaciones. Es una crítica de la situación presente, aunque apenas si hay recomendaciones o propuestas específicas. La segunda parte, dedicada al doctorado, está articulada. Algunas ideas de este capítulo contradicen otras del informe. Le falta por plantear seriamente la idea de universidad-investigadora como futuro de las mejores instituciones universitarias españolas ${ }^{63}$. Un ejemplo del nivel de crítica es cuando empieza reconociendo que «la balanza tecnológica de España es fuertemente deficitaria. El sistema de ciencia y tecnología español posee una capacidad muy reducida de innovación. La empresa española continúa, lógicamente, innovando con tecnologías importadas en su mayor parte» (BARó et al., 2000: 241-242). Dentro de la Universidad, la función investigadora es la que más se necesita desarrollar.

Reconoce la existencia de los procesos de globalización. El mercado único, «condiciona y determina el quehacer de las distintas instituciones universitarias, mas allá de su propia dinámica interna» (BARÓ et al., 2000: 206). Se considera que el futuro de la Universidad española depende menos de los intentos de reorganización propia que de las fuerzas y cambios internacionales. Defiende la libertad de investigación, un valor que yo también considero de enorme importancia, sobre todo dentro del sistema universitario: «La libertad de investigación, que no es sino una prolongación de la libertad de pensamiento, es, sin duda, uno de los pilares sobre los que descansa la ampliación de las fronteras del conocimiento». El principio es importante, y aunque parezca obvio es esencial en un informe de esta categoría. En consecuencia, «la investigación libre debiera ser incluida, con la correspondiente aplicación presupuestaria, en todas las programaciones plurianuales que se realicen con respecto a las actividades de investigación, desarrollo e innovación» (BARó et al., 2000: 237-238). Este capítulo sobre $I+D$ contradice lo que el capítulo sobre docencia critica al profesorado, es decir, su independencia y especialización libre.

La organización del sistema español de I+D no se estructuró de forma adecuada hasta los años ochenta, con el gobierno socialista. La LRU diseñó en 1983 una Universidad que tenía que integrar docencia e investigación. Eso supuso un progreso considerable. Pero la I $+\mathrm{D}$ sigue manteniendo una debilidad institucional. Es además mayoritariamente una responsabilidad del sector público. Las universidades privadas desarrollan poca I + D. Sin embargo, el Informe Universidad 2000 se equivoca, pues no se puede poner a todas las universidades privadas en el mismo saco. La mayoría de ellas no realiza apenas investigación, ni se dedica mucho a doctorado. Pero hay un grupo de universidades privadas (que incluye Navarra, Pontificia de Comillas y, hasta cierto punto, Deusto) cuyos esfuerzos en doctorado e investigación son considerables, en algún caso bastante mejores - per capita - que las universidades públicas. No puede, pues, criticarse a todas las universidades privadas, pues hay tipos distintos ${ }^{64}$.

Según el informe, el sistema de investigación de las universidades públicas se caracteriza por un porcentaje alto de doctores, más de la mitad. No sé si este porcentaje es realmente elevado; más bien me parece bajo. Entre todo el profesorado hay $43 \%$ de doctores. Se supone que el doctorado debe ser un requisito previo para investigar (salvo la tesis doctoral). Que el informe considere que hay muchos doctores entre los investigadores universitarios parece exagerado. Se puede estar de acuerdo en la presencia limitada de personal auxiliar de apoyo, pues apenas hay una persona por cada seis investigadores. En la Universidad española hay áreas de conocimiento en que la investigación todavía no se ha desarrollado.

El sistema público de $\mathrm{I}+\mathrm{D}$, que en buena parte es realizado por las universidades, muestra «insuficiencias serias a la hora de comercializar los resultados de su investigación tecnológica» (BARÓ et al., 2000: 221). Faltan infraestructuras de apoyo a la innovación. El informe aconseja que se genere una cultura empresarial. Hay que «esforzarse por difundir dentro y fuera de la Universidad una nueva cultura que reconozca los valores sociales de la iniciativa empresarial y de gestión, y la capacidad de asumir riesgos» (BARó et al., 2000: 249). Pero más importante que una nueva cultura empresarial, es necesaria una cultura investigadora dentro de la Universidad. El informe no señala suficientemente el aspecto más importante de la Universidad del futuro: la unión de docencia e investigación dentro de los mismos centros, Departamentos, e incluso personas. El objetivo es que todos los/as profesores investiguen, no solamente unos cuantos; y sobre todo que los/as profesores (con doctorado) enseñen a investigar.

En el informe, la crítica del sistema de I + D español, y sobre todo su presencia en la Universidad, está bien realizada. Sin 
embargo, apenas hay propuestas de reforma innovadoras. Las ocho sugerencias más importantes que presenta son las siguientes: 1) Conviene incrementar gradualmente el gasto español en ciencia y tecnología hasta alcanzar las cotas de gasto de la Unión Europea. 2) Eso supone aumentar mucho el gasto público en $I+D$ pero más aún el del sector empresarial privado que es relativamente deficitario. 3) Se propone un incremento de $27 \%$ del personal dedicado a I $+\mathrm{D}$, y $31 \%$ en la proporción de investigadores en la población activa. 4) Se deben tomar medidas para favorecer la relación entre Universidad y empresas a nivel de $\mathrm{I}+\mathrm{D}$, tales como la creación de grupos pluridisciplinares. 5) Hay que potenciar los parques científicos tecnológicos. 6) Es importante desarrollar al mismo tiempo las personas trabajando en I+D y la calidad de los grupos de investigación. Para ello hay que favorecer «la consolidación de grupos o centros de investigación de calidad con la suficiente entidad para poder integrarse en redes internacionales, con una dimensión multi e interdisciplinar que pueda optar a realizar proyectos estratégicos que requieren de un número elevado de científicos y tecnólogos» (BARÓ et al., 2000: 247). 7) Para que el sector científico español, y especialmente el de las universidades, aumente su peso internacional se recomienda: consolidar centros de investigación de excelencia, garantizar la financiación en los intervalos inter-proyectos, entrar en redes de conocimiento científico de ámbito mundial, incrementar los programas de movilidad de profesores e investigadores, incorporar doctores al sector productivo, y en general potenciar la carrera investigadora. 8) También es importante apoyar la creación de empresas por los/as propios investigadores, o por los grupos de investigación, universitarios, para explotar los resultados de su investigación.

La Universidad sigue teniendo el monopolio de formar estudiantes de doctorado, y conceder el título de doctor. La recomendación del informe es que en el futuro sólo las instituciones que otorgan títulos de doctor se denominen «Universidad». No queda claro qué nombre tendrían las otras instituciones, dedicadas más a la docencia. El doctorado es esencial para la formación de investigadores, y para enseñar a investigar. Así lo señala el informe: el «adiestramiento de nuevos investigadores tiene su piedra angular en el doctorado» (BARÓ et al., 2000: 251). Pero reconoce que su consideración social en España es insuficiente. Para superarlo se sugiere facilitar el futuro profesional de los/as doctores dentro, y sobre todo fuera, de la Universidad. Se pretende que el doctorado no solamente valga para la Universidad ${ }^{65}$.

El sistema de selección de estudiantes para el doctorado es insuficiente. Ésta es una de las críticas más agudas del informe: «Sorprende que, mientras para lograr una plaza en la Universidad, en titulaciones con limitación de plazas existe una selección muy exigente que discrimina notablemente en función de las calificaciones, para acceder a los estudios de tercer ciclo y posterior doctorado en algunas áreas no existe ninguna exigencia ni hay apenas competencia» (BARó et al., 2000: 252). Se acepta a casi todos los/as estudiantes, y aun así hay problemas para mantener algunos programas de doctorado debido a la escasez de estudiantes. El informe no señala que el doctorado en una universidad suele ser un sistema de formación del propio profesorado. Sigue un modelo altamente endogámico. Se realiza el doctorado no para ser investigador/a, sino para ser profesor/a. Apenas hay doctores en el sector privado y ni siquiera en otras universidades. Por eso el porcentaje de abandono es altísimo. El informe cita que la proporción de abandono sin terminar la tesis doctoral es $87 \%$, aunque no dice de dónde obtiene ese dato. Sugiere que los doctorandos deben estar bajo la supervisión de una institución, y no exclusivamente de un profesor/a. El sistema europeo se ha preocupado poco por el proceso de formación de los/as doctorandos, concentrando los esfuerzos en juzgar la calidad de la tesis doctoral. Los llamados «cursos de doctorado» son más un trámite que un objetivo ${ }^{66}$. En cambio, en el modelo norteamericano las asignaturas de la «escuela graduada» son difíciles, y requieren una gran inversión de esfuerzo y dedicación a estudiantes y profesores. El informe no recomienda ningún cambio; simplemente constata esa diferencia en la organización del doctorado a los dos lados del Atlántico.

Respecto al doctorado apenas hay propuestas de innovación, aunque algunas están implícitas en la excelente crítica que realiza de su organización y funcionamiento. Se sugiere que el doctorado sea más aplicado, es decir, más cercano a las necesidades de la sociedad: «una mejor adecuación de sus objetivos de investigación a las necesidades de la sociedad, sin que ello suponga renunciar a las exigencias de originalidad de la propia investigación» (BARó et al., 2000: 254). Pero podría darse el consejo contrario: una buena formación doctoral debería ser teórica y básica, poco aplicada a los problemas sociales concretos. Hay opiniones diversas, y no queda claro cuál debería de prevalecer. En la duda el mejor consejo es dejar libertad a los/as propios doctorandos e investigadores. Lo importante es que el tercer ciclo se tome realmente en serio en la Universidad española y se formen doctores para otras universidades y empresas. El futuro de la Universidad debe ser crear universidades-investigadoras a altura internacional; ése es el reto máximo.

\section{Financiación y becas}

El capítulo de «Financiación» acentúa la necesidad que existe en la Universidad española de incrementar los presupuestos, el equipamiento de todo tipo, los recursos para investigación, los salarios del profesorado y las becas a los/as estudiantes. 
No es un problema de incrementar un poco los recursos, sino realmente de duplicarlos. España, para ponerse a la altura de la Unión Europea, debe gastar el doble en enseñanza superior, y para acercarse a Estados Unidos debe al menos triplicar el presupuesto. El informe no pone énfasis en que se requiere más personal, con menos contrato precario, y además mucho mejor pagado (seguramente el doble de la media actual). El informe es partidario de una reforma del sistema de financiación, pero secundariamente al cambio de la organización de cada universidad ${ }^{67}$. Ésa es la equivocación fundamental del informe.

Sorprendentemente el informe ataca la gratuidad de la enseñanza superior. Es ambiguo respecto de la subida de los precios de matrícula. Sobre ello ha habido una fuerte polémica, y el informe accesible en red no deja clara su posición. Empieza diciendo que la tendencia mundial es a subir el precio de la matrícula. Concluye que en el sistema español público la contribución familiar debe permanecer en el $24 \%$. Pero si se duplica el presupuesto general eso supone doblar el precio de las matrí. culas. En contraprestación sugiere la expansión de becarios/as a más del doble (2,3 veces), y la cuantía de becas también a más del doble (hasta 2,7 veces más). Pero en ningún lugar explica cómo se va a conseguir el dinero para financiar la Universidad, ni para subir las becas cinco veces $(5,1)$. El objetivo general del Gobierno es reducir el gasto público, por lo que duplicar el dinero en enseñanza superior, y en investigación, es difícil. El informe nunca diferencia las universidades privadas de las públicas, lo que en un tema de financiación (y becas) es esencial.

Tampoco tiene en cuenta el proceso de universalización de la educación superior. Si se conserva el número de plazas universitarias - actualmente 1,6 millones de estudiantes-y el profesorado correspondiente, es posible llegar a ingresar en la Universidad a más del $90 \%$ de los/as jóvenes en la edad correspondiente antes del año 2015. El éxito se debe a que gracias a la bajada de natalidad de hace dos décadas con los mismos recursos se puede ingresar en la Universidad a toda la población. Eso contando con que no se creen más universidades, lo que parece difícil de controlar. La universalización universitaria es, pues, un objetivo alcanzable. La mitad de cada cohorte de jóvenes que no ingresa en la Universidad es precisamente la que pertenece a familias con menos recursos económicos. La expansión de la educación universitaria es un potente factor de igualación social, además de una conquista educativa.

El sistema universitario español es fundamentalmente un sistema barato y masificado. Tenemos tasas de estudiantes como los países más avanzados del mundo, y presupuestos universitarios tercermundistas. Así no se construye una Universidad de calidad. Por eso se habla tanto de «calidad» y «excelencia», precisamente porque no se está consiguiendo, y el retraso relativo es cada vez mayor. España no tiene universidades-investiga- doras de calidad, ni universidades que se puedan comparar con las mejores del mundo. El problema fundamental es el desfase entre el número de estudiantes y los recursos económicos. Dado que es impensable reducir la tasa de estudiantes universitarios, la única solución es aumentar drásticamente los presupuestos.

Las finanzas de la Universidad son confusas, y los grandes números no cuadran. Según los datos de la OCDE, el gasto por estudiante universitario en España es aproximadamente 900.000 pesetas ${ }^{68}$. Eso supone que el precio de la matrícula oscila entre $11 \%$ y $18 \%$ del coste total por estudiante según carreras ${ }^{69}$. Sin embargo, cuando se calculan los presupuestos oficiales el coste de las matrículas estudiantiles cubre $24 \%$ del presupuesto total, mientras que el Estado paga el $76 \%$ restante. El $24 \%$ del presupuesto no puede ser igual a $11 \%-18 \%$ del gasto. La Universidad tiene más ingresos que los que aparecen en sus presupuestos. El informe no aclara, por ejemplo, cuáles son los ingresos de las universidades a través del overhead de los proyectos de investigación, ni los pagos de las empresas privadas, los ingresos inmobiliarios, los de utilización de edificios o equipamiento de la universidad, explotación de marcas, venta de productos producidos por la universidad, incluyendo publicaciones, cuotas de cursos adicionales (diplomas, másteres, etc.), ingresos deportivos, donaciones de todo tipo o publicidad.

El coste de la Universidad española es $1,1 \%$ del producto interior bruto (PIB), cuando la media de gasto en los países de la OCDE es 1,6\% del PIB. Para ponerse a la par, España necesita aumentar el gasto total en enseñanza superior al menos $45 \%$, eso suponiendo que la media de OCDE no aumente. Si el gasto se mide en dólares por estudiante, la desproporción es mayor, lo que obligaría a elevar el gasto $65 \%{ }^{70}$. Esta discrepancia señala que el sistema no se caracteriza sólo por una fuerte carencia de recursos totales (que deben elevarse 1,5 veces), sino también por una abundancia de estudiantes mayor que otros sistemas de enseñanza superior, por lo que España debería incrementar los recursos 1,6 veces. Estados Unidos gasta por estudiante de enseñanza superior -muchos de ellos/as en enseñanza no universitaria, que es más barata- 3,3 veces más dinero que España. La regla de oro es, pues, que los recursos universitarios españoles se deben duplicar para nivelar la situación media de la OCDE, y triplicar para ponerse a la altura de los países más avanzados. El Informe Universidad 2000 propone una subida mínima del presupuesto (22\%) y quintuplicar los recursos dedicados a ayudas a estudiantes (multiplicar el coste por 5,1 veces). El informe nunca señala de dónde va a salir ese dinero. Al final del capítulo se incluye una simulación equivocada en los cálculos.

El objetivo del informe es doble: desarrollar la financiación de la Universidad y disminuir las desigualdades sociales. El principio no puede ser mejor; los objetivos «deben ser, por una parte, mejorar la eficiencia y la calidad de la enseñanza superior; por otra, avanzar en el logro de una mayor igualdad de opor- 
tunidades» (BARÓ et al., 2000: 262). Por igualdad de oportunidades entiende que «la probabilidad de acceso a la universidad (y de éxito dentro de ella) sea independiente del origen socioeconómico de los estudiantes» (BARÓ et al., 2000: 264). Pero en realidad no se trata tanto de igualdad de ingreso, sino de egreso, es decir, igualdad al terminar la carrera. No puedo estar más de acuerdo. La dificultad fundamental es cuando existen universidades públicas y también privadas. No queda claro en el informe si el sistema de financiación del sistema universitario español (por utilizar su propia denominación) que se propone es aplicable a las universidades privadas, y de qué forma. Los/as estudiantes de universidades privadas deberían poder beneficiarse de las ayudas estatales (becas y préstamos), a nivel de igualdad. Pero el sistema financiero debería incluir un estudio de ambos tipos de universidades.

Las universidades públicas españolas se financian con cargo a tres partidas importantes: 1) las matrículas pagadas por los/as estudiantes, 2) los presupuestos del Estado y 3) los pagos o donaciones del sector privado y de otras instituciones. El pago de matrículas supone $24 \%$ del total, y los pagos del Estado el $76 \%$ restante. La tercera categoría es un cajón de sastre que varía mucho de universidad a universidad, y que no aparece cuantificada. Por ejemplo, una partida importante son los proyectos de investigación (cuyo overbead queda en la universidad respectiva); pero tampoco hay datos fiables. La enseñanza superior: pública es un sistema mixto de financiación. El informe advierte que la tendencia internacional es a aumentar el pago de las familias a través de la matrícula anual. Pero esa cantidad es ya relativamente alta en España si se compara con otros países europeos avanzados. Hay que tener en cuenta que los otros países suelen tener una proporción de estudiantes becados mayor que en nuestro país. España tiene 17\% de becarios/as, pero Gran Bretaña, por ejemplo, tiene $96 \%$ de becarios/as; Holanda, $76 \%$. La tendencia es aumentar el precio de la matrícula, pero también la proporción de becarios, y la cuantía de las becas. Las ayudas tienden a un sistema de préstamos (a devolver al terminar la carrera, o incluso después) y menos a un sistema de becas. Pero suelen coexistir ambos sistemas.

La primera parte del capítulo es una crítica de la gratuidad de la enseñanza superior. El informe está en contra de la gratuidad de la universidad, a pesar de que es un sistema habitual en bastantes países, entre ellos Alemania, los países escandinavos y otros. En el resto de los países de la OCDE los/as estudiantes pagan entre $5 \%$ y $20 \%$ del coste total de los estudios universitarios. En España se alcanza 24\%. La educación universitaria en nuestro país es cara para los/as estudiantes y muy barata para el Estado. El informe es contrario a la gratuidad con diversos razonamientos. Primero, por supuestas razones de equidad no parece «justificarse la idoneidad de la subvención generalizada de las enseñanzas universitarias. La evidencia demuestra que tampoco la gratuidad de la enseñanza basta para alcanzar la igualdad de oportunidades en el acceso a la universidad» (BARó et al., 2000: 268). No explica de qué evidencia se trata, ni hace referencia a ningún estudio concreto. La gratuidad no es la solución total, pero mientras no se demuestre lo contrario, en un sistema universitario cada vez más extenso tendiendo hacia la universalización, es un buen sistema de igualación. El informe llega a afirmar que la gratuidad seria un sistema social regresivo. No presenta datos, y la argumentación no es convincente: «Una consecuencia de la selección socioeconómica del alumnado universitario es que la financiación pública de la enseñanza superior (a través de fuertes subvenciones directas a los centros) podría por sí sola ser regresiva, beneficiándose de ello, sobre todo, las familias de un nivel socioeconómico más elevado» (BARó et al., 2000: 269). En una situación de universalización progresiva de la enseñanza superior esto no es así.

El tema de becas versus presupuestos generales es complicado a nivel internacional. En la enseñanza obligatoria las becas suponen dos cosas: a) un estímulo individual al estudiante y su familia, yb) la posibilidad de conseguir una educación más selectiva o privada. Es obvio que las becas deben concederse a los/as estudiantes que son más inteligentes y prometedores. Pero en la educación no obligatoria, especialmente en la enseñanza universitaria en que los/as estudiantes son todos mayores de edad, a las dos funciones anteriores se le une: $c$ ) permitir la independencia respecto de la familia. Un/a estudiante universitario con beca total - tal y como se propone en el presente informepuede independizarse de la familia, e incluso no es necesario que trabaje y estudie al mismo tiempo. Potencialmente todos los estudiantes (salvo casos muy raros) dependen de sus familias. Si se les otorga una beca eso les permite ser independientes de sus padres, o quizás seguir siendo parcialmente dependientes pero cambiar a una educación privada de mejor calidad. No es aconsejable que el Estado dé becas únicamente para estudiar en universidades públicas. Debe respetar la libertad de los/as estudiantes en la elección de centro y universidad donde desean estudiar; más aún si son estudiantes brillantes, con notas altas. Un sistema de becas universitarias es imprescindible, sobre todo si el precio de la matrícula es tan alto como en España. Pero hay que tener en cuenta que el dinero invertido en becas posiblemente va a revertir en el sector privado. Tampoco está claro qué criterio utilizar en la concesión de becas y préstamos. El presente informe propone que se den únicamente por criterios de pobreza familiar. Pero eso no tiene sentido, pues todos los/as estudiantes son potencialmente pobres en el caso de querer independizarse de sus padres. Si se propone que haya un $40 \%$ de estudiantes viviendo independientemente, no tiene justificación que sean los de clases más bajas. El criterio meritocrático de que sean los que mejores notas obtengan es obvio. Pero es difícil poner en práctica un programa de «independencia» del $40 \%$ de estudiantes universitarios, que no genere un trasvase al sistema privado. Por eso en las discusiones políticas sobre 
sistemas de becas y préstamos la posición conservadora es la que defiende aumentar las becas, y la posición progresista aumentar los presupuestos de las instituciones de enseñanza pública ${ }^{71}$. Curiosamente el informe adopta una posición conservadora, proponiendo quintuplicar las becas (y préstamos), aumentando solamente un $22 \%$ el presupuesto universitario público; y además estableciendo criterios no meritocráticos, sino de menos recursos familiares. No se entiende una postura tan conservadora.

El informe ataca la gratuidad de la enseñanza universitaria. Además de las acusaciones previas de que el sistema no alcanza la igualdad de oportunidades, y que además es regresivo, llega a afirmar que la gratuidad genera estudiantes malos: «La gratuidad de la enseñanza superior no sólo no promueve el esfuerzo de los estudiantes, sino que tiende a crear problemas de selección adversa, atrayendo a la Universidad a estudiantes que no tienen posibilidades de completar los estudios» (BARÓ et al., 2000: 270). No queda claro por qué el Informe Universidad 2000 es tan contrario a la gratuidad del sistema universitario. Dedica bastante espacio, y pone mucho énfasis, en atacar la gratuidad de la enseñanza. No presenta datos ni evidencia que demuestre sus críticas. Su posición contradice los deseos de igualación social expresados al principio del capítulo. Si el coste de matrícula aumenta algunas familias no van a poder pagarla, y además no pueden vivir sin el salario del hijo/a. La única solución es matrícula gratuita, junto con un sistema de beca/préstamo que realmente permita al estudiante vivir independiente de sus padres. Eso supone establecer becas/préstamos de más de 70.000 pesetas mensuales, el triple de lo que se está pagando actualmente. A su vez, en un sistema de enseñanza superior que alcanzase al $75 \%$ de los/as jóvenes, con posibilidad de elegir cualquier universidad en el territorio nacional, al menos la mitad de esos/as jóvenes deberían de recibir una ayuda que les permitiese vivir independientemente. El informe nunca tiene en cuenta ese modelo ideal, aunque trata de aproximarse con una duplicación de la proporción de becarios y de la cuantía de becas. El proceso de universalización de la enseñanza superior va a cambiar radicalmente cualquier planteamiento sobre el coste de matrícula.

La ayuda a estudiantes por préstamos es más práctica que por becas. El informe es partidario de tender a un sistema de préstamos, sobre todo en el caso de estudiantes de los últimos años de carrera ${ }^{72}$. El problema no es el sistema de becas versus el de préstamos, sino si la financiación es suficiente para que los estudiantes se independicen de sus padres. En España hay pocos becarios/as (17\%), y la cantidad media de 225.000 pesetas al año es insuficiente para independizarse. Apenas cubre los gastos de transporte. Además los requisitos son muy estrictos, es decir, hay que ser muy-buen-estudiante y al mismo tiempo muy-pobre. El informe sugiere suprimir los criterios de nota, y conceder las becas solamente por necesidad económica ${ }^{73}$.
Esto es un problema, a la larga poco aconsejable. En Estados Unidos (señala el informe) más de la mitad de los/as estudiantes tienen becas que cubren los costes directos e indirectos de los estudios superiores. Pero hay muchas fuentes diferentes de becas y ayudas, no solamente el Estado.

De forma acertada el informe sugiere que el sistema nuevo de becas/préstamos debe promover la movilidad de los estudiantes «que permitiese la libre elección de centro» refiriéndose en realidad a la elección de universidad incluso en otra ciudad distinta a la residencia familiar. Luego lo aclara mejor: «Parece prioritario desarrollar modelos que faciliten la movilidad de los estudiantes, haciendo efectivo el derecho de elección del centro de estudios para toda la población. El ejercicio de ese derecho está probablemente hoy condicionado tanto por el lugar de residencia como por la renta familiar. Dada la escasa cuantía actual de las becas de movilidad, así como el reducido porcentaje de estudiantes que acceden a ellas, parece conveniente complementarlas con préstamos» (BARó et al., 2000: 284). Eso supondría un progreso considerable. $\mathrm{El}$ informe sugiere que la cantidad ideal sería 600.000 pesetas al año. Con sesenta mil pesetas mes un/a estudiante puede sobrevivir en una residencia estudiantil, o por su cuenta, aunque es una cantidad todavía insuficiente. Supone 2,7 veces más la cantidad media actual de las becas, lo cual es un progreso evidente. Está además en el umbral que permitiría a muchos estudiantes ser económicamente independientes.

La segunda partida económica de las universidades es el pago estatal, que supone $76 \%$ del total. La primera crítica es que el pago según el número de estudiantes debe variarse: «La fórmula lineal de financiación en función del número de estudiantes no es, en general, eficiente. Se recomienda, pues, contemplar factores que contengan incentivos de ajuste a la demanda de estudios, a la producción de titulados de calidad, y que tenga en cuenta, asimismo, la importancia de las economías de escala en las actividades de enseñanza universitaria» (BARÓ et al., 2000: 296). En concreto se proponen varias ideas: 1) dado que el coste relativo disminuye con el número de estudiantes, debería existir una cantidad fija por universidad, y luego una cantidad variable decreciente según el tamaño de la universidad; 2) conceder una financiación extra por cada estudiante admitido en primera opción; 3) para estimular la productividad de las universidades se podría «establecer objetivos razonables de graduación de los estudiantes [...] teniendo en cuenta el rendimiento académico inicial-medido por' las notas de accesode los estudiantes»; 4) además, el informe propone financiar, adicionalmente, otros programas o actividades. En concreto se citan tres: programas de doctorados de calidad con una convocatoria especial para su consolidación, subvenciones a la investigación de los Departamentos, y programas competitivos para incentivar la innovación en las actividades docentes. 
Para el control del gasto el informe es partidario de un sistema que ya se está poniendo en marcha en algunas Comunidades Autónomas, y que se denomina contrato-programa. Se establece entre el gobierno de la Comunidad Autónoma y cada universidad. «La financiación condicionada a ciertos objetivos, con la correspondiente comprobación posterior de su logro, permite conciliar la autonomía de cada institución con su sujeción a los intereses superiores de la colectividad» (BARÓ et al., 2000: 300-301). Yo no soy muy partidario de este sistema de contrato-programa. Supone un nivel de control excesivo sin incremento de los recursos. La universidad trabaja muy tutelada por el gobierno autonómico, y se tiene que ajustar a la planificación prevista. Es un sistema poco ágil, y no incrementa la libertad ni la autorresponsabilidad de las universidades. Son las universidades las que tienen que decidir autónomamente líneas docentes e investigadoras, sin que el gobierno autonómico juzgue si son positivas o negativas. El fenómeno de contratos-programa es parte de una evolución reglamentista con una nueva visión empresarial y de gestión. Parece innecesaria, pues las universidades-investigadoras, sobre todo si son de calidad elevada, saben muy bien cómo gastar los recursos. No necesitan que los/as políticos, los partidos políticos o la burocracia pública les vigile y controle. El refrán de «quien paga manda» es generalmente cierto, pero no debe ser así en la Universidad. La capacidad de innovación, y de variar criterios, líneas de investigación y proyectos docentes es un valor añadido en la Universidad.

Después de estos principios generales el informe vuelve al tema del precio de las matrículas y al tema de becas, en que considera que sus ideas pueden lograr cambios. El informe no cree que haya mucha posibilidad de variar la financiación estatal, por lo que se preocupa más del $24 \%$ de financiación privada (proveniente de las familias y los/as estudiantes). El problema a solucionar es doble: la proporción de becarios en España es baja (17\%), y la cuantía muy reducida (en Gran Bretaña es 3,4 veces mayor, en Francia 1,8 veces). La propuesta del informe es que la proporción del gasto familiar en el presupuesto universitario - que es actualmente $24 \%$ - no varíe. El párrafo en que deja clara su posición aparece en la página 305 y es importante para entender la polémica posterior que ha creado. Dice así (además en negritas): «El sistema de financiación debe mantener un modelo mixto (público-privado). Las cifras actuales permiten observar que la participación privada [se refiere a los/as estudiantes o sus familias] en esta financiación es mayor en España que en otros países del entorno europeo. Es recomendable, por tanto, que la participación privada a través de las tasas, por lo menos, no supere el porcentaje actual en el conjunto de los fondos de financiación de las instituciones univetsitarias» (BARÓ et al., 2000: 305). El informe es, pues, partidario de no aumentar el porcentaje actual que representa el pago de las matrículas (es decir, 24\%). Pero como, por otro lado se recomienda el aumento de los presupuestos de las uni- versidades, el precio absoluto de cada matrícula aumentaría correlativamente. Si se duplica el presupuesto global -lo que es deseable - entonces la matrícula costaría el doble. El informe es, pues, expansionista en cuanto al precio de la matrícula, aunque antes reconoce que en España se pagan matrículas caras para estudiar en la Universidad.

Tras la publicación en la web del Informe Universidad 2000 se desató una polémica, que tenía una cierta justificación. El movimiento estudiantil acusaba al informe de proponer subidas en las matrículas. El informe señala mantener el porcentaje de contribución de las familias, pero como también se propone aumentar el gasto universitario, en realidad el informe es favorable a un incremento sustancial en números absolutos del precio de matrícula. En un sistema como el español en que el coste de matrícula es ya alto, y en donde el sistema tiende hacia la universalización, no parece la mejor medida a tomar. Además, dadas las experiencias en otros países, especialmente el caso de la UNAM en México (cerrada durante nueve meses y medio), la política de aumento de matrículas no es aconsejable. El informe toma una posición contraria a la gratuidad de la enseñanza superior, que es luego atacada por el estudiantado. Era innecesario que el informe incluyese una crítica $\tan$ fuerte a la gratuidad de la enseñanza, pues nadie en España parece abogar por un sistema gratuito. Además, el informe no defiende nunca la universalización de la enseñanza superior (tasas de $75 \%$ o más de la cohorte respectiva), lo que también hace sospechosa su posición.

En los presupuestos generales de las universidades el informe es cicatero. Además, aumenta el control del gasto por el gobierno autonómico respectivo. En cambio, en el tema de becas y préstamos el informe es bastante generoso, en parte como sistema para equilibrar las desigualdades creadas por el coste proporcional del $24 \%$ pagado por los/as estudiantes. La propuesta se puede resumir en un objetivo doble: 1) Se propone aumentar la proporción de estudiantes que reciben ayuda del porcentaje actual $17,3 \%$ al $40 \%$. El informe es consciente de que este incremento de 2,3 veces es todavía insuficiente para lograr la igualdad, pero representaría un avance positivo. 2) El importe medio de las becas actuales es de 225.000 pesetas año. Anteriormente (página 285) el informe propone que la cantidad ideal sea 600.000 pesetas anuales. Ahora adopta una posición más cauta y sugiere 400.000 pesetas. En los cursos primeros (supongo que se refiere a primero y segundo, o sea, al primer ciclo) la fórmula es $40 \%$ de becas, de 400.000 pesetas cada beca al año. En los cursos superiores (lo que equivaldría al segundo ciclo) propone $10 \%$ de becarios y un 30\% adicional de estudiantes con préstamos, con un importe medio de 600.000 pesetas/año.

En mi opinión, la discusión sobre la cantidad es poco importante (debería variar con la inflación) siempre que permita la independencia total de los/as estudiantes respecto de sus 
padres, se eliminen los condicionantes de clase social y los/as estudiantes puedan cambiar de residencia (incluso de ciudad). La cantidad de 600.000 pesetas/año está cercana a la suficiencia, pero la de 400.000 es claramente insuficiente. Lo que hay que tener en cuenta en el cálculo del gasto en ayudas a estudiantes es que tanto el porcentaje de becarios/as (40\%) como la cantidad más alta propuesta (600.000 pesetas anuales por beca o préstamo) son insuficientes. Pero al menos es una mejora sustancial respecto de la situación precaria actual. El cálculo aproximado de los millones de pesetas necesarios para el plan de ayuda a estudiantes sería entonces el siguiente: ${ }^{74}$

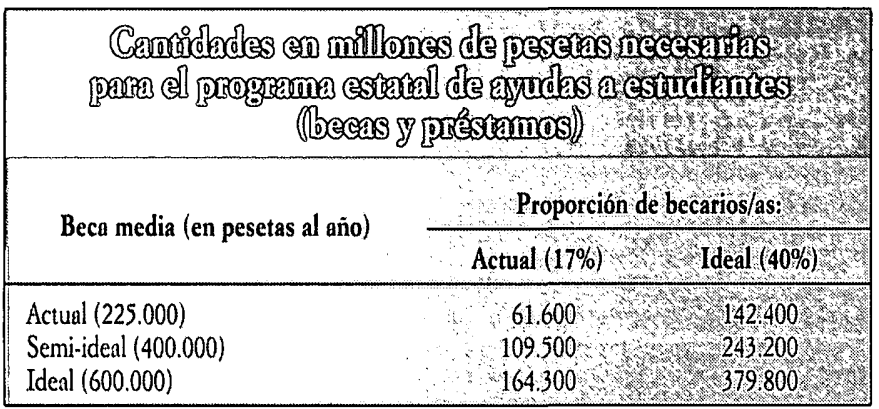

La situación más ideal es, pues, incrementar el número de estudiantes 2,3 veces, y aumentar la cuantía media de las becas 2,7 veces. Una alternativa «semi-ideal» es aumentar la cuantía solamente a 400.000 pesetas, es decir, 1,8 veces. Ésta es una posición quizás más realista. Entre el coste real actual $(61.600$ millones de pesetas anuales) y la solución más ideal $-40 \%$ de becarios con becas de 600.000 pesetas/año- hay que multiplicar la cantidad en ayudas por 6,2 veces. La situación semiideal supondría multiplicar la cantidad actual por 3,9 veces. El modelo mixto, que es el que finalmente propone el informe, con becas para los/as estudiantes de primeros años de 400.000 pesetas/año, y para los años siguientes un sistema mixto de becas ( $10 \%$ de estudiantes) y préstamos ( $30 \%$ de estudiantes), supondría 311.500 millones de pesetas, es decir, multiplicar el coste del programa por 5,1 veces ${ }^{75}$. No queda claro en el informe cómo se va a quintuplicar, o incluso sextuplicar, el dinero estatal dedicado a ayudas a estudiantes universitarios. Es una elevación seguramente necesaria (aunque todavía insuficiente) que supone una inversión pública considerable: 318.000 millones de pesetas anuales más que lo que se está gastando actualmente, si se aplica la hipótesis «ideal» ${ }^{76}$. No es la CRUE quien financia esta inversión en ayudas a estudiantes, sino el Estado.

El programa de ayudas propuesto por el informe es generoso, pues supone dedicar cinco o seis veces más dinero (estatal) a ayudar a los/as estudiantes universitarios. Aunque el coste de las matrículas se doblase en números absolutos, en el caso también ideal de que el presupuesto general de la Universidad se multiplicase por dos para hacerse homologable a la Unión
Europea, el programa de becas multiplicado por cinco o seis equilibraría seguramente la desigualdad social que supone el coste de los estudios universitarios en España. Lo más efectivo sería asegurar que las becas se ponen en marcha antes de la elevación del precio de las matrículas. Lo contrario sería desastroso. La propuesta más cauta es, pues, empezar por el sistema de ayudas (becas y préstamos) y sólo posteriormente permitir la elevación del coste en números absolutos del precio de la matrícula universitaria. El informe es generoso en ayudas a estudiantes, pero poco en dar más poder a los estudiantes. Falta en todo el informe un análisis sobre el papel de los/as estudiantes en el sistema universitario, o las formas de incrementar ese poder y hacerlo más efectivo. Es curioso que un informe sobre la reforma de la Universidad, que proviene del colectivo de los rectores de las universidades españolas, se olvide de un capítulo o sección sobre los/as estudiantes. Mantiene una visión paternalista de la Universidad.

$\mathrm{El}$ informe incluye al final del capítulo una simulación de la evolución en las fuentes de financiación de la educación superior, con el cálculo del coste de la reforma económica propuesta. Los cálculos parciales son confusos y no incluye una tabla con las cifras finales. Primero, propone una subida del $22 \%$ del gasto por estudiante. Esto es confuso, pues (en la página 303) ya se había calculado que el incremento necesario en el gasto anual por estudiante debería ser 65\%; o como mínimo $45 \%$ si se utiliza el gasto total en educación superior como porcentaje del PIB. La simulación final reduce, pues, las expectativas a la tercera parte del incremento necesario. En ningún lugar se explica este cambio a la baja. El número de estudiantes de enseñanza superior se sitúa con bastante realismo en 1,78 millones, de los que 1,5 millones corresponden a la Universidad ${ }^{77}$. A pesar del incremento del $22 \%$ en el gasto global por estudiante, se mantiene el pago proporcional de matrículas del $24 \%$, lo que significa que se aplica un $22 \%$ de incremento al precio de matrículas en números absolutos. La simulación final considera, sin embargo, que el mayor crecimiento correspondería a la ayuda pública a los/as estudiantes, «con un aumento de los fondos cifrados en 174 mil millones de pesetas». Sin embargo, la situación ideal de becas que el informe propone previamente no requiere 174 mil millones de pesetas adicionales, sino 318 mil millones adicionales (la diferencia es $83 \%$ más). En el párrafo final del capítulo se explica que: «en las universidades se pueden utilizar 140 mil millones para alcanzar igualmente una cobertura del $40 \%$ de becarios en los dos primeros cursos, con una beca de un importe medio de 400.000 pesetas al año. En los últimos cursos, los objetivos serían alcanzar la cifra de un $10 \%$ de becarios, junto con un $30 \%$ de perceptores de préstamos-renta (con un importe medio de 600.000 pesetas al año). En total se pasaría, pues, a un gasto en ayudas a estudiantes universitarios en torno a los 174 mil millones de pesetas (144 mil millones en becas y 30 mil millones al año en préstamos)» (BARÓ et al., 2000: 310). Las cifras están equi- 
vocadas: no serían necesarios 174 mil millones, sino $250 \mathrm{mil}$ millones de pesetas más, es decir, una diferencia en el cálculo del $44 \%$. Todo eso contando con que el modelo que se presenta tampoco es el ideal ${ }^{78}$.

Según esta simulación final en una década el sistema de enseñanza superior se incrementaría pasando de 1,1\% del PIB a 1,52\% al final del período. Eso supone $38 \%$ de incremento. Pero como en 1995 España mantenía ya un retraso de $45 \%$, es imposible que con $38 \%$ de incremento en toda una década se acorten distancias con el resto de los países de la OCDE. Incluso si los países de la OCDE no incrementasen el gasto en enseñanza superior en toda una década - lo que es altamente improbable-España estaría retrocediendo. Los cálculos realizados por el informe son, pues, inadecuados. Además, nunca se explica cómo se espera financiar la reforma.

\section{Profesorado y otro personal}

A pesar del título «Personal de la Universidad», la mayor parte del capítulo trata del profesorado, muy poco del personal de administración y servicios (PAS), y nada de otro tipo de personal contratado, o del que trabaja con contratas en las universidades. No incluye ideas sobre los salarios del personal, los procesos de feminización, la distinción entre universidades privadas y públicas, o la carrera investigadora. En su conjunto presenta una propuesta de reforma que es regresiva. En el capítulo no hay una unidad de pensamiento y los planteamientos son contradictorios. La propuesta que realiza de tres carreras docentes, y siete tipos de profesores, es difícil que alguna vez se aplique. La mayoría de las propuestas del informe reduciría la calidad de la Universidad española.

Los recursos humanos en la Universidad pueden ser de seis tipos: docencia, investigación, dirección, administración, servicios y otro personal. En «otro personal» se incluyen trabajadores a veces no contratados directamente por la universidad, sino indirectamente a través de contratas, por ejemplo, para la limpieza o mantenimiento de edificios. El informe escribe solamente sobre dos grupos: personal docente y administrativo. El resto no se menciona, ni se proponen reformas. Inicia la discusión con una cierta ironía, afirmando que «a veces conviene recordar a las Administraciones que los destinatarios de la actividad de las Universidades son los estudiantes y la sociedad en su conjunto, y no el personal que ya forma parte de la institución, como son los profesores y el personal de servicios y administración» (BARÓ et al., 2000: 317). El informe mantiene un tono bastante negativo sobre el personal, sobre todo el profesorado, que es injustificable.
Empieza avisando que propone una reforma con más tipos de profesorado y personal. «Se ha de proceder a una ampliación flexible de las figuras funcionariales o contractuales.» El objetivo es «flexibilizar las categorías docente-investigadoras y de servicios y administración, para permitir que cada universidad lleve a término su propio plan estratégico para diseñar el perfil de sus recursos humanos, tendente a resolver sus necesidades específicas» (BARÓ et al., 2000: 318) ${ }^{79}$. Luego sólo aumenta el número de categorías en el caso del profesorado. El argumento es que a causa de la escasa competitividad que ofrece la Universidad se «sugiere la necesidad de contemplar la dedicación a tiempo parcial de determinados perfiles académicos-profesionales» (BARÓ et al., 2000: 318). Es un argumento contradictorio, pues si se reconoce la baja calidad de la Universidad española - lo que es cierto - no se va a arreglar con más contratos a tiempo parcial, sino más bien lo contrario. La Universidad española tiene ya un $45 \%$ de profesores contratados, la mayoría a tiempo parcial. Entre el profesorado universitario sólo $43 \%$ tiene doctorado. La categoría de «profesor asociado», que es confusa y ha permitido una proletarización encubierta, es el 36\% del profesorado, una proporción demasiado alta. Cualquier política que quiera elevar la calidad de las universidades españolas debe tratar de disminuir la proporción de profesorado contratado a tiempo parcial, y aumentar la proporción del profesorado funcionario, con doctorado, con seguridad en el empleo, y trabajando en exclusiva. Sobre todo hay que aumentar la proporción de catedráticos que es sólo $9,3 \%$. También es importante incrementar la proporción de mujeres en el profesorado que es solamente $33 \%$, cuando la proporción de estudiantas es $53 \%{ }^{80}$.

El informe añade más burocracia a la selección y organización del profesorado. El coste de tanta burocracia no compensa la calidad que pretende conseguir. Exige definir el perfil de cada puesto de trabajo con toda minuciosidad. «Hay que establecer los tipos de competencias evaluables, entre las cuales hay que incluir asimismo aquellas características o rasgos individuales difíciles de obtener o de modificar a corto plazo, como son la capacidad para comunicar, la capacidad de dirección, el liderazgo, la capacidad para la resolución de conflictos, la capacidad para innovar, las relaciones interpersonales para un trabajo en equipo, la disposición para el autoaprendizaje o el compromiso para la permanente mejora, etc.» (BARó et al., 2000: 323). Es una burocracia excesiva tener que especificar todo este detalle. Los/as colegas saben evaluar globalmente la calidad y el potencial de un candidato/a a la universidad sin tener que especificar nada de eso por escrito. Además el énfasis en características como «relaciones interpersonales» o «resolución de conflictos» tiene poco sentido para el profesorado. Lisa y llanamente lo que una universidad busca es contratar a los mejores científicos/as que existen, a los más importantes en su especialidad, que más y mejor han publicado; y no a especialistas en relaciones públicas ${ }^{81}$. 
Los problemas del profesorado definidos por el informe se resumen literalmente en: 1) «la pérdida del punto de vista de conjunto, por ausencia del principio de inducción»; ${ }^{82} 2$ 2) un personal poco comprometido con la institución y con sus fines; 3) la pérdida de valor y a veces hasta la degradación de la función docente en relación con la función investigadora, y 4) la falta de una planificación racional y de una optimización del esfuerzo investigador en las universidades. El primer problema no se entiende, el segundo es inevitable, el tercero es falso, y el cuarto innecesario. Es increíble que un informe de esta categoría afirme que en España la función docente se degrada a causa de la investigación. El problema número uno de la Universidad española es la carencia de investigación competitiva a nivel internacional. Cualquier cambio en el profesorado debe llevar al reforzamiento de su papel investigador, nunca lo contrario ${ }^{83}$

Lo que desea el informe es que el profesorado «se comprometa con la institución a la que pertenece y cumpla sus funciones con sentido colectivo e institucional» (BARÓ et al., 2000: 325). Eso está bien como deseo, pero el informe no entiende que la fidelidad del profesorado es con su profesión, con sus colegas (sobre todo internacionales), y no con la institución local. Éste es un hecho observable en todas las universidades del mundo. Esa «fidelidad» al área de conocimiento es precisamente lo que permite el progreso en la formación docente y en la investigación científica. Lógicamente, la independencia de los/as profesores respecto de la universidad que temporalmente les acoge es un hecho que pone nerviosos a los rectores y gerentes, pero es una característica con la que se tiene que contar. Sin embargo, el informe decide «afrontar el problema de la eficiencia», mostrando la «urgencia de preparar aquellas actuaciones que incrementan la eficiencia de la Universidad, comprometiendo a sus miembros, con un sentido menos individual y más colectivo» (BARó et al., 2000: 326). $\mathrm{El}$ informe aparece un poco obsesionado por controlar al profesorado y convertirlo «desde arriba» en más eficiente.

El informe propone quitar la tarea de selección de profesorado a los colegas y al Departamento, para concentrar el poder en «la institución», es decir, en el rectorado y gerencia. Establece «la necesidad de profundizar en el establecimiento del perfil de las plazas a concurso, perfil que debe ser definido por la institución -en el desarrollo de su plan estratégicoy no por el grupo de personas - de un departamento casi siempre- que podrían intentar sólo favorecer a uno de sus integrantes» (BARÓ et al., 2000: 323). El sistema de concursos actual incluye profesorado de otras universidades. El informe propone que la elección del candidato ganador en los concursos sea realizada por administradores o el equipo rectoral, y no por colegas del mismo área de conocimiento. ¿Cómo van a evaluar los conocimientos científicos? Los/as administradores saben administrar, pero desconocen las materias científicas que hay que evaluar y la calidad de la investigación específica.
El informe es también sensible al movimiento de penenes --profesores no numerarios- que se produjo en los años ochenta, y que parece que vuelve a reproducirse en el inicio del siglo XxI. Entonces, tres cuartas partes del personal universitario en España era contratado. El movimiento de penenes ejerció una presión fuerte para obtener «la idoneidad», es decir, la estabilidad en el empleo. El incremento de estudiantes ha llevado de nuevo a las universidades a contratar más profesores. La carencia de presupuesto obliga a que muchos sean contratados con fórmulas precarias, como la de «profesor asociado» en su origen un invento para permitir a los médicos ejercer su profesión y ser al mismo tiempo profesores en los hospitales clínicos universitarios. Luego se ha utilizado para contratar profesores normales, incluso con dedicación total a la universidad, pero con un salario parcial. En la actualidad 36\% del profesorado total son profesores asociados. El informe reconoce que son «figuras contractuales precarias» y que estas personas presionan al sistema para lograr una estabilización en su empleo. La posición del informe es dura: «La carrera académica ha de encauzar la expectativa natural de promoción profesional; pero también ha de establecer de modo claro que la formación en las tareas académicas (de enseñanza y de investigación) no garantiza necesariamente la plaza de funcionario» (BARó et al., 2000: 336). ¿Por qué no? Lo lógico es que en la carrera docente se empiece por ayudante, se pase a titular y se termine en catedrático/a. No entiendo que haya contradicción en que la inmensa mayoría de profesores lleguen a ser catedráticos/as. El puesto de catedrático no debería ser la excepción, sino la norma en una vida académica. Supone un salario más digno, seguridad en el empleo, posibilidades extras de investigar, libertad para innovar y una mayor capacidad para formar a otros/as profesores. El porcentaje de catedráticos/as, que actualmente es $9 \%$, debería elevarse mucho, triplicarse en los próximos años. Sin embargo, el Informe Universidad 2000 propone -inexplicablemente- que se aumente la proporción de profesorado con contrato parcial y sin doctorado. No se entiende.

La desconfianza respecto de los profesores se extiende en el informe también a los doctores: «El recién doctorado se ha preparado para tener una aproximación adecuada al método científico, pero las condiciones exigidas para optar al título de doctor nada tienen que ver con la iniciación a la tarea de enseñar. En consecuencia es imprescindible completar la formación de los docentes en aspectos metodológicos, particularmente en el manejo de los instrumentos que las nuevas tecnologías ponen a disposición del aprendizaje» ${ }^{84}$. El informe termina este razonamiento con una propuesta sorprendente: «Para el ejercicio de la docencia el doctorado no sería requisito necesario.»Si se sigue este consejo, la calidad de la Universidad española se deterioraría aún más.

Se inventa una estructura de profesorado en tres carreras, que explícitamente se denominan: 1) carrera académica, 2) carre- 
ra meramente docente, y 3) carrera exclusivamente investigadora. Estas tres carreras dan origen a siete tipos de profesorado: ayudante, ayudante doctor, profesor asociado, titular docente, titular investigador, profesor titular de universidad y catedrático. Es decir, la innovación es que haya dos tipos de ayudantes $\mathrm{y}$ tres tipos de titulares. Nunca explica el informe las diferencias salariales de estos siete tipos. Tampoco cómo se pasa de una categoría a otra. En otra parte del informe se habla de la necesidad de introducir flexibilidad en la Universidad y menos reglamentismo, para lo que sería bueno que cada universidad se organizase como prefiera. Pero, en cambio, aquí establece un sistema incluso más rígido y estratificado que el actual, inventando la figura del profesor que no investiga ni tiene doctorado. La posición del informe es que para enseñar en la Universidad no es necesario el doctorado. En mi opinión, la figura del «titular docente» es un invento anacrónico.

Sobre salarios el informe solamente señala que podrían ser variables, incluyendo «incentivos retributivos adicionales» en forma de «premios consolidables». Propone revisar los criterios de asignación de los complementos de productividad, y eliminar la limitación actual del número de tramos de evaluación de la actividad investigadora. Pero no explica las diferencias salariales de las siete nuevas categorías de profesores que inventa, ni si realmente va a haber diferencias salariales dentro de cada categoría (independientemente de los incentivos). El problema fundamental del profesorado universitario en España es que muchos están a tiempo parcial, con salarios muy bajos, y que las personas en exclusiva cobran salarios bajos, no competitivos. En algunas ciencias e ingenierías la dedicación a la universidad está penalizada con sueldos mucho más bajos que la empresa privada. Con ello las personas que realizan el doctorado y se dedican a la universidad no se sienten motivadas, ni son los mejores estudiantes. A nivel de catedrático/a el salario entre universidad y empresa privada es cada vez más disonante. Pero el informe no trata esos temas.

El problema fundamental para llevar a cabo la reforma que propone el informe es que España apenas necesita ya una expansión de profesorado. Pero requiere un incremento considerable de los salarios y las condiciones de trabajo del profesorado. Como el alumnado está estabilizado en torno a 1,6 millones de estudiantes, y la tasa de estudiantes por profesor (17) no es muy alta, las posibilidades de incrementar en números absolutos el profesorado actual es limitado. La reforma supondría una reestructuración del profesorado que ya existe en la Universidad, lesionando seguramente derechos adquiridos de muchos. No creo que esta reforma se vaya a aplicar nunca. Si se hiciese, la calidad de la Universidad española descendería aún más. Es una reforma absurda y anacrónica.

El informe critica la endogamia del sistema actual de concursos de profesorado. Se inventa un nuevo sistema de concursos de profesorado. Considera que en España hay una «ausencia de una auténtica carrera académica». No queda claro a qué se refiere con ello. Afirma que «sería muy conveniente que, en los próximos años, se insistiera menos en los procedimientos para la selección del profesorado y más en las garantías de una adecuada formación del mismo» (BARó et al., 2000: 346). No son incompatibles. Pasa luego a explicar un nuevo sistema de selección de profesorado, que no va a tener tan en cuenta la investigación científica de los/as candidatos: «Conviene reflexionar acerca de la oportunidad de modificar parcialmente el peso excesivo que ha tenido hasta ahora el curricula de investigación en los procesos de acceso a las plazas de docencia-investigación» (BARÓ et al., 2000: 347). Es lo contrario: el peso de la investigación científica en los concursos ha sido reducido, y ello explica que la Universidad española sea tan poco competitiva a nivel internacional. El informe recalca que el profesorado que se va a dedicar a docencia no debe ser medido con otros criterios que no sean docentes. Afirma que no se requiere doctorado para ser profesor ${ }^{85}$.

La selección del profesorado nuevo, según el informe, no debe realizarse por colegas o personas de la misma disciplina. «La selección de tales expertos entre los pertenecientes al área de conocimiento a la que se refiere la plaza que hay que cubrir no es el camino mejor» (BARó et al., 2000: 348). Pretende pasar la responsabilidad de selección del profesorado de la misma especialidad a comités externos a la especialidad. La propuesta es: «Una decisión de la universidad, articulada a partir de la responsabilidad de quienes detentan la representación y el gobierno de las instancias adecuadas y no del grupo de docentes e investigadores de la universidad que se dedican a las mismas tareas profesionales que quien opta a la plaza que se convoca. Una opción alternativa sería depositar la capacidad de decisión en un grupo reducido de académicos independientes, de alto prestigio científico, de distintos campos del saber y que configurarían un verdadero Comité Académico de la institución universitaria con capacidad para decidir, para un período determinado, sobre la totalidad de las plazas convocadas» (BARÓ et al., 2000: 349). Este Comité Académico sería nombrado supuestamente por el rectorado. Pero seguidamente el informe contradice la idea de la creación del Comité Académico externo, para definir un procedimiento de selección distinto. El procedimiento se explica con un poco más detalle (en las páginas 350-351 del informe), en dos etapas: 1) Preselección: un comité de especialistas externo - pero de la misma especialidad- emite un informe razonado sobre cada uno de los/as candidatos «desglosando en el mismo los aspectos de docencia, de investigación, de gestión y de cualquier otra actividad a evaluar». Aclara: «este sistema de preselección favorecería, sin duda, la decisión ulterior, por cuanto no se limitaría a establecer (muchas veces por mera votación) quién es el mejor, sino a proponer quiénes son los más adecuados en cada actividad, por separado». 2) Selección. La institución que haya convocado la plaza «sería la que tendría que resolver del mejor modo posible su 
necesidad». Aclara que «para llevar a cabo esta decisión es bueno que la universidad esté representada exclusivamente por personas que representan a la propia institución». No explica si deben ser profesores, personal directivo o administrativo de la universidad.

La combinación de una selección que no es realizada por la profesión, con tres carreras académicas y siete niveles de profesorado, supone una situación desfavorable para elevar la calidad de la Universidad española. Se propone aumentar la contratación temporal y con dedicación parcial. Si además se institucionaliza la separación de docencia e investigación, no se demanda el doctorado para ser profesor y se excluyen los criterios de investigación científica en la promoción del profesorado, el resultado final puede ser nefasto. No se entiende cómo el equipo redactor ha podido llegar a semejantes conclusiones ${ }^{86}$. Son todas las medidas contrarias de las que serían necesarias para elevar el nivel de calidad de la Universidad.

\section{Excelencia y calidad}

El capítulo séptimo del Informe Universidad 2000 se titula «Calidad y acreditación». Es un capítulo corto y teórico, que explica las experiencias de evaluación en la Universidad española desde los años ochenta, e introduce una propuesta de acreditación. La mayor parte de lo que dice es adecuado, pero se olvida de la evaluación del personal directivo de las universidades (incluyendo gerencia y rectorado). Aplica la evaluación de la calidad al resto de los grupos, instituciones y personal; pero no a los dirigentes o a los órganos de gobierno. Se inicia con la afirmación de que «alcanzado el límite previsible de su crecimiento cuantitativo, el reto actual de la Universidad parece radicar en su esfuerzo de calidad» (BARó et al., 2000: 361). Efectivamente, parece que la Universidad española no crece, pues el número de estudiantes se muestra constante en los últimos años. En 1997 España alcanza el millón y medio de estudiantes universitarios, pero luego esa cantidad se estabiliza: 1,54 millones en 1997, 1,57 millones en 1998, 1,58 millones en 1999, y, según datos provisionales, 1,58 millones en el año 2000. Parece como si se hubiese alcanzado techo; pero no es cierto.

La realidad es que cada vez hay más personas que acceden a la universidad, ya que las cohortes de población de dieciocho-diecinueve años son mucho más pequeñas por causa de la bajada de natalidad hace dos décadas. Además, ahora no aumenta más la matriculación relativa de mujeres; son ya $53 \%$, estable desde 1995). Se está democratizando la Universidad. Las personas que acceden a la universidad cada vez provienen de clases sociales más bajas. Si sigue así se logrará ingresar en la universidad a las dos terceras partes de cada cohorte de dieciocho-diecinueve años, lo que representaría un éxito. Otra cosa es la desigualdad social de los/as estudiantes que terminan la carrera. Es inexacto, pues, que la Universidad ya no sea un problema de «cantidad». La cantidad, es decir, la expansión numérica supone una mayor igualación social. No se trata de crear más plazas universitarias (con las que hay es suficiente para quince años), sino de aumentar la «calidad» de la enseñanza, crear más igualdad social entre los/as estudiantes que terminan la carrera y lograr la excelencia en la investigación científica.

La definición operativa de «calidad universitaria» es en sí un problema; al que le hemos dedicado un libro entero titulado Excelencia: Calidad de las universidades españolas (terminado en junio de 2000). En el presente informe se insiste que tiene que utilizarse una combinación de autoevaluación interna y evaluación externa. Además, «debe incluir la presentación pública de un informe». El propio Informe Universidad 2000 es una crítica de la calidad de la Universidad española, y al mismo tiempo una propuesta de reforma. La evaluación de la calidad universitaria empezó en España por el Consejo de Universidades a finales de la década de los ochenta, desarrollando el Programa Experimental de Evaluación de la Calidad de las Universidades entre 1992 y 1994, y luego el Plan Nacional de Evaluación de la Calidad a partir de 1995. Este Plan realiza al menos tres convocatorias y un primer Informe sobre la calidad de las Universidades.

El Informe Universidad 2000 propone crear un programa mixto de evaluación y de acreditación. Avisa que la acreditación tiene el peligro de rutinizarse o normalizarse, lo que a la larga puede crear «inconvenientes a las actitudes innovadoras». El capítulo contiene ideas adecuadas sobre evaluación, acreditación y calidad, aunque sin presentar datos. Sugiere que cada universidad debería incluir un plan de evaluación de la calidad de tres procesos: 1) docente, 2) investigación y 3) gestión. Estos programas de calidad deberían «ser objeto de un seguimiento atento por parte de la universidad y a este respecto deben ser liderados por el rector» (BARó et al., 2000: 383). No queda clara la razón para insistir en que sean liderados por el rector. No especifica nada nuevo sobre cómo pueden hacerse las evaluaciones. El tono es excesivamente general e incluso tautológico, como cuando afirma que «el objetivo último de los programas de calidad del Plan Estratégico es la mejora de la calidad» ${ }^{87}$.

La única idea nueva es proponer la creación de una Agencia Nacional de Acreditación, para toda España. No especifica si incluye también a las universidades privadas. Da sugerencias para su composición, lo que es otro caso típico de misplaced concreteness: «Podría estar integrada por un número reducido de personalidades del mundo académico y profesional, nacionales o extranjeras, de reconocido prestigio y larga trayectoria en actividades y funciones relacionadas con el análisis de la 
calidad del sistema universitario, asistidos por un número suficiente de técnicos y personal de apoyo». Detalla aún más: «se debería acudir a fórmulas de nombramiento por acuerdo entre e] consejo de coordinación que se sugiere y la conferencia de rectores de universidades españolas» (BARó et al., 2000: 390). Es sospechosa la insistencia en que la evaluación debe ser controlada por los rectores, y que además la Agencia Nacional de Acreditación se debe nombrar y funcionar en estrecha relación con la CRUE ${ }^{88}$. Dado que el informe está redactado por un equipo nombrado por la CRUE, es impropio que llegue a este tipo de propuestas. La mayor dificultad no está en evaluar al profesorado (ya se hace en la mayoría de universidades), o al alumnado (se realiza todo los años), o a los investigadores (hay sistemas múltiples funcionando), sino en evaluar a los rectores, órganos de dirección y gerencia. El principio de que toda evaluación adecuada debe ser externa debe mantenerse. Por lo tanto, la Agencia que evalúa y acredita no puede depender de los rectores, ni de la CRUE. El informe parte de ideas adecuadas, desarrolla pocas ideas nuevas y llega a conclusiones desafortunadas. Pero mantiene un cierto nivel teórico.

\section{Organización y poder}

La organización es el tema principal de la reforma de la Universidad, según la propuesta del Informe Universidad 2000. Sin embargo, aparece hacia el final, como si fuese consecuencia de la reforma de las diversas partes de la enseñanza superior. El capítulo se limita a decir lo que ya existe, a describir la situación salpicándola con alguna crítica ligera. Sólo hacia el final presenta, muy breve y esquemáticamente, una propuesta de modelo de estructura de gobierno. No es muy diferente de la actual, aunque incluye algunos rasgos típicos de las universidades de Estados Unidos. Termina con una propuesta que pretende dar más poder a los rectores.

Hasta hace poco no era necesario hablar de organización de las universidades ${ }^{89}$. «Durante años, las universidades espanolas no han tenido una necesidad acuciante de desarrollar estrategias propias, ya que la mayoría de las decisiones venían fijadas de antemano por la Administración y carecían de capacidad o instrumentos para ejercer la suficiente autonomía exigida para la determinación de la orientación global de la propia Universidad. La referencia a un modelo único de Universidad impedía elaborar una visión, una misión y una dirección estratégica propias» (BARó et al., 2000: 436). Lo moderno es que haya tipos distintos de universidades, cada vez la autonomía real sea mayor. Pero hay una dificultad considerable en tratar de cambiar una organización anárquica pero innovadora - como es la Universidad - en una organización racional, burocrática, y predeterminada. Tampoco queda claro que eso sea lo más aconsejable. La «prueba del pastel» de la calidad de una Universidad sigue siendo su capacidad de innovación, y el avance del conocimiento. La transmisión del conocimiento es un tema mucho más fácil, aunque comporta un esfuerzo. Establecer una organización para innovar requiere, como se dice en español, mucha mano izquierda, es decir, autonomía, libertad y cierto grado de heterodoxia. Los modelos manageriales de eficiencia y eficacia, con elevado control, evaluación y accountability, suelen ser poco efectivos en la Universidad.

El capítulo vuelve al tema de la «planificación estratégica» que nunca se termina de explicar en el informe. Es más bien un comodín para no tener que concretar algunas propuestas de cambio. En un capítulo sobre organización llama la atención que no haya referencia a los/as estudiantes. El informe es una propuesta paternalista, realizada «desde arriba». Es un capítulo sin datos, con pocas propuestas, y las que hay son confusas. Mezcla un modelo-Estados Unidos con un modelo propio centrado en el poder del rector. El capítulo de organización dice poco nuevo porque ya lo ha ido exponiendo en los capítulos anteriores. Completa el informe con una propuesta de reforma del «Gobierno y administración». Parte de la idea de que las actuales universidades no pueden cubrir todos los campos y objetivos; deben de ser flexibles, tomar decisiones y especializarse. Eso lleva a que acepten diversas formas organizativas ${ }^{90}$.

La organización universitaria actual es confusa. En mi opinión, está llena de organismos que se vigilan unos a otros. Cada grupo de presión ejercita el poder a través de un veto point (una especie de derecho a veto), es decir, negándose a que alguna medida o política determinada se lleve a cabo. El poder no les sirve para hacer cosas sino para oponerse a propuestas determinadas. El veto point sólo funciona cuando las propuestas se hacen explícitas (en una reunión, por ejemplo). El informe señala que los cargos directivos de los centros y los Departamentos «tienen unas atribuciones poco claras y escasamente definidas». Las gerencias se han ido extendiendo, «se han ido profesionalizando» se asegura. Desde mi punto de vista, han ido consiguiendo más poder. Todavía el gerente es nombrado directamente por el rector, pero la gerencia es cada vez un equipo más extenso y permanente. La LRU instituyó el Departamento como la unidad docente básica; no lo es tanto de investigación.

Las innovaciones que presenta el informe derivan de su propio esquema previo de enseñanzas disciplinarias y profesionales. La propuesta de crear un primer ciclo disciplinar generalista - una especie de college - lleva al informe a proponer que haya una organización académica responsable de gestionarlo. En Estados Unidos sería un Dean (decano). Pero también las carreras profesionales tienen Dean. El informe soluciona el problema anterior de diversificación de carreras por tipos, con organizaciones ad boc paralelas a la organización general de la universidad. Para la enseñanza profesional propone también una 
estructura organizativa propia. En Estados Unidos se trata de las Escuelas de Derecho, de Medicina, de Administración de Empresas, etc. Además, estaría la Graduate School, que integra las otras enseñanzas, lo que en España son las Facultades. El informe propone que la gestión del college, y de las enseñanzas profesionales, se confíe a «responsables —académicos o no académicos- nombrados por los órganos centrales de cada universidad» (BARÓ et al., 2000: 434). El modelo propuesto por el informe se parece mucho al norteamericano. Incluso llega a proponer que el nombre de «Facultad» se podría reservar como una denominación corporativa del profesorado, al estilo de la faculty en Estados Unidos. Paralelamente a la docencia hay centros o institutos de investigación que se han ido creando directamente (la LRU lo permite) o a partir de la consolidación de grupos de excelencia. Hasta aquí lo que es común en la propuesta con los modelos extranjeros.

El informe muestra también algunas divergencias curiosas: 1) Exige la «fijación clara y explícita de los objetivos de la Universidad», algo que seguramente no es necesario. 2) Propone que los Departamentos se agrupen (al menos algunos) según grandes áreas del conocimiento científico. No queda claro por qué se aconseja eso. El sistema actual es ya muy similar a lo que ocurre en Europa y en los países de la OCDE. No es preciso cambiarlo. 3) Señala que se necesita más control: «Existen déficits notables en relación con la efectiva rendición de cuentas de las universidades ante la sociedad y con el nivel de eficiencia exigible en la gestión de los recursos que la sociedad pone a disposición de la universidad» (BARó et al., 2000: 438). No es aconsejable controlar demasiado los recursos que son escasos; y eso es lo que está sucediendo en España. El objetivo de la Universidad no debe ser tanto su evaluación, como su desarrollo.

Con estas ideas el informe define la propuesta de un modelo de estructura de gobierno común a las universidades ${ }^{91}$. Primero, propone la creación de un órgano de gobierno máximo que sea único, es decir, agrupando dos actuales: la Junta de Gobierno y el Consejo Social. «El órgano máximo de gobierno (equivalente a la Junta o Consejo de Gobierno de la Universidad) podría estar formado tanto por miembros de la comunidad universitaria como por representantes de los intereses sociales y de las administraciones y entidades que apoyan a la universidad» (BARÓ et al., 2000: 439). Parece estar pensando en un Board of Trustees. Estoy de acuerdo, pues la existencia de dos cabezas - Junta de Gobierno de la Universidad, y Consejo Social_ lleva a que se obstaculicen mutuamente.

En segundo lugar, se propone una simplificación organizacional. La propuesta es un poco enigmática, y por eso la copio literalmente: «Debería simplificarse la estructura, composición y competencias de los órganos colegiados. Esto significa que deberían mantenerse únicamente los órganos adecuados para el correcto gobierno universitario, su composición se reduciría a proporciones razonables para su funcionamiento eficiente, y sus competencias - salvo en el caso del máximo órgano de gobierno- deberían ser fundamentalmente de asesoramiento, propuesta y control» (BARÓ et al., 2000: 439). Si entiendo bien, se propone un control bastante más centralizado, con todo el poder ejecutivo en el rector y en la Junta o Consejo de Gobierno de la Universidad, que integraría al propio Consejo Social, y que estaría presidida por el rector. Los demás órganos de la universidad serían consultivos o de gestión, pero no decisorios. Se propone, pues, un sistema mucho más centralizado. El informe sugiere un cambio organizativo, en la línea de las universidades estadounidenses, con enseñanzas disciplinares y profesionales, cada una de ellas con su administración propia. Pero más importante que esa copia del modelo de Estados Unidos (sin citarlo) es que el informe propone dar mucho más poder a los rectores: todo el poder ejecutivo dentro de la universidad. Junto al rector prevé una gerencia y administración más managerial. Es sorprendente que un informe financiado por la CRUE, y cuyos autores han sido nombrados por los rectores, proponga dar mucho más poder a los rectores ${ }^{92}$.

\section{Aplicación de nuevas tecnologías}

El último capítulo del libro, el noveno, incluye en realidad dos temas diferentes: «Redes tecnológicas y redes universitarias». Están juntos porque utilizan —con un significado distinto- la misma palabra: red. El primer tema es sobre la aplicación de nuevas tecnologías, y el segundo sobre universidades múltiples. No tienen mucho que ver, y por ello separo su análisis. El punto de partida es la importancia de las nuevas tecnologías de información y comunicación (utiliza el acrónimo TIC), es decir www, netscape, internet, bancos de datos, medios de comunicación por red, bibliotecas computerizadas, artículos científicos por red, utilización de ordenadores en las aulas universitarias, reuniones o clases virtuales, etc. Considera que es uno de los factores externos de mayor cambio en la Universidad. Sin dar datos que legitimen esa opinión, afirma que «se advierte una fuerte resistencia del personal académico y administrativo a la introducción de las TIC en el modelo pedagógico» (BARÓ et al., 2000: 458). Yo considero que es lo contrario; se produce una adhesión relativamente rápida. El problema es que muchas universidades ponen en marcha sistemas de información y comunicación, pero incompletos, de calidad baja, con bastantes problemas de funcionamiento. La red trabaja despacio, a veces queda interrumpida, se «cuelga», es poco fiable, hay bastantes virus y problemas, algunos centros universitarios están cerrados los fines de semana o vacaciones, faltan ordenadores apropia- 
dos, muchos ya no funcionan adecuadamente, etc. Los/as profesores tienen acceso, pero los/as estudiantes escasamente. Esto hace que el sistema sea poco fiable. El problema es similar a las bibliotecas universitarias, que tienen bastantes libros de un tema pero casi nada de otro, falta la bibliografía internacional más reciente o esencial y hay discontinuidades graves en las revistas. Los/as buenos investigadores/as apenas pueden confiar en la biblioteca de su universidad, que suele ser muy pequeña $(0,4 \text { millones de volúmenes de media })^{93}$. El informe sugiere que se desarrollen inmediatamente las nuevas tecnologías TIC. Es una propuesta apropiada, pues el retraso español es evidente.

El informe propone además que «las universidades entren en el espacio de la educación a distancia en la que se combina la docencia presencial con ciertas dosis de docencia virtual» (BARÓ et al., 2000: 458). Sin embargo, no da razones de por qué hay que desarrollar prioritariamente la educación a distancia. No especifica si así se avanza más el conocimiento, es una forma de hacer mejor investigación, de centralizar recursos quitándoselos a los Departamentos, o porque es un buen negocio. No da razones; solamente sugiere «entrar» prioritariamente en educación a distancia. Sin embargo, más adelante reconoce que «las universidades han de fortalecer los servicios de sus campus. Los estudiantes no acuden a la Universidad sólo por exigencias académicas. En la mayoría de los casos, el desarrollo personal del estudiante sólo se consigue integrándose plenamente en el medio universitario. En este sentido, el estudiante que acude a los campus universitarios adquiere una educación y una experiencia mucho más ricas que un estudiante que sigue una enseñanza de carácter virtual» (BARó et al., 2000: 466). El informe incluye opiniones contradictorias. Globalmente parece partidario de una idea de multiversidad, que incluye formas diversas de aprendizaje, entre ellas a distancia, de educación permanente, e incluso virtuales ${ }^{94}$. El informe considera que el incremento mayor de la enseñanza superior se va a producir en educación continuada. Pero no ofrece datos de tendencia para afirmar eso. Es posible que en las universidades-investigadoras de mayor calidad del mundo una cierta expansión se puede producir por la educación virtual a distancia. Pero en España —en mi opinión - la expansión mayor debería concentrarse en el desarrollo de universidades-investigadoras, presenciales, con mucha mayor calidad que las actuales. Desarrollar la educación continuada, a distancia y virtual, antes que incrementar sensiblemente la investigación científica y los estudios de tercer ciclo (doctorado) de calidad es una equivocación.

El informe considera que la financiación de las nuevas tecnologías debería ser un presupuesto a detraer del resto de los objetivos actuales de la Universidad: «La contención del gasto universitario por estudiante aconseja que la financiación de estas tecnologías se lleva [debería decir «lleve»] a cabo mediante una redistribución de los fondos, aunque en ocasiones se pueda acudir a aportaciones externas. Esta redistribución debería pro- ponerse el establecimiento de un fondo propio, estable y con recursos adecuados a los objetivos previstos» (BARó et al., 2000: 462). No queda claro lo que realmente se propone con este párrafo, ni quién va a controlar ese fondo. El informe termina contaminándose del «tono virtual» de las nuevas tecnologías, con párrafos complicados, pero ideas ingenuas ${ }^{95}$. Entre otras obviedades está que «las universidades han de facilitar el acceso de los estudiantes a la tecnología» (BARÓ et al., 2000: 465). España es uno de los países de Europa con una tasa menor de ordenadores por población, y de conexión a Internet; «por tanto, las universidades deberían, prioritariamente, desarrollar políticas de ayuda a los estudiantes para disponer de un ordenador adecuado a sus estudios y de acceso a la red» (BARÓ et al., 2000: 465). Esto es bastante obvio, y habría pocas personas en contra de la propuesta. El problema es el coste, cómo hacerlo y los sistemas de ordenadores. Para reforzar la idea el informe añade que «la "Sonoma State University of California" ha hecho obligatoria para sus nuevos estudiantes la tenencia de un ordenador». El ejemplo no puede estar peor elegido, pues es una universidad desconocida, que en el mundo científico no cuenta. Debería de haber puesto otro ejemplo que ratificase que el acceso a un ordenador por estudiante supone un avance cualitativo ${ }^{96}$. Las universidades importantes suelen adoptar una política de wait and see: esperar, y evaluar luego el progreso que supone cada moda. Tienen tiempo así de decidir la mejor estrategia para convertirse en líder de los cambios que realmente suponen una ventaja. La calidad de una universidad reside en la docencia realizada por profesores excelentes, y en su investigación científica competitiva a nivel internacional. Que eso luego se comunique oralmente (como es usual) o a través de métodos virtuales es secundario ${ }^{97}$. Sólo las universidades de calidad muy baja, que no son competentes para producir avances importantes en el conocimiento, tienen que llamar la atención de las familias y alumnos/as con supuestos avances de tecnologías nuevas. Pero lo que importa es el contenido, no la forma.

El capítulo adopta una actitud ambigua sobre las nuevas tecnologías. Se muestra entusiásticamente partidario de ellas, pero no explica los avances que prevé. Es igualmente favorable la educación a distancia, pero no explica bien por qué razones quiere que se ponga en marcha inmediatamente. El resto del capítulo son obviedades sobre las nuevas tecnologías en un mundo globalizado. No hay propuestas de reforma novedosas ni interesantes. Es un tema que, según está formulado, podría haberse excluido del informe.

\section{Redes de universidades}

El último tema del libro debería haber sido casi el primero: la cooperación entre universidades, y lo que en el mundo se 
conoce como redes de universidades, y multicampus. Reconoce la mundialización del conocimiento, bajo la influencia de un mercado único. Pero la globalización es una idea que el informe no analiza críticamente ${ }^{98}$. Considero que la Universidad es una de las pocas instituciones sociales que tiene como tarea el análisis crítico de la globalización y el establecimiento de soluciones para evitar los problemas negativos que conlleva el mercado único. Ésa es una responsabilidad intelectual considerable.

$\mathrm{El}$ informe considera que «la red, entendida como forma de colaboración no jerárquica entre universidades, o entre éstas y la Administración Pública y el sector productivo, supone una apuesta estratégica de cara al futuro desarrollo de las universidades» (BARÓ et al., 2000: 468). Es una obviedad, sobre todo si no se define la metáfora «apuesta estratégica». Escribe solamente ideas ya sabidas, como que la cooperación entre universidades posibilita una mejor formación, el reconocimiento de los títulos, y la multidisciplinariedad de los estudios ${ }^{99}$. Las ventajas de la colaboración entre universidades son múltiples. Las más interesantes que cita el informe permiten: 1) la diversificación de actividades, 2) experimentar soluciones a problemas comunes, 3) compartir riesgos, 4) la movilidad de alumnado y profesorado, 5) la internacionalización de los planes de estudio, 6) establecer programas de doctorado o de postgrado comunes y 7) una mejor comunicación de la investigación producida en cada universidad. Curiosamente no cita las posibilidades de bibliotecas comunes entre varias universidades. $\mathrm{La}$ idea más importante es la posibilidad de crear una red auténtica de universidades públicas en España. Suponen ya medio centenar de instituciones, bien repartidas por el territorio español, con muchos recursos, que alcanzan a una comunidad de más de millón y medio de personas. Esa red sería un objetivo importante que el informe podría haber definido con algo de detalle, sugiriendo posibilidades concretas de colaboración. Pero el tema no aparece en el informe.

$\mathrm{El}$ informe menciona las joint ventures, que traduce como «alianzas estratégicas» ${ }^{100}$. Son normalmente entre la universidad y empresa privada o similar. Puede ser también con una institución pública, pero que tiene objetivos no necesariamente educativos. Advierte de que requieren una concreción de la cooperación, así como de las formas de practicarla. Insiste en la misma idea: «Las alianzas estratégicas con otras organizaciones pueden contribuir a mejorar la situación financiera de las universidades y a fortalecer su autonomía. Para alcanzar estos objetivos, la estrategia de las universidades no debería confiar en una sola alianza estratégica. Las universidades deben abrirse a múltiples valoraciones con otras entidades, coordinando debidamente las diferentes alianzas en base a sus propios objetivos estratégicos» (BARó et al., 2000: 477) ${ }^{101}$. La sobreutilización de la palabra «estrategia» dificulta el entendimiento del párrafo.

Al final el informe vuelve a un tema que debería haber discutido antes, que es el de universidad multicampus. Lo típico de las universidades públicas españolas es que han crecido continuamente. Hasta el año 2000 no han parado algunas, y sólo las más grandes. Las universidades públicas incrementan el número de estudiantes y carreras, sin una previsión de tamaño final. Recientemente algunas universidades autonómicas se han dividido en universidades provinciales. Andalucía ha creado una universidad en cada provincia, Cataluña hace lo mismo, y Canarias crea universidades en las islas más grandes. Pero la Universidad del País Vasco no se ha dividido a pesar de que tiene campus en las tres provincias, diseminada incluso en varias ciudades. La Universidad del País Vasco es un ejemplo español de multicampus. Seguramente es para poder competir con las universidades privadas de Deusto o Mondragón. El informe debería de haber tomado una posición clara sobre el tema de universidades independientes frente a universidad multicampus. Pero es un tema que apenas menciona. Recomienda que «las universidades de gran tamaño deberían adoptar formas de acentuada descentralización - mediante la organización de un «sistema» [...] - o debería plantearse su división» (BARó et al., 2000: 478-489). Pero no define objetivos específicos. Tampoco se atreve a definir la creación de una red de universidades públicas españolas, ni las posibilidades del multicampus.

Con estas ideas termina abruptamente el Informe Universidad 2000. Finaliza con ideas y planteamientos que debería de haber introducido al principio del informe. No presenta una reforma estructurada de la Universidad española, sino una serie de objetivos dispersos y concretos, en contradicción unos con otros. Se inicia explicando que la educación superior no universitaria es muy importante, pero luego no la analiza. Tampoco realiza una crítica sistemática, ni un análisis científico, del sector universitario español. Es una provocación que trata de generar un debate sobre el futuro de la Universidad, no una reforma estructurada. Tampoco es una posición unánime del conjunto de rectores españoles. Es más bien una pedrada en el lago, cuyo objetivo es producir ondas en la superficie.

\section{Más allá de 2001}

No conviene entender inadecuadamente el título del presente documento: «Reinventando la Universidad». La Universidad española no necesita reinventarse. Ya existe, y funciona moderadamente, sobre todo teniendo en cuenta los recursos que utiliza. El retraso español no es de modelo de Universidad, sino de recursos y equipamiento. Informe Universidad 2000 es un esfuerzo ingente de escritura, que equivoca la forma de elevar la calidad de las universidades españolas. El objetivo no debe ser reinventar la Universidad, cambiando toda su organización, sino dotarla de medios. No conviene cambiar de nuevo el sistema de Departamentos y de Áreas de Conocimiento. 
Estratificar aún más el profesorado, aumentando los contratos a tiempo parcial, es una equivocación. Dedicarse de lleno a la educación a distancia, olvidando la educación presencial, es poco inteligente. En las universidades públicas basta con algunos cambios necesarios, y sobre todo con una inyección considerable de recursos en presupuesto, equipamiento y salarios. Esos recursos nuevos deben de ser por lo menos del doble, y en algunos casos el triple.

Se requiere una decisión política. No hay que buscar culpables, y menos aún achacar todos los problemas al profesorado o al estudiantado. Tampoco se trata de centralizar el profesorado ni de proletarizarlo aún más. A la situación actual se ha llegado a través de décadas de falta de imaginación de las personas que tienen el poder, tanto en el Gobierno central como en los autonómicos, así como en la dirección (rectorado-y-gerencia) de las universidades. El objetivo final no debe ser elaborar «planes estratégicos», ni sustituir los sistemas actuales de organización por evaluaciones economicistas. La Universidad tampoco va a funcionar mejor con gerencias obsesionadas con evaluarlo todo (menos a ellas mismas). El sistema funciona basado en la responsabilidad del profesorado. En el mundo globalizado actual el invisible college adquiere una importancia considerable para promover la calidad universitaria. Cada vez más el control profesional es mundial, y además casi instantáneo.

No se trata de reinventar nada, sino de conseguir que en España haya un puñado de universidades-investigadoras de referencia, competitivas a nivel internacional. Eso sólo se consigue multiplicando por diez los libros de las bibliotecas y los ordenadores en las universidades españolas; por seis las becas a los/as estudiantes; multiplicando por tres los salarios de los profesores; triplicando los recursos para investigación; incrementando sensiblemente la proporción de profesoras; $y$ sobre todo duplicando los presupuestos de las universidades públicas. No hay otra solución mágica que invertir esos recursos, y esperar luego unas décadas a que fructifiquen. Evaluar la pobreza suele ser contraproducente. El cambio se logra con más recursos en las manos responsables de las personas que ya hacen docencia e investigación en la Universidad. El objetivo más ambicioso es ampliar la Universidad a la casi totalidad de la población, precisamente la que más lo necesita. Ésa es la labor ineludible en el siglo XXI.

$* \quad * \quad *$

En España en la actualidad hay una polémica considerable sobre la calidad de las universidades (públicas y privadas). No hay todavía acuerdo sobre cómo medir esa calidad, pero sí en que hay que cuantificarla de forma científica y lo antes posible. El presente artículo es parte de un estudio mucho más extenso titulado Excelencia: Calidad de las universidades españolas, terminado en el año 2000 (538 páginas). Los tres mismos autores hemos calculado casi un centenar de indicadores para todas las universidades españolas, utilizando índices y tasas sobre los datos oficiales publicados por el Estado. Nuestra propuesta aquí de cinco indices de calidad es debatible. La experiencia de otros países avanzados es que el análisis de la excelencia debe de realizarse sucesivamente, por aproximación, a partir de la discusión científica y corrección de los índices anteriores. La medición de la calidad se va ajustando poco a poco, basándose en datos precisos y no en ideologías personales. Tras finalizar el estudio de las diversas universidades españolas, nuestro equipo de investigación está actualmente realizando el primer análisis comparativo serio de la calidad universitaria de España respecto del resto de los países del mundo. Utilizamos para ello los bancos de datos de la Unesco y de la OCDE en París. Consideramos que la calidad debe medirse tanto a nivel intra (dentro del país), como a nivel inter (comparativa con otros países) ${ }^{102}$. La Sociología se demuestra como un área de conocimiento utilísima para establecer pautas e índices de calidad universitaria. Nosotros hemos realizado la primera aproximación que se publica sobre el caso español. Esperamos que ahora otros científicos/as señalen deficiencias, propongan correcciones al centenar de indicadores y a los cinco índices, estimulando así una investigación adecuada sobre la excelencia universitaria ${ }^{103}$.
' Para comentarios o información adicional se puede contactar con: Jesús M. de Miguel, Catedrático de Sociología, Departamento de Sociología y Análisis de las Organizaciones, Universitat de Barcelona, Avenida Diagonal 690, 08034 Barcelona, tel. 93402 1406, e-mail: demiguel@eco.ub.es.

${ }^{2}$ Ezequiel Baró, et al., Informe Universidad 2000 (Madrid: Conferencia de Rectores de las Universidad Españolas CRUE, 2000), 484 pp. Los doce autores son: Ezequiel Baró, Josep M. Bricall, Julio Fermoso, Ramón Lapiedra, Francisco Michavila, Esteve Oroval, Miguel Á. Quintanilla, Toni Rivero, Josep Roig, María Jesús San Segundo, Francesc Solà y Fernando Tejerina. Sólo un autor de los doce es mujer. El informe fue encargado un año y cuatro meses antes por la CRUE, por su presidente Saturnino de la Plaza, rector de la Universidad
Politécnica de Madrid. La Secretaría General de la CRUE organizó seis encuentros durante la primavera de 1999. El informe final está fechado en Barcelona el 15 de marzo de 2000 .

${ }^{3}$ Se utiliza Universidad con mayúscula cuando se refiere al sistema o sector universitario completo, y universidad en minúscula para referirse a la organización concreta que imparte enseñanza superior. Cuando es necesario se diferencia entre universidades privadas y universidades públicas, mientras que el término Universidad se refiere a ambas.

${ }^{4}$ Ministerio de Educación y Ciencia, La educación en España: Bases para una política educativa (Madrid: Ministerio de Educación y Ciencia, 1969). Se conoce como el Libro Blanco. 
s Ministerio de Educación Nacional y OCDE, Las necesidades de educación y el desarrollo económico-social de España para 1970 (Madrid: Ministerio de Educación Nacional, 1963). Se conoce como Proyecto Regional Mediterráneo.

${ }^{6}$ Fundación Foessa, Informe sociológico sobre la situación social de España 1970 (Madrid: Euramérica 1970), 1634 pp., ver especialmente el capítulo 14 «Educación y ciencia»: 833-1050; y en José L. Romero y Amando DE Miguel, El capital humano: Ideas para una planificación social de la enseñanza en España (Madrid: Fondo para la Investigación Económica y Social de la Confederación Española de Cajas de Ahorros, 1969), 263 pp., denominado a veces como Libro Negro.

7 Jesús M. DE Miguel, Anatomía de una Universidad: Para un estudio de sociología de las organizaciones (Barcelona: Dopesa, 1979).

${ }^{8}$ Jaime MARTin Moreno y Amando DE Miguel, Universidad, fábrica de parados: Informe sociológico sobre las necesidades de graduados universitarios en España y sus perspectivas de empleo (Barcelona: Vicens-Vives, 1979), 193 pp. La contribución de Amando DE Miguel con diversos estudios de la Universidad española es excelente. Otro ejemplo de sus libros es Reformar la universidad (Madrid: Guadarrama, 1973), $223 \mathrm{pp}$.

9 Amparo Almarcha, Autoridad y privilegio en la universidad española: Estudio sociológico del profesorado universitario (Madrid: Centro de Investigaciones Sociológicas, 1982), 376 pp. Entre sus varios artículos recomiendo: Amparo AlmaRCHA, Benjamín GonzÁlez y Celia GonzÁlez, «Cambio y desigualdad en el profesorado universitario», Revista Española de Investigaciones Sociológicas, No. 66 (1994): 117.139.

${ }^{10}$ Marisa Garcia de Cortázar y María A. Garcia de León, Mujeres en minoría: Una investigación sociológica sobre las catedráticas de universidad en España (Madrid: Centro de Investigaciones Sociológicas, 1997), 88 pp. El Informe Universidad 2000 no trata el tema de discriminación por género.

${ }^{11}$ Leonardo SÁNCHEZ-FERRER, «From bureaucratic centralism to self-regulation: The reform of higher education in Spain», West European Politics, vol. 20, No. 3 (1997): 161-184. Recomiendo mucho su lectura. Es un excelente artículo, con una crítica atinada sobre la reforma del sistema universitario español.

12 Francisco Michavila y Benjamín Calvo, La universidad española boy: Propuestas para una politica universitaria (Madrid: Editorial Síntesis, 1998), 318 pp. Francisco Michiavil (fue secretario general del Consejo de Universidades y rector de la Universidad Jaume I de Castellón) es uno de los doce autores del Informe Universidad 2000.

${ }^{13}$ Al final del primer capítulo el Informe Universidad 2000 incluye unos extractos literales de la LGE y de la LOGSE (pp. 86-90) sin comentarios.

${ }^{14}$ No queda claro si el documento en red excluye todas las referencias bibliográficas, o si no existen. En cualquier caso su ausencia es llamativa, y un problema para el análisis del informe.

15 También es una crítica a la política de la enseñanza superior de la Generalitat de Cataluña y del partido Convergencia y Unión.

${ }^{16}$ Jesús M. DE Miguel, Estructura y cambio social en España (Madrid: Alianza Editorial, 1998), 681 pp. Ver especialmente las pp. 47-48, 118-119, 141-142, 232-234 y 473-490. Para temas específicos se puede consultar el índice analítico: «educación (enseñanza)» (p. 662) y «universidad» (p. 680).

17 Jesús M. DE Miguel, Jordi Caïs y Elizabeth Vaquera, Excelencia: Calidad de las universidades españolas (Barcelona y Washington DC: Universitat de Barcelona, y Georgetown University, junio 2000), mimeo, $541 \mathrm{pp}$.

${ }^{18}$ Se puede consultar la bibliografía del libro Excelencia anteriormente citado. Entre lo más destacable están los libros: Philip G. ALTBACH, Robert O. BERDAHL y Patricia J. Gumport (eds.), American Higher Education in the Twenty-first Century: Social, Political, and Economic Challanges (Baltimore: The Johns Hopkins University Press, 1999), 484 pp.; Burton CLARK (ed.), The Research Foundations of Graduate Education: Germany, Britain, France, United States, Japan (Berkeley: University of California Press, 1993); Arthur M. CoHEN, The Shaping of American Higher Education: Emergence and Growth of the Contemporary System (San Francisco: Jossey-Bass, 1998), 495 pp.; Jan CuRrIE y Janice Newson (eds.), Universities and Globalization: Critical Perspectives (Thousand Oaks, California: Sage, 1998), 339 pp.; Ronald G. Ehrenberg (ed.), The American University: National Treasure or Endangered Species? (Ithaca: Cornell University Press, 1997), 171 pp. (Una recensión de este libro aparece en la Revista Española de Investigaciones Sociológicas en 1999.) Sandra L. Johson, Sean C. Ruș y Coopers \& Lybrand (eds.), Rein- venting the University: Managing and Financing Institutions of Higher Education (Nueva York: John Wiley \& Sons, 1995), 401 pp.; Donald KENNEDY, Academic Duty (Cambridge: Harvard University Press, 1997), 310 pp.; Terrence J. MAC TAGGART (ed.), Seeking Excellence Through Independence (San Francisco: Jossey-Bass, 198), 212 pp.; Jaroslav Pelikañ, The Idea of the University (New Haven: Yale University Press, 1992), 238 pp.; David Warner y David Palfreyman (eds.), Higher Education Management (Buckingham: The Society for Research into Higher Education \& Open University Press, 1996), 242 pp.; David S. Webster, Academic Quality Rankings of American Colleges and Universities (Springfield, Illinois: Charles C. Thomas, 1986). La contribución más importante es la de The Carnegie Foundation for the Advancement of Teaching, con sus numerosos informes de obligada referencia en cualquier estudio serio. Recomiendo la lectura de Ellen CondurfFE Lagemann, Private Power for the Public Good: A History of The Carnegie Foundation for the Advancement of Teaching (Nueva York: The College Board, 1999). Un libro cuya referencia es obligada sigue siendo el de Clark KERR, The Uses of the University (Cambridge, Mass.: Harvard University Press, 1995), originalmente publicado en 1963, en su cuarta edición con 226 pp.

19 Todas las citas al Informe Universidad 2000 aparecen por su primer autor en orden alfabético, Ezequiel BARó, ya que el documento no distingue niveles de autoría entre sus doce autores.

${ }^{20} \mathrm{La}$ insistencia en denominarlo Informe Universidad 2000, así con el año dos mil explícito, le proporciona una fecha de caducidad desfavorable. Dentro de varios años ya nadie va a consultar un informe que se data en el año 2000, aunque las reformas que propone sean de más largo alcance.

${ }^{21}$ Incluso el formato es poco adecuado. Aunque hay diferencias ostensibles entre capítulos, los párrafos son demasiado cortos, sin llegar a elaborar ideas completas. Las tablas de datos que se presentan no están elaboradas y no hay un análisis relacional ni causal (sólo incluye datos absolutos o porcentajes, con pocas tasas). El estilo es barroco, con los adjetivos delante de los sustantivos. No hay referencia a otros estudios, ni incluye bibliografía. No se conocen las fuentes del estudio, ni el origen exacto de los datos que manejan. Algunos porcentajes o datos aparecen con excesiva minuciosidad (con decimales, por ejemplo) cuando el nivel de análisis no lo permite o es innecesario. Hay bastantes casos de misplaced concreteness, cuando en realidad faltan los datos más importantes para conocer la realidad y evaluarla. El informe no cita fuentes, ni estudios previos, apenas los datos que utiliza, y no incluye un análisis de esos datos. Es, pues, un ejemplo de la calidad de investigación que todavía se publica en nuestro país.

.2 Véase, por ejemplo, la crítica en el QU Butlletí d'Informació sobre la Qualitat Universitaria, No. 5 (2000): 4.5. Este boletín volandero (de apenas 8 páginas en papel de calidad excesiva para ser una publicación pública sobre «evaluación de calidad») es el órgano de difusión de la Agencia para la Calidad del Sistema Universitario en Cataluña. En vez de realizar estudios científicos serios sobre la enseñanza superior (no debería ser sobre universidades solamente) es un vehículo ideológico con pretensiones exageradas y poco interés científico (como no sea para el análisis de las ideologías). Es una pena que agencias públicas como éstas no dediquen su esfuerzo y recursos públicos a un análisis más científico. La crítica al Informe Universidad 2000 en ese número 5 es excesiva y poco atinada. Precisamente critica lo que no debería. El Gobierno central está falto de estudios sobre las universidades, pero las Comunidades Autónomas están todavía en una situación peor.

${ }^{23}$ Zell MiLLeR, «Ten crucial things the next president should do for colleges» The Chronicle of Higher Education, vol. 46, No. 45 (14 julio 2000): B4.

${ }^{24}$ The Carnegie Foundation for the Advancement of Teaching.

${ }^{25}$ Otro ejemplo es cuando señala que el objetivo principal de la enseñanza es «el aprendizaje por parte del alumno; de manera que en el binomio "enseñan. za-aprendizaje" es imprescindible poner el énfasis en este último aspecto, entendiendo la enseñanza como un sistema para facilitarlo; como un medio más que como un fin en sí mismo. El aprendizaje es algo personal en tanto que es un proceso que produce un cambio en el estudiante, cambio referido no sólo a su modo de pensar y sentir, sino también en su actuación, respondiendo así a los tradicionales saberes, como saber, saber hacer y saber estar» (BARÓ et al., 2000: 16). El «como» debería ir acentuado. El nivel es obvio, demasiado general, y algo anticuado. No toma decisiones ni posiciones innovadoras. Es un informe que en su mayor parte no ofrece temas para debate, salvo algunas decisiones posteriores polémicas sobre el profesorado y los recursos financieros de la universidad. 
${ }^{26}$ Valientes sic; en BARó et al. (2000: 20). Ha habido dos momentos importantes de reforma de la enseñanza superior en España, el Libro Blanco y la Ley General de Educación hacia el final de la dictadura franquista, y la Ley de Reforma Universitaria en la primera época del gobierno socialista. En ninguno de los dos casos se trataba de «valentía». Es posible que el actual Gobierno conservador lleve a cabo una nueva reforma de la enseñanza superior en los próximos años.

${ }^{27}$ A veces hay fronteras ambiguas y excepciones de tipo histórico.

${ }^{25}$ «La reforma de los planes de estudios que, con buen criterio, introdujo la LRU se vio obstaculizada por la participación de intereses corporativos, intereses que derivan, en gran parte, de la tradición estamental legada por la Dictadura [sic]. Esta circunstancia ha puesto de manifiesto graves limitaciones estructurales en el tipo de gobierno de la Universidad española [...]. En este contexto, el profesorado estuvo más atento a establecer nuevas titulaciones a partir de especialidades disciplinares y de investigación que a atender las necesidades que la sociedad expresa y que ya llegaban a la Universidad, singularmente a través de las peticiones de los estudiantes [...]. Así cuando una titulación propuesta suponía una innovación, la lógica del sistema pedía la correspondiente creación disciplinar de un área de conocimiento o de un departamento, creación motivada a veces más por los deseos de independencia de los profesores respecto de otras áreas de conocimiento que por la existencia de un fundamento de carácter científico que la sustentara» (BARÓ et al., 2000: 23).

29 BARÓ et al. (2000: 27), cursivas añadidas.

30 «Penenes» es la abreviatura de Profesores No Numerarios. La «idoneidad» se refiere a paso automático a profesor numerario, sin realizar el concurso.

${ }^{31}$ El artículo más claro sobre la endogamia universitaria es el del sociólogo Mariano FernÁNDEZ EnGUrTA, «Endogamia no, incesto y partenogénesis», El País (16 de agosto de 2000): 10.

${ }^{32}$ Un ejemplo típico: Joan F. PONT, De universitate: Sobre la naturaleza, los miembros, el gobierno y la bacienda de la universidad pública en España (Barcelona: Publicaciones de la Real Academia de Ciericias Económicas y Financieras, 1999), $180 \mathrm{pp}$. El autor imita a propósito un estilo medieval de escribir. La contestación por José J. PINTó se inicia así: «Con unción y profundo respeto, he escuchado el discurso del recipendiario, docto, penetrante, que suscita inquietud científica, pleno de extraordinaria erudición y excelentemente construido. Porque además de estas cualidades y de su ortodoxa estructuración, tiene el singular aliciente de suscitar en su primera parte de manera sumamente viva y polémica, la atención y sobre todo el interés del estudioso, para después con el rigor de su raciocinio, profundizar, aquilatar, precisar, dibujar, con trazos firmes e indelebles, los conceptos dando así una magnífica enseñanza de equilibrio, maduración, sensatez y prudencia, corresponde a la alta categoría científica y académica de su autor, y a su condición de jurista fino y perspicaz» (p. 145). Las propuestas del discurso en la Real Academia tienen poco sentido, siendo impresentables a nivel internacional.

33 La tercera parte de las 35 tablas del informe (doce tablas) son datos de la OCDE, de un informe titulado Education At a Glance publicado en 1999. Otro tercio son tablas oficiales españolas: ocho tablas con datos del Instituto Nacional de Estadística, una del Ministerio de Educación y Ciencia, y otra del Consejo de Universidades. El otro tercio son tablas de estudios particulares, destacando un bloque de nueve tablas de María Jesús SAN SEGUNDO, con investigaciones de 1998 y 1999. Hay entre ellas una de SAN SEGUNDO y VAQUero de 1998. Las citas exactas nunca aparecen en el informe. Tres tablas son de un estudio sobre Financiación de la innovación de la Fundación COTEC en 1999. Hay otra tabla de Pérez y Peiró de 1999 del que se ignora el título del estudio o su referencia exacta. Una cuarta parte de las tablas son pues de investigaciones de María Jesús SAN SEGUNDO, que sería interesante conocer en su totalidad, pero que el informe no proporciona la referencia. SAN SEGUNDO es la única mujer entre los doce autores del informe.

${ }^{34}$ Los datos no incluyen a los/as estudiantes de doctorado, que en la estadística universitaria no son estudiantes «normales». Eso demuestra que el sistema español es fundamentalmente un sistema de primer y segundo ciclo, y que los programas de doctorado son servicios de formación del propio personal de cada universidad. Una discusión con los datos aparece en el capítulo tercero de Jesús M. DE MigueL, Jordi CAIS y Elizabeth VAQUERA, Excelencia: Calidad de las universidades españolas (Barcelona y Washington DC: Universitat de Barcelona y Georgetown University, 2000).
${ }^{35}$ Son además los países que tienen datos fiables sobre enseñanza superior. Muchos otros países fuera de la OCDE sencillamente no tienen datos, o los datos que publican son infiables.

${ }^{36}$ Los datos incluyen la población adulta entre veinticinco y sesenta y cuatro años, en 1996. La tabla 4 en la página 50 del informe tiene algún error en la media de los países, pues no suma $100 \%$.

${ }^{37}$ La tabla 9 (p. 56) incluye datos sobre personas que terminan la carrera con referencia a la población en la edad típica de terminar esos estudios: $11 \%$ diplomatura, $15 \%$ licenciatura y $1 \%$ doctorado. De estudios superiores no universitarios hay muy poco: ocho veces menos que la media de la OCDE. En diplomatura (equivalente a college) hay un tercio menos de lo que corresponde con la media. En licenciatura y similar es igual a la media, igual que el doctorado. Parece necesario, pues, expandir los niveles iniciales de la enseñanza superior: universitaria y no universitaria. La relación entre nuevos matriculados/as y personas que terminan la carrera no está clara en la tabla 12 (p. 59). Parece que en las Facultades la proporción es cada vez menor ( $59 \%$ en cinco años, datos para 1995) mientras que ocurre lo contrario en las Escuelas Técnicas Superiores (62\% en seis años). Según eso, en las Facultades cada vez terminan la carrera menos estudiantes en los años previstos. Quizás se debe al cambio de carreras de cinco a cuatro años. Los datos que se presentan son algo confusos y no permiten una evaluación más adecuada.

${ }^{38}$ Un experimento es la Licenciatura de Humanidades que ofrecen algunas universidades españolas. Es una carrera de cuatro años, generalista, pero fundamentalmente «de letras».

${ }^{39}$ Se refiere a varones, de dieciséis a sesenta y cuatro años de edad, y al año 1995. La tabla pertenece a un estudio de María Jesús SAN SEgundo de 1997 (es decir, anterior al encargo del informe por la CRUE). M. J. SAN SEGUndo es una de las personas que redactan el informe, la única mujer. La nota de la tabla no se entiende bien: «Rendimientos estimados a partir de ecuaciones min. cerianas de ingresos. Las ecuaciones incluyen sólo las variables educativas y de experiencia, así como la dedicación parcial, como variables explicativas, para muestras de sustentadores principales asalariados» (BARÓ et al., 2000: 54)

${ }^{40}$ Los datos no están estandarizados por edad y género. Para llegar a conclusiones válidas sería preciso tener esos datos.

${ }^{41}$ La tabla 8 del informe no menciona el año al que se refieren los datos. Supongo que es 1995 o quizás 1996, con un total de $20 \%$ de paro. El estudio está realizado por SAN SEGUNDO y VAQUERO, y fechado en 1998, aunque no aparece la referencia exacta del estudio. Se refiere a personas activas, excluyendo ayudas familiares «La experiencia laboral (potencial) se mide a partir del año de finalización de los estudios» (BARÓ et al., 2000: 55).

${ }^{42}$ Por ejemplo, entre 1995 y 1998 se crearon cinco universidades públicas y nueve privadas.

${ }^{43}$ Estos datos se pueden calcular a partir de la tabla 20 (p. 67 del informe). No queda claro si la beca media (225.700 pesetas año) supone además el coste de la matrícula, o si ya está incluida en esa cantidad.

${ }^{44}$ En cierto tipo de recursos, el factor de multiplicación debe ser bastante mayor. Por ejemplo, las bibliotecas universitarias españolas tienen de media cuatrocientos mil volúmenes. Se entiende que una biblioteca universitaria para facilitar la investigación debe superar los dos millones de volúmenes. Por lo tanto, las bibliotecas españolas deben, de media, multiplicar por cinco su tamaño.

${ }^{45} \mathrm{El}$ territorio MEC incluye las Comunidades Autónomas que no tienen trans. feridos los recursos universitarios, es decir, todas menos Andalucía, Canarias, Cataluña, Comunidad Valenciana, Galicia, Comunidad Foral de Navarra y País Vasco. El gasto público por estudiante universitario en el territorio MEC es 507.000 pesetas, mientras que en Cataluña es 585.000 pesetas. Las diferencias son grandes: Navarra gasta $52 \%$ más que la Comunidad Valenciana, se supone que para desarrollar la Universidad Pública de Navarra, como alternativa a la Universidad de Navarra, que es del Opus Dei.

${ }^{46}$ En los datos hay una contradicción, pues en la tabla 22 se aprecia que Cataluña gasta por alumno/a apenas $15 \%$ más que el territorio $M E C$, y aproximadamente sólo $8 \%$ más que la media de España. Sin embargo, en la tabla 23 el coste de las universidades catalanas es $37 \%$ más elevado que la media. (Véanse las pp. 69-70.) La contradicción podría deberse a que la lista incluye solamente 38 universidades públicas, cuando en ese año en España hay 44 universidades públicas. Pero la diferencia no puede explicarse así. Seguramente los datos provienen 
de fuentes distintas (no se puede saber, pues en ambos casos no se especifican, sino que son de un estudio previo de María Jesús SAN SEGUNDO en 1998). Unos son datos de los presupuestos autonómicos, y otros de universidades concretas.

${ }^{47}$ Ése parece ser el caso de Cataluña con la Universidad Pompeu Fabra que destaca, con mucho, por encima de todas las universidades. Tiene más del triple de gasto.

${ }^{48}$ La proporción de doctores no parece ser un indicador de calidad, sino más bien de antigüedad de la universidad. Además de UNED con 69\% de doctores, las universidades con más doctores son las de Santiago (69\%) y la de Oviedo (59\%). Universidad Pompeu Fabra apenas tiene $15 \%$ de doctores. Universidad Autónoma de Barcelona, que es una de las mejores universidades españolas, tiene $45 \%$ de doctores, sólo un poco por encima de la media (que es $43 \%$ en las 36 universidades para las que hay datos en 1995).

${ }^{49}$ El capítulo primero del informe incluye la llamada Declaración de Bolonia, que es una declaración conjunta de los Ministros/as de Educación europeos, reunidos en esa ciudad italiana, en junio de 1999. El texto en inglés recomienda la adopción de un sistema universitario basado en dos ciclos: undergraduate y graduate. Este modelo es el que ya existe en Estados Unidos. Incluye también un extracto de la Ley General de Educación (LGE) de 1970, y los artículos 30 a 35 de la Ley de Ordenación General del Sistema Educativo (LOGSE).

${ }^{50}$ «Hay que insistir que sólo un número reducido de países — con extensas y sólidas comunidades e instituciones científicas - están situados en la frontera científico-tecnológica mundial. La mayoría de países —entre ellos España, por supuesto- están más o menos alejados de esta frontera; entre ambos grupos hay un desfase científico-tecnológico de mayor o menor entidad» (BARÓ et al., 2000: 114). Es interesante notar la expresión «por supuesto» en este párrafo.

${ }^{51}$ A veces el modelo no se explica bien, y aparecen ideas raras como la de una educación universitaria para saber utilizar bien el tiempo libre: «El sistema educativo y, en especial; las universidades deberían desempeñar un papel determinante en el reequilibrio de los procesos de formación para dotar a la población de las habilidades de producción necesarias y, también, de las habilidades de consumo que les permitan satisfacer sus necesidades intelectuales y culturales y ocupar más positivamente su creciente tiempo libre» (BARó et al., 2000: 122). Es curiosa esta idea de la universidad para generar en las personas babilidades de consumo, y la ocupación positiva de su creciente tiempo libre.

s2 Es la herencia de una universidad elitista, que enseñaba a una minoría de la sociedad. Las carreras de primer ciclo — de tres años de duración- como Enfermería, Empresariales, o las numerosas Escuelas Técnicas, son incluso más profesionales que las Facultades.

53 Así advierte que «hacer coincidir en un mismo plenario al Ministro de Educación y Ciencia y a los Consejeros de educación de las Comunidades Autónomas, por un lado, y a los rectores de las universidades, por otro, no siempre facilita la discusión y los acuerdos, especialmente en casos en que se abordan conjuntamente temas de índole general o en los que difícilmente puedan separarse los aspectos de gobierno y administrativos de los académicos. Las nuevas tendencias imponen una reducción de la reglamentación universitaria y, como ya se ha indicado, unas formas de actuación más flexible, que tienen en la programación y en la evaluación sus instrumentos privilegiados» (BARÓ et al., 2000: 143). Podría argumentarse exactamente lo contrario: que un Consejo así puede evaluar conjuntamente problemas universitarios de una forma más global y, por lo tanto, realizar una política universitaria más juiciosa.

${ }^{54} \mathrm{El}$ informe deja claro esa propuesta centralista: «La formación continuada se plantea como un servicio con trazos propios, diferenciados de los ya habituales de la Universidad pero dependiente de los organismos centrales de la misma» (BARÓ et al., 2000: 158).

5s «Difícilmente puede pedirse a dichas instituciones flexibilidad e iniciativa si se las somete a exigencias previas que, en la mayoría de los casos, son el origen de entorpecimientos inútiles y de retrasos. Se ha constatado suficientemente que cuando las Administraciones Públicas regulan con excesivo detalle los procedi. mientos y los trámites para la aprobación de los programas y la organización de las enseñanzas disminuyen considerablemente las innovaciones curriculares» (BARÓ et al., 2000: 181-182).

${ }^{56}$ El debate se inicia afirmando que «No se van a plantear problemas de demarcación de instituciones sino de estructuras de los estudios, exigiendo en todo caso a aquéllas que los acojan con el rigor necesario para que, en cada caso, se garantice la transparencia de la oferta y se delimiten las correspondientes responsabilidades» (BARÓ et al., 2000: 168). No se entiende.

57 «Para ello, se debería definir la carga de estudios en forma de módulos más amplios al de las materias de duración anual o plurianual» (BARó et al., 2000: 173).

${ }^{58}$ Más adelante se contradice de nuevo cuando señala: «se permite a los estudiantes la posibilidad de configurar sus propios itinerarios docentes, aumentando la flexibilidad de los curricula con una mayor participación de materias a determinar por quiénes siguen los estudios e importan decisivamente las expectativas de los estudios que se cursan» (BARó et al., 2000: 191). El informe es a veces partidario de una gran flexibilidad y variedad, $y$ otras de un plan de estudios más común y general (menos especializado). No llega a establecer claramente una opinión para todo el sistema universitario.

${ }^{59}$ Hay excepciones a esta regla, pues hay universidades con el nombre de College, como Boston College.

${ }^{60}$ Cursivas añadidas (BARó et al., 2000: 196).

${ }^{61}$ Las citas corresponden a las pp. 199 y 200, en BARÓ et al., 2000. El Informe Universidad 2000 termina creyéndose su propia reforma. Se autoconvence que se va a aplicar, y empieza a entrar en detalles fuera de contexto. Así, por ejemplo, empieza a definir la forma en que se van a organizar las tutorías de los/as estudiantes, dando consejos como: «El plan de consultas del estudiante a su asesor debe considerarse como una actividad fundamental de su vida universitaria; $y$, por ello, debería programar y preparar rigurosamente las visitas al asesor» (BARÓ et al., 2000: 193). Es un caso típico de misplaced concreteness. Ese nivel de organización debe dejarse enteramente —en su caso— a las universidades.

62 «Todas las anteriores observaciones y sugerencias no plantean llevar a cabo una reforma precipitada de la legislación vigente, ni tampoco una rápida transformación del sistema actual de enseñanzas. Pretenden, a lo sumo, señalar algunos caminos para contribuir a lograr una mayor aproximación entre la actual universidad y la sociedad» (BARó et al., 2000: 199). Es lo que ellos denominan como proceso de adaptación.

${ }^{3}$ Ver Jesús M. DE Miguel, Jordi Caïs y Elizabeth VAQuera, Excelencia: Calidad de las universidades españolas (Barcelona y Washington DC: Universitat de Barcelona y Georgetown University, 2000), 541 pp.

${ }^{i 4}$ El sector privado es dicotómico en casi todos los indicadores de calidad.

is «Se sugiere llevar a cabo modificaciones en el diseño del tercer ciclo, de manera que se prestigie el título de doctor, como garantía de formación de calidad para acceder a puestos cualificados y también como fase previa para quien pretenda seguir después la carrera académica» (BARó et al., 2000: 256).

"6 Hay que «evitar que se ofrezcan como programas de doctorado lo que no son sino meras adiciones de contenidos teóricos en un departamento» (BARó et al., 2000: 256).

67 «La mejora de la eficiencia de las universidades no descansa únicamente en reformas de sus modelos de financiación, sino que requiere modificaciones de sus estructuras de gestión interna y también de sus órganos de gobierno, con el fin de potenciar la elaboración de políticas que permitan definir estrategias a medio y largo plazo de estas instituciones» (BARÓ et al., 2000: 268). Yo pienso que es al revés: primero es necesaria una buena reforma de los recursos económicos, consiguiendo el doble de financiación. Sólo después, y en segundo lugar, sería preciso realizar algunas transformaciones organizativas. El problema fundamental es financiero, no organizativo.

${ }^{68} \mathrm{El}$ dato es 4.944 dólares al año por estudiante, en 1995. Está en dólares convertidos usando la paridad del poder de compra, incluyendo universidades públicas y privadas, y basado en estudiantes equivalentes a tiempo completo. Los datos aparecen en la Tabla 14 del informe. Al cambio de 184,3 pesetas por dólar, supone 911.179 pesetas año por estudiante. Si una matrícula media de la Universidad está entre unas 100.000 y 160.000 pesetas al año, el coste pagado por cada estudiante teóricamente sería entre $11 \%$ y $18 \%$, pero es que además hay un $17 \%$ de estudiantes con beca.

${ }^{69}$ Hay que tener en cuenta que $17 \%$ de los/as estudiantes no pagan la matrícula, pues están becados.

${ }^{70}$ La discusión de estos datos brutos aparece en la página 303, pero se refiere también a las Tablas 13 y 14 del informe (en el primer capítulo, pp. 60 y 61). 
${ }^{71}$ Así en la campaña presidencial estadounidense, en el verano de 2000, la posición de los republicanos (Bush) es aumentar las becas de estudios, mientras que los demócratas (Gore) defienden el incremento de las ayudas fiscales a las instituciones públicas de enseñanza. Una discusión de estas diferencias entre conservadores y progresistas aparece en el artículo del sociólogo Norman BIRNBAUM, «Los demócratas, divididos» El País (14 de agosto de 2000), en las páginas de opinión (pp. 9-10)

${ }^{72}$ Se recomienda la «utilización prioritaria de las becas para ofrecer a todos los estudiantes una oportunidad de acceso a la enseñanza superior en los primeros años. En cambio, en los ciclos posteriores se puede ofrecer ayuda financiera en forma, prioritariamente, de préstamos-renta, a devolver únicamente cuando los titulados tengan unas rentas que superen los ingresos medios del país. Con ello, se establecería un pacto entre generaciones para contribuir a la financiación de la enseñanza superior pública» (BARó et al., 2000: 276). Este pacto entre generaciones debería también incluir la enseñanza superior privada.

${ }^{73}$ «El incumplimiento de los requisitos académicos lleva a muchos de los estudiantes de los tramos de renta más baja a perder su beca. Para resolver estos problemas se sugiere modificar los programas de becas con el fin de reducir o incluso eliminar el peso de los criterios académicos en su concesión para dar la misma oportunidad a personas de diferente condición socioeconómica» (BARó et al., 2000: 279). No existe un estudio global en España sobre las becas y becaros/as universitarios. Sería necesario para poder realizar una política más acertada.

${ }^{74}$ El cálculo realizado por mí, en base a los criterios del informe, se realiza sobre la estimación oficial (del Ministerio) del número de estudiantes en el curso 1999-2000, que es 1.582.698. Si se mantiene el porcentaje de $17,3 \%$ de becarios supone 273.807 estudiantes. El ideal de $40 \%$ de becarios se referiría a 633.079 estudiantes. En los datos que se presentan aquí he redondeado las cifras, pero todos los cálculos se han realizado con los números exactos.

"El informe es cauto al explicitar que «antes de generalizar el sistema de préstamos-renta parece conveniente introducir un programa experimental de movilidad» (BARÓ et al., 2000: 307).

${ }^{76}$ Todo esto contando con que el número de estudiantes sea estable, lo que parece va a ser la pauta más previsible durante los próximos años. Es la primera vez que el número de estudiantes universitarios va a permanecer constante.

77 A esa cifra se llegó ya en 1997 (1,54 millones de estudiantes universitarios), y en el año 2000 en que se escribe el informe hay ya 1,58 millones de estudiantes en la Universidad. No se espera que disminuyan mucho, aunque son posibles oscilaciones pequeñas en los próximos años dependiendo de la caída de la fecundidad hace dos décadas, el acceso de nuevas capas sociales a los estudios universitarios, el proceso de privatización de la Universidad española, la tasa de desempleo y el desarrollo económico.

is Ni siquiera el ideal sería suficiente.

79 El informe menciona el «plan estratégico» varias veces, a menudo cambiando la terminología. Así, utiliza expresiones como «planteamiento estratégico plurianual», «plan estratégico global», e incluso «planificación estratégica». Pero nunca explica realmente a qué se refiere con ello.

${ }^{{ }^{\natural}}$ En otros países europeos se están aplicando políticas para que la proporción de mujeres entre los catedráticos aumente hasta el $20 \%$. España está muy retrasada en estos indicadores; pero el informe ni siquiera los menciona.

${ }^{81} \mathrm{El}$ informe mantiene un lenguaje tecnocrático que recientemente domina algunas propuestas de reforma universitaria en el mundo, pero con poca efectividad. Un ejemplo de lenguaje tecnocrático: «Se establece paulatinamente un cambio cultural en la estructura organizativa de la institución, que tiende a introducir racionalidad y mensurabilidad a lo que tradicionalmente han sido proyectos vagos e intangibles sobre estrategias de futuro» (BARÓ et al., 2000: 323). La única estrategia de futuro para elevar la calidad de la Universidad española es duplicar los presupuestos, contratar a más profesores en exclusiva, que realicen investigación financiada por la universidad, y con salarios bastante más altos. Introducir la supuesta racionalidad de una nueva elite managerial y tecnocrática no es la solución de la Universidad.

82 No se entiende.

${ }^{83}$ Además, es lo que se propone en el capítulo cuatro, que se contradice abiertamente con el sexto.
${ }^{84}$ Cursivas añadidas (BARó et al. 2000: 339). Es increíble que un informe en el año 2000, y encargado por la Conferencia de Rectores de las Universidades Españolas, pueda llegar a escribir cosas semejantes.

${ }^{85}$ «Se considera necesario que los procedimientos para la selección del personal académico destinado, total o parcialmente, a tareas docentes valoren particularmente la trayectoria docente de los propios candidatos; no sólo en cuanto a su experiencia medida en años, sino también en cuanto a la familiarización de dichos candidatos con los nuevos métodos pedagógicos y sistemas didácticos y con el empleo de las tecnologías que puedan emplearse para favorecer el aprendizaje» (BARó et al., 2000: 347). A veces parece que el informe se refiere a profesores de bachillerato, no de universidad.

${ }^{86}$ Sobre el personal de administración y servicios el informe dedica cuatro páginas (pp. 352-355), en donde no propone nada nuevo.

${ }^{87}$ Cursivas añadidas (BARÓ et al., 2000: 383). Es bastante tautológico.

${ }^{88} \mathrm{El}$ texto parece incluso sugerir a los propios autores del informe para esa tarea.

${ }^{89}$ Hay muy pocos estudios de la universidad como organización. Un ejemplo puede verse en Jesús M. DE Miguel, Anatomía de una Universidad: Para un estudio de sociologia de las organizaciones (Barcelona: Dopesa, 1979).

${ }^{90} \mathrm{La}$ LRU «implantó un modelo híbrido de coordinación y de gestión de la Universidad» (BARó et al., 2000: 419). Hasta entonces la llamada «autonomía universitaria» había sido una bandera política contra la dictadura, con una aspiración que jamás se había conseguido. Las llamadas universidades «Autónomas», en Barcelona y Madrid, creadas en 1971, no son más autónomas que el resto de las universidades públicas españolas. Sólo las universidades privadas son autónomas.

${ }^{91}$ Supongo que la estructura que se propone es solamente para las universidades públicas. Nada se dice de las privadas.

${ }^{92}$ El capítulo termina con una llamada, moralista, a la «profesionalidad», término que no llega a definir bien: «Los cuadros directivos de la Universidad, tanto los de dirección y gobierno como los administrativos, deberían ejercer con suficiente profesionalidad sus funciones para poder así garantizar la continuidad en los temas esenciales de la acción de gobierno de la Universidad» (BARÓ et al., 2000: 441). El capítulo había comenzado señalando «un claro desplazamiento de la gestión universitaria hacia la adopción de sistemas más profesionalizados» (BARÓ et al., 2000: 405). Los organismos de gestión universitaria han copiado los modelos «profesionales» del profesorado que se basan en una libertad considerable junto con un nivel elevado de responsabilidad. Ahora sólo le queda por copiar el valor de la imaginación e innovación. Las propuestas de este capítulo son un paso pequeño hacia adelante.

${ }^{93}$ Se entiende que para una universidad-investigadora de tamaño medio (las universidades españolas son bastante grandes) se necesitan al menos dos millones de volúmenes. Con menos es imposible mantener un nivel adecuado de investigación y de docencia. En España sólo la Universidad Complutense tiene 2,1 millones de volúmenes. La siguiente es la biblioteca de la Universidad de Barcelona con 1,5 millones de volúmenes.

${ }^{94} \mathrm{La}$ idea de la «multiversidad» fue acuñada por Clark KERR en 1963, en la edición de su conocido libro The Uses of the University. Aquí manejamos la cuarta edición de 1995, bastante aumentada.

${ }^{95}$ Un ejemplo del tono tecnocrático virtual: «Las universidades han de introducir la reingeniería de procesos administrativos y la gestión por proyectos en la docencia. Asimismo se aconseja su estandarización en las diferentes unidades de una universidad e incluso entre universidades, para hacer frente a sus elevados costes fijos de implementación» (BARÓ et al., 2000: 464). «Implementación» (dotación de los medios necesarios para hacer algo) es un anglicismo no reconocido todavía.

${ }^{96}$ En España varias universidades privadas se han anunciado en los últimos meses afirmando que «regalan» un ordenador personal a cada estudiante que se matricula. Son las peores universidades españolas. La aceptación inmediata y sin crítica de las modas suele ser un indicador de mala calidad.

${ }^{97}$ Además, lo normal es empezar por programas para los/as antiguos alumnos, y sólo posteriormente hacerlos accesibles al resto de la población. Para ello las universidades suelen integrarse en consorcios, o programas interuniversitarios, que mejoran las posibilidades docentes y logran un mercado mayor.

${ }^{98}$ Recomiendo las lecturas seleccionadas por Anthony GiDDENS en Runaway World: How Globalization is Reshaping our Lives (Londres: Profile Books, 1999), 
104 pp., ver especialmente el capítulo primero (pp. 6-19), y la bibliografía aconsejada (pp. 83.97). Hay una traducción reciente en la editorial Taurus.

${ }^{99}$ Sugiere además que la colaboración no sea solamente entre las universidades de la Unión Europea.

${ }^{100}$ La palabra «estratégica» aparece excesivamente en el informe, y siempre con significados varios y poco claros.

\section{${ }^{101}$ Cursivas añadidas}

${ }^{102}$ Véase el libro de Jordi Caîs, Metodología del análisis comparativo (Madrid: Centro de Investigaciones Sociológicas, 1997) 201 pp. Es el número 21 de la colección Cuadernos Metodológicos.

${ }^{103}$ Los tres autores del Departamento de Sociología y Análisis de las Organizaciones, de la Universidad de Barcelona, agradecen muy especialmente a Raül Tormos (Universidad Autónoma de Barcelona), quien colaboró activamente en cálculos, tablas y discusión de ideas. A su vez, Xavier Escandell Tur (University of Illinois, Urbana-Champaign) ayudó en los cálculos originales realizados hace un lustro. El catedrático Julio Iglesias de Ussel entonces decano de la Facultad de Ciencias Políticas y Sociología de la Universidad de Granada (actualmente Secretario de Estado de Educación y Universidades) impulsó esta investigación y su presentación pública en Granada. El catedrático de Bioquímica de la Universidad de La Laguna - Enrique Meléndez Hevia- fue una fuente de inspiración. Algunas ideas se discutieron finalmente con Andreu Mas-Colell. El director de esta revista, catedrático Carlos Alba Tercedor, de la Universidad Autónoma de Madrid (mucho antes de que supiéramos que el artículo se iba a publicar en esta revista) contribuyó con ideas, críticas y documentación de todo tipo. Fue además una compañía intelectual valiosísima en Georgetown University, donde ser terminó de redactar el estudio. En esa universidad los dos «Sams»-Samuel Barnes y Eusebio Mujal-León- fueron un constante acicate y ayuda iDa gusto encontrar extranjeros que estiman tanto a España! La investigación original fue financiada por el Ministerio de Educación, Cultura y Deporte, así como por la Cátedra Príncipe de Asturias en Georgetown University. Gracias, pues, a SAR el Príncipe Felipe de Borbón, y a Endesa, por su apoyo e interés en la mejora del sistema universitario español. Hay otras personas bondadosas que nos han ayudado durante estos años; ellos/ellas ya saben quién son; nuestras mejores gracias. Cualquier sugerencia sobre el estudio es bienvenida: demiguel@eco.ub.es. 
